\section{OPEN ACCESS}

Edited by

Marco Leonti,

University of Cagliari, Italy

Reviewed by:

Michał Tomczyk,

Medical University of Bialystok,

Poland

Jianbo Wan,

University of Macau, China

${ }^{*}$ Correspondence:

Devesh Tewar

dtewari3@gmail.com

Javier Echeverría

javier.echeverriam@usach.cl

Atanas G. Atanasov

atanas.atanasov@univie.ac.at

${ }^{\dagger}$ These authors have contributed equally to this work and share first authorship

Specialty section:

This article was submitted to

Ethnopharmacology,

a section of the journal

Frontiers in Pharmacology

Received: 28 June 2019 Accepted: 09 December 2019

Published: 14 February 2020

Citation:

Singh L, Joshi T, Tewari D, Echeverría J, Mocan A, Sah AN, Parvanov E, Tzvetkov NT, Ma ZF, Lee YY, Poznánski P, Huminiecki L,

Sacharczuk $M$, Jóźwik $A$, Horbańnczuk JO, Feder-Kubis J and Atanasov AG (2020) Ethnopharmacological Applications Targeting Alcohol Abuse:

Overview and Outlook.

Front. Pharmacol. 10:1593. doi: 10.3389/fphar.2019.01593

\title{
Ethnopharmacological Applications Targeting Alcohol Abuse: Overview and Outlook
}

\begin{abstract}
Laxman Singh $^{1 \dagger}$, Tanuj Joshi ${ }^{2 \dagger}$, Devesh Tewari ${ }^{3,4+*}$, Javier Echeverría ${ }^{5 *}$, Andrei Mocan ${ }^{6}$, Archana N. Sah ${ }^{2}$, Emil Parvanov ${ }^{7}$, Nikolay T. Tzvetkov ${ }^{8,9}$, Zheng Feei Ma ${ }^{10,11}$, Yeong Yeh Lee ${ }^{11}$, Piotr Poznański ${ }^{4}$, Lukasz Huminiecki ${ }^{4}$, Mariusz Sacharczuk ${ }^{4}$, Artur Jóźwik ${ }^{4}$, Jarosław O. Horbańczuk ${ }^{4}$, Joanna Feder-Kubis ${ }^{12}$ and Atanas G. Atanasov ${ }^{4,13,14,15^{*}}$

${ }^{1}$ Centre for Biodiversity Conservation \& Management, G.B. Pant National Institute of Himalayan Environment \& Sustainable Development, Almora, India, ${ }^{2}$ Department of Pharmaceutical Sciences, Faculty of Technology, Kumaun University Bhimtal Campus, Nainital, India, ${ }^{3}$ Department of Pharmacognosy, School of Pharmaceutical Sciences, Lovely Professional University, Phagwara, India, ${ }^{4}$ Institute of Genetics and Animal Breeding of the Polish Academy of Sciences, Jastrzebiec, Poland, ${ }^{5}$ Department of Environmental Sciences, Faculty of Chemistry and Biology, Universidad de Santiago de Chile, Santiago, Chile, ${ }^{6}$ Department of Pharmaceutical Botany, "luliu Hațieganu" University of Medicine and Pharmacy, Cluj-Napoca, Romania, ${ }^{7}$ Institute of Molecular Genetics, Academy of Sciences of the Czech Republic, Division BIOCEV, Prague, Czechia, ${ }^{8}$ Institute of Molecular Biology "Roumen Tsanev", Department of Biochemical Pharmacology and Drug Design, Bulgarian Academy of Sciences, Sofia, Bulgaria, ${ }^{9}$ Department Global R\&D, NTZ Lab Ltd., Sofia, Bulgaria, ${ }^{10}$ Department of Public Health, Xi'an Jiaotong-Liverpool University, Suzhou, China, ${ }^{11}$ School of Medical Sciences, Universiti Sains Malaysia, Kota Bharu, Malaysia, ${ }^{12}$ Faculty of Chemistry, Wrockaw University of Science and Technology, Wybrzeże Wyspiańskiego, Wrockaw, Poland, ${ }^{13}$ Department of Pharmacognosy, University of Vienna, Vienna, Austria, ${ }^{14}$ Institute of Neurobiology, Bulgarian Academy of Sciences, Sofia, Bulgaria, ${ }^{15}$ Ludwig Boltzmann Institute for Digital Health and Patient Safety, Medical University of Vienna, Vienna, Austria
\end{abstract}

Excessive alcohol consumption is the cause of several diseases and thus is of a major concern for society. Worldwide alcohol consumption has increased by many folds over the past decades. This urgently calls for intervention and relapse counteract measures. Modern pharmacological solutions induce complete alcohol self-restraint and prevent relapse, but they have many side effects. Natural products are most promising as they cause fewer adverse effects. Here we discuss in detail the medicinal plants used in various traditional/folklore medicine systems for targeting alcohol abuse. We also comprehensively describe preclinical and clinical studies done on some of these plants along with the possible mechanisms of action.

Keywords: alcohol, binge drinking, alcoholism, drug abuse, fatty liver, natural products

\section{INTRODUCTION}

Excessive alcohol consumption in the age range group of 15-64 years is responsible for 1 out of 7 deaths and 1 out of 13 death cases in men and women, respectively, which involve drinking during pregnancy, binge drinking, heavy drinking, and underage drinking (Sacks et al., 2015; Baldassarre et al., 2018). High alcohol intake is leading to $5.9 \%$ of all lethal cases among people, and excessive alcohol consumption puts around 5.1\% of disease burden on the world (Organization and Unit, 2014).

Alcohol addiction and abuse is a complex disorder associated with biological, emotional, and social factors, which often leads to health problems-such as liver cirrhosis, hypertension, 
coronary artery disease, central nervous system disorders, alcohol-induced cardiomyopathy, and gastrointestinal disorder-and deteriorates economic prosperity of the family. Worldwide alcohol consumption has increased many folds over the decades, and abuse and addiction have been on the rise. The liver-the primary site for alcohol metabolism-is the most affected organ: excessive alcohol consumption causes cell to die, leaving scar tissue in their place. Prolonged high intake results in cirrhosis, which makes detoxification difficult while the organ is susceptible to infection and inflammation.

The adverse effects of the conventional medications for treatment of mainly the liver diseases caused by acute or chronic alcohol consumption are the reason for search of new alternative ways of cure. Under this circumstances, natural products are attractive option for treatment of alcoholinduced liver impairment (Ao et al., 2009). At present there is no therapeutic cure for alcoholic liver disease (ALD); hence, the development of novel medicines that are effective against alcoholic injury is the need of the hour (Kim et al., 2014). The modern pharmacological approaches are believed to play a vital role in achieving complete alcohol self-restraint and prevent relapse, but have limited efficacy with high adverse effects (Addolorato et al., 2005).

As far as the terminology is concerned, current use of alcohol can be demarcated as drinking at least one drink during the past 30 days and binge drinking can be defined as consumption of five or over five drinks in a day. Studies on the current alcohol use showed that $51 \%$ of adults who are above 18 years and $56 \%$ of adults who are between the age group of 18 to 44 drink alcohol regularly (Schiller et al., 2012). Excessive drinking is seen among $30 \%$ of the existing drinkers (Naimi et al., 2003). In the United States, 92\% of adult heavy drinkers show a pattern of binge drinking in the last 30 days (Town et al., 2006). Thus, to combat the threat of alcoholism in the society, natural products can play a key role, with advantage of no or minimal adverse effects (Xu et al., 2005).

Various in vitro experiments involving HepG2 cells when treated with ethanol produced a significant reduction in glutathione (GSH) levels (Gutierrez-Ruiz et al., 1999; Kaur et al., 2009) and the generation of reactive oxygen species (ROS) (Ogony et al., 2008). One example of a natural product studied in this cellular model is antroquinonol, a tetrahydroubiquinone derivative that occurs mainly in the mycelium of Antrodia camphorata (Angamuthu et al., 2019). Pretreatment with antroquinonol in a dose-dependent manner provides protection to HepG2 cells against cellular lipid peroxidation and hepatic enzyme generation induced by ethanol. Additionally, sustained depletion of GSH by ethanol was also reversed by antroquinonol pretreatment (Kumar et al., 2011). Other than this, antroquinonol pretreatment is also known to provide protection to hepatic cells against oxidative stress produced by ethanol. The possible mechanism of action involves upregulation of expression of nuclear factor erythroid 2-related factor 2 (Nrf-2) gene that in turn downstream antioxidant genes arbitrated through mitogen-activated kinase proteins (MAPs) (Kumar et al., 2011).

\section{Development and Course of Alcohol Abuse}

Alcohol addiction and abuse steadily progresses with time. Various researchers have given diverse stages regarding the progression of alcoholism. These stages vary in numbers according to the point of view of different researchers. According to their definitions, first, second, third, and fourth stages of alcoholism have been categorized as pre-alcoholic, early alcoholic, middle alcoholic, and late alcoholic, respectively. In the pre-alcoholic stage, the person is involved with social drinking, which does not cause any significant problems. An organism exposed to a slow increase in the amount of alcohol intake may start developing tolerance towards it. The habit of drinking, which is believed to relieve anxiety, stress, pain, and similar problems, may be the first step in addiction forming. In stage two of alcoholism, the person feels a mixed feeling of development of discomfort due to absence of alcohol intake and a strong desire to get alcohol. The person at this stage lies about his/her drinking habits to family and friends. The alcoholic finds new methods to secretly consume alcohol. Tolerance towards alcohol gradually progresses in this stage. In stage three, the symptoms of alcoholism become visible to friends and family. The relationship of the alcoholic with his/her family and friends begins to deteriorate. The alcoholic develops symptoms of alcohol abuse like weight loss or weight gain, facial redness, sluggishness, stomach bloating, etc.

The alcoholic now begins to suffer from severe complications like liver cirrhosis, dementia, and other ailments, which may lead to the loss of employment. Round-the-clock consumption progressively becomes an addiction and reduces or dislodges other activities, deteriorates the well-being of the family, and estranges friends. At this stage an attempt to get out of the habit results in hallucinations, tremors, and similar phenomena. Help can be found in professional rehabilitation centers (https://www. alcohol.org accessed on 01.03.2019). Prolonged alcoholism leads to psychological and physiological alterations inside the body andamong others-negatively affects various neurotransmitters.

There are various mechanisms associated with alcohol abuse, addiction, and dependence. One important effect by which alcohol leads to drug addiction and subsequently to its abuse is its effect on neurotransmitters. In acute alcohol ingestion, alcohol up-regulates GABAergic transmission and interferes with transmission of glutamate. Thus, due to intake of alcohol, the balance between the inhibitory and excitatory inputs is disturbed in the brain. In chronic alcohol ingestion, the brain in its attempt to attain equilibrium in presence of alcohol undergoes neuroadaptations and this leads to enhancement in the level of glutamate and decrease in the level of gamma-aminobutyric acid (GABA). The activities of other neurotransmitters like serotonin, dopamine, adenosine, and glycine are also altered by alcohol. Apart from this, it interacts with the opioid system, endo-cannabinoid system, and nicotinic cholinergic system as well as cholinergic transmission. It has been investigated by 
scientists that interactions of various molecules with the opioid receptor system can be the reason behind their addiction and dependence-producing effects. This is supported by the fact that drugs like morphine, which interact with the opioid receptor system, have considerable addiction and dependence causing potentials. It has also been pointed out that the reinforcing effect of alcohol might be due to its interaction with the opioid receptor system. Studies have also shown that there is a very strong correlation between alcohol addiction and genetics. Genetic factors can play an important role in favoring the development of addiction by determining what neurochemical changes would be produced on both acute as well as chronic ingestion of alcohol. Thus, alcohol may produce drug addiction and abuse through a variety of mechanisms (Pickens and Svikis, 1988; Nestler, 2004; Tripathi, 2013; Michalak and Biala, 2016).

\section{Current Conventional Pharmacotherapy of Alcohol Dependence}

Alcohol addiction, abuse and dependence have become severe problems affecting the lives of many people throughout the world. Currently at many rehabilitation centers, multiple allopathic drugs are being used to treat alcohol addiction and its complications. Though many allopathic drugs have proven to be a useful aid to combat alcoholism, yet drugs alone are not a complete answer for treatment of alcoholism. Successful treatment of alcoholism requires a combination of both psychological therapy as well as pharmacotherapy. Many drugs like benzodiazepines (BDZs) and disulfiram have been used in the treatment of alcohol dependence for many years but they have their own merits and demerits. Sometimes they may not prove to be very effective in an alcoholic patient and they have a potential to cause a variety of adverse effects. For example, by using BDZs in alcohol dependence, the alcoholic might himself/ herself get addicted to BDZs. Also, in some studies it has been found that BDZs are not very effective in reducing craving associated with alcohol consumption. Similarly, taking disulfiram precludes even small amounts of alcohol or else severe adverse reactions within the body are likely to occur. Thus, the main action of disulfiram becomes its biggest drawback (Addolorato et al., 2002; Tripathi, 2013).

Many conventional drugs are in use for treatment of emergencies associated with alcohol addiction. One such is BDZs, having sedative, anxiolytic, and hypnotic action. BDZs have been tried in patients suffering from acute alcohol intoxication and showing aggressive behavior. They have been used as a replacement of alcohol, as a measure to stop the onset of withdrawal reactions precipitated by discontinuation of alcohol. In certain alcoholic patients, the person suffering from anxiety is reported to develop alcohol dependence. This is backed by research highlighted blending genetic similarities in the predisposition to develop anxiety and alcoholism. Thus, the use of BDZs enables the alcoholic person to cope with anxiety and trauma and it also protects the health care professionals against the aggressive behavior of the alcoholics. However, continuous use of BDZs in acute alcohol intoxication draws serious implications such as the following: it can lead to hypotension, impairment in consciousness, and depression of respiration (Addolorato et al., 2002; Shpilenya et al., 2002; Tripathi, 2013). So, one has to be conscious prescribing such formulations unless fully acquainted with the case study.

Contrarily, metadoxine and flumazenil, a competitive antagonist of BDZs, have been tried to enhance the rate of recovery from unconsciousness alcoholic state (Addolorato et al., 2002). For treatment of alcohol withdrawal syndrome, gamma hydroxybutyric acid (GHB), chlordiazepoxide, diazepam, and baclofen have also been tried, which play a key role in diminishing symptoms associated with withdrawal reactions like agitation, depression, anxiety, etc. Similarly, drugs like tiapride, tioridazine, and haloperidol have been found to be useful in treatment of delirium tremens (Mayo-Smith, 1997; Addolorato et al., 1999; Gallimberti et al., 2000; Addolorato et al., 2002).

Relapse of alcoholism is a major problem associated with the efforts to leave alcohol. Many drugs that have anti-craving, aversion-causing, and anti-reward effects have been used. Disulfiram is used as an important aversion-causing drug. Unpleasant reactions are produced if a person on disulfiram takes even very small quantity of alcohol. This strengthens the resolution of the alcoholic to refrain from consuming alcohol. The fact of the matter is ethanol metabolism by enzymes alcohol dehydrogenase $(\mathrm{ADH})$ and aldehyde dehydrogenase (ALDH2) converts this first into acetaldehyde and then into acetic acid derivative, respectively. Disulfiram here plays a key role by inhibiting the enzyme ALDH2 as a result of which acetaldehyde is not converted to acetic acid. Subsequently, upon alcohol consumption the levels of acetaldehyde are increased and acetaldehyde produces unpleasant reactions like headache, respiratory depression, diarrhea, vomiting, nausea, hypotension, flushing, etc. Treatment with disulfiram has its own drawbacks in that concurrent alcohol consumption triggers serious reactions as mentioned above. Awareness of this fact must be raised on the part of the patient. The use of disulfiram is strictly prohibited in conditions like cardiopathy, diabetes, nephropathy, pregnancy, and in patients having history of drug allergy and hypersensitivity. Various drugs have also been used to reduce craving with different mechanisms. Some drugs reduce the craving for alcohol by mimicking the action of alcohol, whereas other drugs decrease the pleasant sensation associated with alcohol consumption (anti-reward effect) (Addolorato et al., 2002; Tripathi, 2013).

Similarly, GHB acid is used to decrease craving associated with alcohol consumption. It shows alcohol mimetic action and acts by producing interference in the functioning of some neurotransmitter systems like the mesolimbic cortical system. It does so by producing changes in levels of serotonin, dopamine, and GABA in brain. The downside of using GHB is that patients may start craving for GHB itself. GHB carries abuse and dependence producing liability, though this incidence is low but still supervision is highly recommended in using GHB treatment on alcoholics (Addolorato et al., 1996; Addolorato et al., 1997; Gallimberti et al., 2000; Gessa et al., 2000; Addolorato et al., 2002). Another class of drug is baclofen, which acts as a $\mathrm{GABA}_{\mathrm{B}}$ agonist that is conventionally used as a centrally acting 
muscle relaxant but now it has also found use in treatment of alcohol dependence. Baclofen leads to alcohol abstinence and decreases craving. An advantage of baclofen is that it does not carry abuse liability but still more studies are needed to evaluate the risk/benefit ratio of baclofen (Addolorato et al., 2000; Colombo et al., 2000; Addolorato et al., 2002).

Opioid receptor antagonist like naltrexone is also currently used drug for treatment of alcoholism. It is believed that the opioid system is involved with the compulsive and reinforcing effects of alcohol that lead to craving desire associated with alcohol use. Thus, naltrexone is effective in decreasing craving towards alcohol. The disadvantage of naltrexone is that naltrexone produces side effects like insomnia, headache, vomiting, etc., and these can become more pronounced if the patient continues to consume alcohol. Also it is contraindicated in hepatic insufficiency and acute hepatitis (Volpicelli et al., 1992; Croop et al., 1997; Addolorato et al., 2000; Tripathi, 2013). Likewise, acamprosate is a drug that decreases the activity of the excitatory components of the brain. It does so by affecting calcium ion channels. It decreases craving and leads to alcohol abstinence. In a study, acamprosate has not shown to be very effective in the treatment of alcohol dependence and many studies are still needed to establish its effect in treatment of alcoholism (Paille et al., 1995; Sass et al., 1996; Addolorato et al., 2002).

Selective serotonin reuptake inhibitors (SSRIs), like fluoxetine, etc., have also found application in treatment of mood disturbances in alcoholics and their mechanism in treatment of alcoholism has been attributed to both GABAergic and serotonergic actions. SSRIs are basically effective in alcoholics with mood disturbances and provide a relief in alcoholics with depressive symptoms. Drugs like citalopram and sertraline are more effective in alcohol dependence with a late onset. Buspirone, which acts as a partial agonist at $5-{ }^{\mathrm{HT}} 1_{\mathrm{A}}$ receptor, is a helpful drug in alcoholics with anxiety (Gorelick and Paredes, 1992; Sellers et al., 1994; Kranzler et al., 1995; Malec et al., 1996; Tripathi, 2013).

Another class of drug is the metadoxine that helps in restoring neuropsychological behavior in alcoholics to normal. In patients it was found to decrease psychomotor agitation, compulsive desire, aggressiveness, and improved work efficiency, emotions, and relationships in alcoholics. Metadoxine improves ethanol metabolism by affecting the liver enzyme system. Also levels of adenosine triphosphate (ATP) and release of acetylcholine and GABA are increased in the brain.

In summary, it can be said overall that conventional pharmacotherapy helps in the treatment of alcohol dependence and addiction, yet it has its own set of disadvantages and harmful effects. Thus, newer and safer treatment of alcohol dependence is still miles away (Bono et al., 1991; Caballeria et al., 1998; Stefanini et al., 1999).

\section{EFFECTS OF ALCOHOL CONSUMPTION ON HEPATIC AND CARDIOVASCULAR SYSTEMS}

A major causative agent for chronic liver disease (CLD) in the USA and Europe (Younossi et al., 2011; Blachier et al., 2013) is alcoholism. In 2010, 14.5 million disability-adjusted life-years and approx. 0.5 million deaths around the world were caused by ALD (Rehm et al., 2013). Excessive use of alcohol leads to hepatic steatosis (O'Shea et al., 2010), but only a subset of patients are known to develop clinically significant liver disease, depending on various behavior factors, genetic predisposition, and comorbidities. Out of these, one of the most important ones is obesity (Raynard et al., 2002; Parker et al., 2018). Alcohol has not only had a direct harmful effect on liver but indirect effect on other organs also. Dangerous use of alcohol alters adipose tissue functions and causes liver-damaging effects and progression of ALD (Parker et al., 2018).

Reasons behind different types of liver diseases in general are alcohol abuse, toxic drugs, metabolic disorders, hepatitis virus types A, B, and C, and chemicals, among others (Friedman, 2003). One of the most common reasons behind liver diseases in north-western Europe, United States, and other parts of the world is alcoholism and this condition is associated with mortality rates of $5 \%$ to $6 \%$ (Morris et al., 2012). Heavy alcohol consumption for a longer duration leads to higher risk of development of liver diseases (Younossi, 1998). Binge drinking leads to development of acute alcoholic hepatitis and if the problem becomes excessive it can even become life threatening (De et al., 2009). Many studies indicate that the levels of ROS, cellular lipid peroxidation, nitric oxide (NO), hepatic enzymes, cytokines, alanine aminotransferase (ALT), aspartate aminotransferase (AST), and tumor necrosis factor-alpha (TNF $\alpha$ ) are enhanced by excessive ingestion of alcohol and play a vital role in progression and etiology of alcohol-induced hepatic diseases (Gutierrez-Ruiz et al., 1999; Nah et al., 2005; Kumar et al., 2011). Due to excessive free radicals generation by alcohol consumption, there is spontaneous reduction in the glutathione levels as well (Gutierrez-Ruiz et al., 1999; Kumar et al., 2011). Raised accumulation of intracellular ROS in hepatic cells and oxidative stress are key effects of ethanol exposure and these effects lead to the hepatic diseases (Das and Vasudevan, 2007).

Acetaminophen (paracetamol) is implicated as the causative agent of $42 \%$ of all the cases of acute liver failure (ALF) in the USA (Larson et al., 2005). A high risk factor of ALF is associated with consumption of acetaminophen in elderly, alcoholics, and in those cases where there is an overdose with this drug (Sass and Shakil, 2005; Dart and Bailey, 2007; Rhodes et al., 2011). There are higher incidences of acetaminophen toxicity in case of chronic alcoholics, people suffering from malnutrition, and the elderly (Larson et al., 2005; Dart and Bailey, 2007).

Various mediators of alcohol metabolism directly or indirectly lead to liver injury. Cytochrome P450 2E1 (CYP2E1) is the major enzyme that metabolizes alcohol. CYP2E1 does not produce any damage to liver if the amount of alcohol ingested is not excessive. However, if the amount of alcohol consumed by a person is very high, CYP2E1 leads to the formation of ROS like hydrogen peroxide, superoxide anion radical, and highly reactive conjugated adducts (Lu and Cederbaum, 2008).

Pro-fibrogenic cytokines, such as platelet-derived growth factorbeta (PDGF- $\beta$ ), transforming growth factor-beta (TGF- $\beta$ ), and connective tissue growth factor (CTGF) are released by hepatic 
stellate cells (HSC) on activation (Pinzani and Marra, 2001; Parsons et al., 2007). Inhibition of HSC activation is the main goal for the treatment of hepatic injury induced by alcohol consumption (Wang et al., 2006).

Important immune and endocrine functions relating to adipose tissues can be also altered by alcohol. These effects further enhance the toxic effect of alcohol on liver. Release of non-esterified fatty acids (NEFAs) into the systemic circulation occurs as a result of enhanced lipolysis in adipose tissues (Parker et al., 2018). Steatosis, insulin resistance, and hepatic inflammation result due to uptake of NEFAs by the liver (Parker et al., 2018). Liver function is also altered by changes in the adipokines secretion by adipocytes. There are convincing studies providing evidence on the actions of leptin, which serves as a proinflammatory and profibrotic agent. At last, adipose tissue inflammation caused by alcohol or obesity fosters the pro-inflammatory cytokines release into circulation and this results in a direct damage to liver and also leads to liver tissue infiltration by immune cells (Parker et al., 2018).

Endocrine function of adipose tissues is changed by consumption of alcohol and this varies depending on its use pattern and also the existence and stage of ALD (Parker et al., 2018). Circulating adiponectin is increased by both moderate (Sierksma et al., 2004; Beulens et al., 2006; Beulens et al., 2008; Brien et al., 2011) and high levels of alcohol (Hillemacher et al., 2009). In patients with ALD, there is maintenance of elevated serum adiponectin levels (Tacke et al., 2005), and the higher the adiponectin levels are, the greater will be the severity of ALD (Kaser et al., 2005; Kasztelan-Szczerbinska et al., 2013). Studies done on human adipocytes by in vitro methods have given evidence that expression of adipocytes is modulated in presence of alcohol (Ajmera et al., 2017).

Light consumption (0.1-5 g per day) of alcohol has several benefits like alcohol in low levels reduces severity of metabolic syndrome (Sun et al., 2014) and risk of cardiovascular disease (Costanzo et al., 2010); however, high amount consumption of alcohol (> 26 g per day) enhances risk of cardiovascular mortality (Costanzo et al., 2010). A close link between non-alcoholic fatty liver disease (NAFLD) and metabolic syndrome increased the death of the patients. There is correlation between dangerous consumption of alcohol and individual components of metabolic syndrome in general (Fan et al., 2006; Bessembinders et al., 2011; Briasoulis et al., 2012) and this correlation is directly proportional (Parker et al., 2018).

Alcoholism is a commonly encountered problem and has a significant effect on adipose tissues. Normal function, structure, and distribution of adipose tissue are disturbed by harmful use of alcohol. Liver functions are altered directly or indirectly by alterations in adipose tissues and this in turn leads to ALD. Inflammatory changes in adipose tissue are immediately reversed by stopping consumption of alcohol, and experimental ALD is improved by drugs that restore the functions of ALD to normal (Parker et al., 2018).

Alterations in adipose tissue by alcoholism occur in a similar manner in obesity and NAFLD as well. Risk of morbidity and mortality related to liver problems is enhanced by synergism of obesity and alcohol consumption. There should be awareness among physicians who are treating patients with ALD regarding the consequences of adipose tissue dysfunctions affecting the functions of liver. They should also develop effective plans for management of insulin resistance and obesity. Knowledge into the extra hepatic actions of alcohol involvement in the development of ALD will help in development of efficient treatments (Parker et al., 2018).

\section{ALCOHOL AND NICOTINE: A DANGEROUS COMBINATION}

Worldwide nicotine and alcohol are often abused in combination as drugs and lead to deaths of 9 million people every year in a combined manner (Ostroumov et al., 2015). There is a strong evidence of positive correlation between use of nicotine and alcohol (DiFranza and Guerrera, 1990; Miller and Gold, 1998; Dani and Harris, 2005; Weitzman and Chen, 2005; Barrett et al., 2006). There is more vulnerability of binge drinking in both regular smokers and non-regular (non-dependent) smokers than non-smokers (Weitzman and Chen, 2005; Harrison et al., 2008; Campbell et al., 2012).

Some subjective rewarding alcohol effects are enhanced through nicotine and vice versa (Glautier et al., 1996; Kouri et al., 2004; Rose et al., 2004). In addition, nicotine can influence alcohol consumption in a longer run. Use of nicotine at a young age enhances the development of disorders associated with consumption of alcohol later in life (Grant, 1998; Chen et al., 2002; Jensen et al., 2003; Riala et al., 2004). In agreement with the literature, nicotine administration to animals can enhance subsequent self-administration of alcohol in them (Blomqvist et al., 1996; Smith et al., 1999; Le et al., 2003; Bito-Onon et al., 2011; Doyon et al., 2013a). However, there are also certain conflicting reports in which nicotine administration did not have any influence on alcohol consumption; rather nicotine administration reduced alcohol consumption (Dyr et al., 1999; Nadal and Samson, 1999; Sharpe and Samson, 2002).

There are various diverse molecular targets throughout the central nervous system (CNS) on which ethanol and nicotine act, but a common pharmacological action is also shared by these drugs (Dani and Bertrand, 2007; Dopico and Lovinger, 2009). It is put forward that common modulation of the brain stress hormone system and mesolimbic dopamine (DA) system leads to the interactions between ethanol and nicotine (Larsson and Engel, 2004; Funk et al., 2006; Doyon et al., 2013b). Substances for abuse (drugs) target the DA system and the development of addiction is due to the dysregulation of the DA system (Luscher and Malenka, 2011; Sulzer, 2011).

Increased susceptibility to drug and alcohol abuse can be associated with blunted transmission of DA (Volkow et al., 1996; Martinez et al., 2005; Ostroumov et al., 2015). By modifying the function of neural substrates that are targets of both alcohol and nicotine, nicotine can influence consumption of alcohol. Some examples of these substrates are stress hormone systems linked 
with glucocorticoids and corticotropin releasing factor $(\mathrm{CRH})$, and the mesolimbic DA system (Larsson and Engel, 2004; Funk et al., 2006; Doyon et al., 2013b; Ostroumov et al., 2015). Ethanol and nicotine both have complex pharmacological actions and act on several targets present in the nervous system. According to different studies, reinforcing effects of ethanol and nicotine combination might arise from multiple mechanisms and different areas of the brain (Leao et al., 2015; Ostroumov et al., 2015).

\section{ALCOHOL AND CANNABIS}

A 9-year survey was done between 2002 and 2010 by questionnaires about the use of alcohol, stimulants, and cannabis in 3,099 human immunodeficiency virus (HIV)-infected men and the study was termed as Veterans Aging Cohort Study (VACS) (Adams et al., 2018). In this study, the changes in the VACS index were analyzed by the above-mentioned substances. Alcohol and narcotic drugs influenced on progression of HIV disease by mechanisms like poor adherence to pharmacological therapy of HIV, increase in symptoms of depression, immune suppression, neurocognitive dysfunction, and respiratory infections (Arnsten et al., 2002; Kapadia et al., 2005; Hinkin et al., 2007; Sullivan et al., 2011; Langebeek et al., 2014; Kalichman et al., 2015; Adams et al., 2018). A fact that is important regarding the health of public is that drug and alcohol use is common among HIV-infected individuals (Chander et al., 2006; Mimiaga et al., 2013).

In general, cannabis use does not impact mortality in a negative manner, whereas there is a greater risk of mortality associated with stimulant use as compared to a lower risk of alcohol use among men infected with HIV in care (Adams et al., 2018). Association between stimulant use and mortality risk can help in its treatment in a targeted manner. Also the knowledge that frequent use of stimulant can lead to dangerous consequences can help patients to reduce or stop the use of stimulants. There is a greater impact of sociodemographic characteristics on mortality risk as compared to stimulants, alcohol, or cannabis use. Reduction of impact of racial differences and poverty by specific programs can be useful in improving the health of male veterans suffering from HIV/AIDS (Adams et al., 2018). Still, sufficient studies are required to draw conclusive remarks for effect of the cannabis use and alcohol consumption.

\section{BRIEF HISTORY OF ALCOHOL CONSUMPTION}

Although opinion differs as to when the humans first started to produce or became familiar with alcoholic beverages, their use dates back to ancient civilizations. Substantive historical and archaeological evidence implies the Stone Age [8000 Before the Common Era (BCE)] as the dawn of fermentation products (Guidot and Mehta, 2014). It was fermented mare's milk in ancient Siberia that appears to have been the first alcoholic drink.
Its production today known as "Kumis" continues in some parts of Russia (Guidot and Mehta, 2014). The use of alcoholic beverages is reported in various religious ceremonies, social gatherings, or in day-to-day life.

Several excavation sites around the globe unearthed jarsdating it back to 7000-6600 BCE Northern China (McGovern, 2013), 5400-5000 BCE in Hajjin Firuz in Iran (Gately, 2008), 4000 BCE in ancient Egypt (Lucia, 1963), 2700 BCE in Babylonians (Hyams, 1965), 1000 BCE in Mexico (Gately, 2008), and 700 BCE in Greece (Hanson, 2013) - that were used for storing alcoholic beverages that were prepared form grapes, berries, rice, honey, wheat, and barley. With the commencement of the second and first centuries BCE, alcohol intoxication was no longer rare among the common people. India and China have very well-established and extensively documented traditional medicine systems [Ayurveda and traditional Chinese medicine (TCM)] counteracting the ill-effects of alcohol consumption.

\section{History of Alcohol Consumption in China}

China has a rich legacy of fermentation products. Of the several recipes used for different products, one of the prominent being the beer recipe, that is in use over 5,000 years, made by fermenting ingredients such as tubers, Job's tears, barley, and broom millet (Wang et al., 2016). Some scholars have put forward the hypothesis that beer brewing by Shang tradition has its roots in the Neolithic Yangshao period (5000-2900 BCE), which dates back to the time of numerous agricultural settlement in the Yellow River Valley (Li, 1962; Huang, 2000; Wang et al., 2016).

Also, there is a similarity in terms of style in brewing vessels found in the Yangshao period like jiandiping (pointed-bottom vessel) amphorae and funnels, and those found in the modern ethnographic records and the historical period (Wang et al., 2016). But there is no direct confirmation of alcohol production from the Yangshao sites. There is a link between beer brewing and an increase in complexity in social structure marked by competitions among particular settlements, their hierarchical structure, and construction of large public buildings. Consumption of alcohol became common during feast days and rituals, with the beverages being financed by the elites, which was especially true of the late Yangshao period in the Wei River region (Liu, 2005), an area known as "the cradle of Chinese civilization" (Wang et al., 2016).

\section{History of Alcohol Consumption in India}

Alcohol consumption in India was in practice since the ancient times. During the Vedic period (ca. 1500-700 BCE) alcoholic drinks were used in various religious festivals, consumed widely by warriors groups, and a few other sections of society (Achaya, 1991; Sharma et al., 2010). The use of this also continued during post-vedic era, during Islamic invasion, British rule, and significantly increasing in the present scenario (Sharma et al., 2010). During the Vedic period, alcohol consumption is marked by evidence gathered by excavation of chief ingredients from various archaeological sites, which implies alcohol was produced more than 4,000 years ago, i.e., it was contemporary with ancient civilizations of Mesopotamia, Egypt, and China. 
Vedic literature refers to alcoholic beverages as soma and sura with the former being considered a sacred drink, and the latterthe drink of the common people. Alcohol consumption in the ancient days had certain restrictions: while Kshatriyas (warriors) were allowed to consume alcohols, Brahmins were completely forbidden to do so. In the post-Vedic period (700 BCE-1100 $\mathrm{CE})$, the tradition of drinking alcohol continued and it was served on special occasions like moving into a new house or during weddings. Also, we find alcohol usage mentioned in the epic book of Ramayana and Mahabharata (Prakash, 1961; Singh and Lal, 1979; Boesche, 2002; Sharma et al., 2010). In the Mauryan period of Indian history ( $4^{\text {th }}$ century BCE), the production and sale of alcohol was under strict control and there were special houses set up for drinking. Some of these facts have been mentioned by Kautilya (prime minister of Chandra Gupta Maurya). Kautilya has also mentioned the names of various alcoholic preparations like "prasanna" and "medhaka" made from fermented wheat flour and rice, respectively (Achaya, 1991; Boesche, 2002; Sharma et al., 2010).

During this period some sections of society like the Tantric sect incorporated the use of alcohol as an essential part of their religious ceremonies. They made madya (wine) an essential component of their ganachakra (tantric assembly). Two main medical practitioners of the post-Vedic India were Charaka and Sushruta. Charaka wrote that alcohol in right amounts at a right time and with enough food is beneficial. He posited that moderate drinking leads to preservation of intelligence, provides nourishment, digestion and pleasure, while Sushruta wrote about the use and abuse of alcohol.

Consumption of alcohol during the Islamic rule comes out with stick to prohibition, as liquor is forbidden in Islam; but still wine was used on a regular basis in royal or princely courts. At the start of the British and European colonial rule in India opium and cannabis were more popular, but slowly under the patronage of Europeans alcohol consumption began to thrive in India. A new brand of beer was developed by George Hodgson (London) for India, which was light in nature and had a bitter taste so later beer in India began to be known as "Indian Pale Ale." Also Edward Dyer from England established a brewery in Kasauli in the Himalayan region and it was called Dyer's Lion Beer and was credited with being the first commercially produced beer in Asia. Moreover, it found popularity among British troops. At the end of the $19^{\text {th }}$ century the Indian movement for independence grew stronger and leaders like Balgangadhar Tilak (during the first decade of $20^{\text {th }}$ century) urged the people to start boycotting British government licensed liquor shops. Also, women like Kasturbai, also known as Kasturba Gandhi (wife of Mahatma Gandhi) led strong movements against liquor sale and consumption. Alcohol consumption at this moment of time was considered a bad habit associated with the British and was highly condemned by women organizations, nationalists, and others. Alcohol consumption was spread by Indian soldiers and office clerks who served for the British and embraced the western culture of consuming alcohol (Wolpert, 1997; Saxena, 1999; Parkar et al., 2001; Benegal, 2005; Pryor, 2009; Sharma et al., 2010). An independent India imposed various laws and regulations on the production and sale of liquor, differing from state to state. Still, the consumption of alcohol continued to increase, and in between 2010 and 2017 a net increase of $38 \%$ was recorded from 4.3 to $5.9 \mathrm{~L}$ per adult per year. Apart from this, there are several states such as Andhra Pradesh, Gujarat, and Bihar where there are complete prohibition of alcohol.

In today's scenario consumption of lighter drinks like wine and beer is increasing at a remarkable rate with time. Drinking at a young age and social drinking is gaining popularity day by day and this is reflective of the changing Indian society. Many restaurants, bars, and social places have come up in India to meet social and urban drinking demands. Though people in India are now beginning to follow the concept of moderate and safe drinking, still a large percentage of people in India consume alcohol in a manner that is hazardous to them and the society. Education and proper counselling regarding alcohol consumption and the attendant dangers will have a bigger role to play in coming years to overcome this changing scenario in changing Indian society (Chandra et al., 2003; Singh and Bloom, 2004; Verma et al., 2004; Benegal, 2005; Sivaram et al., 2008; Sharma et al., 2010).

\section{ALCOHOL ABUSE AND SOCIAL IMPLICATIONS}

The alcohol use disorder (AUD) afflicts $20-30 \%$ of men and 10 $15 \%$ of women throughout the world according to the data compiled by the American Psychiatric Association (APA, 2013; Grant et al., 2015). A recent report of WHO estimated that in 2016 , over half (3.1 billion people or $57 \%$ ) of the global population over 15 years of age had abstained from drinking alcohol in the last 12 months and around 2.3 billion people are currently drinkers (WHO, 2019). Moreover, substantive figure, i.e., half of the populations of Americans, Europeans, and Western Pacific countries were indulged in alcohol consumption (WHO, 2019). According to Global Burden of Diseases, Injuries, and Risk Factor Study (GBD, 2016), data compiled from 1990 to 2016 for 195 countries and territories demonstrated that alcohol was the major contributor leading to death, disability, and bad health. In 2016 alone, the cause of death and disability due to alcohol consumption stands at the seventh leading risk factor, accounting to about $2.2 \%$ of female deaths and $6.8 \%$ of male deaths. But when the data was subcategorized for a special category of age group between 15 and 49 years, the scenario transformed from the seventh leading risk factor to the leading cause of deaths. The attributable death count stands at $3.8 \%$ for females and $12.2 \%$ for males.

Similarly, Borges and co-worker reported dose-response estimates for the odds ratio (OR) and population attributable risk of acute alcohol consumption and road traffic injury (RTI) (Borges et al., 2017). In this study the data was obtained and analyzed from 1,119 RTI patients who reached 16 emergency departments in countries like Trinidad and Tobago, Dominican Republic, Brazil, Guatemala, Costa Rica, Guyana, Nicaragua, Panama, Mexico, and Argentina. The results of the study 
highlights that 1 in every 6 RTI patients in emergency department agreed to have alcohol intake $6 \mathrm{~h}$ prior to injury. This figure was five times higher when compared to not drinkers. Thus, decreasing the intake of alcohol to low to moderate levels ( $\leq 4$ drinks) had significant impact on population burden and risk.

Applying local and global measures immediately in areas like Latin America and the Caribbean to decrease consumption of alcohol can reduce usage of alcohol among pedestrians, drivers, and passengers involved in RTI (WHO, 2010; Borges et al., 2017).

Due to low availability of methods to prevent alcohol consumption and treatment of alcohol-caused disorders in low- and middle-income countries, an e-health portal was launched by the World Health Organization (WHO) on December 6, 2012 relating to alcohol and health in a webbased self-help program. In such countries, the introduction of an effective e-health program can lead to a positive impact on people's health, as they provide self-help to people regarding alcohol consumption and the health complications related to it (Dedert et al., 2015).

Cognitive-behavioral therapy and self-help health programs have had significant effect among the programs targeting alcohol abuse in countries with high economic status (Riper et al., 2011; Riper et al., 2014; Sundstrom et al., 2017). Web-based programs are easily accessible for individuals who are at a high risk for developing disorders based on alcohol consumption and are supposed to prevent further health complications (Riper et al., 2011). Also some drinkers (referred to as hidden drinkers) who usually do not contact any health professionals for one reason or another can profit from these web-based programs and this is of great importance to the public health (Schaub et al., 2016; Schaub et al., 2018).

\section{ETHNOPHARMACOLOGICAL APPLICATIONS TARGETING ALCOHOL ABUSE}

This limited efficacy and associated adverse effects have urged us to deepen our understanding of the complementary approaches used in traditional and folk medicine. Notably, recent experimental evidence has proved the effectiveness of some herbal remedies (Carai et al., 2000; Xu et al., 2005; Abenavoli et al., 2009) with few possible side effects, and natural products in general are an established source of pharmacologically active molecules (Atanasov et al., 2015; Yeung et al., 2018).

The use of traditional products/formulations aims to target at: (a) reducing the desire to drink; (b) impeding gastrointestinal absorption of alcohol; and (c) expediting the process of alcohol and its metabolites clearance rate form the body (Xu et al., 2005).

XJL [Natural Pharmacia International [NPI] preparation \#28 (NPI-028)] is an herbal medicine developed in China and has been used for decades to decrease the intoxicating effects of alcohol. Extracts of Pueraria montana var. lobata (Willd.) Maesen \& S.M.Almeida ex Sanjappa \& Predeep (syn. Pueraria lobata (Lour.) Merr. (kudzu) and Citrus $\times$ aurantium L. (syn. Citrus reticulata) are among the many plant extracts that have been used in preparing XJL. The exact mechanism of action of kudzu is unknown but studies carried out on isoflavones like daidzein, daidzin, and puerarin (phytochemicals found in kudzu extract) have concluded that these phytochemicals decrease the consumption of alcohol by alterations in monoamine oxidase (MAO)-acetaldehyde pathways or mitochondrial ALDH2 pathways (Keung, 2003; Lukas et al., 2013).

Chunggan extract (CGX) is a commercially marketed herbal medicine of 13 herbs, which finds its utility as a potent "liver cleaning" agent (Choi et al., 2006; Kim et al., 2014). Kim et al. (2014) observed pharmacological properties of CGX with the main focus on molecules related to alcohol metabolism and profibrogenic cytokines. They also saw the mechanism in ratderived HSC cell line (using HSC-T6 cells) (Kim et al., 2014).

Recent experimental development to the application of herbal and traditional medicines has led to the isolation and characterization of pure and active compounds such as daidzin, daidzein, and puerarin from Pueraria montana var. lobata (Willd.) Maesen \& S.M.Almeida ex Sanjappa \& Predeep, iboganine from Tabernanthe iboga Baill., tanshinones I and II, cryptotanshinone, and miltirone from Salvia miltiorrhiza Bunge, hyperforin from Hypericum perforatum L., ginsenosides from Panax ginseng C.A.Mey., and withanolide D and withaferin A from Withania somnifera (L.) Dunal etc., that are some of the widely studied and well-known species suppressing alcohol intake in experimental animals (Sweetnam et al., 1995; Butterweck et al., 1997; Rezvani et al., 2002; Abenavoli et al., 2009; Zhu et al., 2017). These substances are known to put forth their effects by influencing several of the neurological systems, thereby suppressing drinking behavior. In this section, Table $\mathbf{1}$ provides a brief summary on various plant species and natural products derived from them and their proposed mechanisms of action in the context of alcohol intake. The chemical structures of some of the important discussed natural products are presented in Figure 1.

\section{METHODOLOGY}

We collected and documented scattered information on counteracting of alcohol abuse through medicinal plants. The synonyms of the various species were cross-checked with the plant databases (https://mpns.science.kew.org). Afterwards, the available articles on respective species were retrieved using popular search engines and various databases, for instance, Scifinder, Science Direct, PubMed, Scopus, Mendeley, JOAP, Microsoft Academic, and Google Scholar. The keywords used were alcohol dependence, addiction, complimentary medicines, phytotherapy, ethnopharmacology, and ethnobotany, alcohol dehydrogenase enzyme, dopamine, gamma-amino butyric acid, etc. The data was congregated through the Boolean information retrieval method using plant name along with "AND” operator (Pohl et al., 2010; Tewari et al., 2017a) followed by alcohol dependence and addiction. No prerequisite limitations on publications, i.e., language, year, and publication type (original 
TABLE 1 | Plants used for prevention and treatment of alcohol abuse in different folk medicine practices.

\begin{tabular}{|c|c|c|}
\hline Botanical name & $\begin{array}{c}\text { Main phytochemical } \\
\text { structure }\end{array}$ & Possible mechanism \\
\hline
\end{tabular}

Pueraria montana var. lobata (Willd.) Maesen \& S.M.Almeida ex Sanjappa \& Predeep (syn. Pueraria lobata (Lour.) Merr.)

Salvia miltiorrhiza Bunge

Hypericum perforatum L.

Panax ginseng C.A.Mey.

Tabernanthe iboga Baill.

Withania somnifera (L.) Dunal

Macropiper methysticum

(G.Forst.) Miq. (syn. Piper

methysticum G.Forst.)

Thunbergia laurifolia Lindl.

Banisteriopsis caapi (Spruce ex Griseb.) Morton

Corydalis yanhusuo (Y.H.Chou \&Chun C.Hsu) W.T.Wang ex

Z.Y.Su \& C.Y.Wu

Lophophora williamsii (Lem. ex SalmDyck) J.M. Coult.

Mescaline (3,4,5-trimethoxy-

Hovenia dulcis Thunb. $\beta$-phenylethylamine)

Isoflavones derivatives (daidzin, puerarin)

Phenanthrenequinones compounds including cryptotanshinone, tanshinones I, II, and miltirone

Phloroglucinol derivatives (adhyperforin, hyperforin), and anthraquinone derivatives (hypericin, pseudohypericin) Ginsenosides

lbogaine

Withanolide D and withaferin A

Kava lactones

Iridoid glucosides of 8-epigrandifloric acid and 3'-O- $\beta$ glucopyranosyl stilbericoside

Beta-carbolines, such as harmine, harmaline, and tetrahydroharmine $(\mathrm{THH})$ Lev-tetrahydropalmatine (LTHP)

Ampelopsin, hovenitins I, II, \& III, laricetrin, myricetin, and gallocatechin

$\gamma$-linolenic acid (GLA)
1. Reversible inhibition of mitochondrial ALDH-2 and increase of 5-hydroxyindole 3- acetaldehyde (5HIAL) (Keung and Vallee, 1998a; Keung and Vallee, 1993b; Lu et al., 2009).

2. Alteration of BDZ receptors positioned on GABA-chloride channel complex (Shen et al., 1996; Keung and Vallee, 1998).

3. Alcohol-induced inhibition and disruption of hippocampus function leading to the suppression of cfos protein (FOS) expression (Jang et al., 2003; Rezvani et al., 2003).

1. Militirone, low-affinity ligand for central $G A B A_{A}-B D Z-$ binding site, thus acting as a partial agonist and implying an anxiolytic effect (Lee et al., 1991).

2. Miltirone partly inhibits upsurge in mRNA levels of the $\alpha 4$ subunit of GABA that was persuaded

through ethanol withdrawal in cultured hippocampal neurons (Mostallino et al., 2004; Zhu et al., 2017).

3. Tanshinone IIA improves alcoholic liver disease by decreasing lipopolysaccharide and Kupffer cell sensitization induced by alcohol (Yin et al., 2008).

4. Cryptotanshinone inhibits ALD through hindering fatty acid synthesis and hepatic cell death (Yin et al., 2009).

1. Inhibits the uptake of serotonin and noradrenaline (aminergic transmitters) in the synaptic nerve endings (Butterweck et al., 1997; Kumar et al., 2006).

2. Increase in level of serotonin, dopamine, norepinephrine or through stimulation of opioid and sigma receptors in the CNS (Müller et al., 1997; Panocka et al., 2000).

1. Increase of metabolism of alcohol and decreased blood alcohol levels (BALs) by enhancing ADH activity and plasma clearance (Lee et al., 1993).

2. Incite the microsomal ethanol-oxidizing system and ADH action and thereafter fasten the removal of acetaldehyde while shunting the excessive hydrogen into lipid biosynthesis (Abenavoli et al., 2009). 1. Suppressive effect on alcohol intake by regulating several neural pathways particularly dopaminergic and serotonergic systems (Deecher et al., 1992; Sweetnam et al., 1995; Overstreet et al., 2003).

2. Interacts with k-opiate receptor and inhibits k- receptor mediated dopamine release in rats (Deecher et al., 1992; Reid et al., 1994).

Blocks GABA receptors binding and up-surges chloride influx in absence of GABA (Gupta and Rana, 2008; Lu et al., 2009; Ruiu et al., 2013).

1. Binding to multiple locations in the brain and interaction with different neurotransmitters and significant inhibition of the uptake of noradrenaline, but not serotonin (Sällström Baum et al., 1998). 2. Also affects the concentration of dopamine and its metabolites that is/are in turn associated with altered behavioral response in rats (Sällström Baum et al., 1998).

1. Increase of blood flow signals in amygdala, nucleus accumbens, frontal cortex, and caudate putamen (areas in the brain linked with addictive drug pathways) (Thongsaard et al., 2005).

2. Shares similarity with amphetamine in increasing potassium-triggered dopamine release from rat striatal slices, suggesting the potential efficacy for addictive drugs is dopamine-dependent

(Thongsaard and Marsden, 2002).

1. Harmine and harmaline showed substantial inhibitory (in vitro) activity against MAO-A and -B in human brain and stimulate dopamine release (Samoylenko et al., 2010).

2. THH can also inhibit serotonin reuptake (Samoylenko et al., 2010).

1. L-THP inhibits oxycodone-induced hyperactivity (Liu et al., 2005).

2. Anti-addictive properties may be due to dopamine transmission antagonism.

3. Inhibits dopamine receptors D1 and D2 and acts upon the nigra-striatal neuronal pathways and inhibits pre- and post-synaptic receptors (Marcenac et al., 1986; Jin, 1987).

4. Prevents L-type $\mathrm{Ca}^{2+}$ channels inhibition; here it is notable that $\mathrm{L}$-type $\mathrm{Ca}^{2+}$ channel inhibition is vital for the development of drug tolerance, sensitization, and dependence (Jin, 1987).

The mescaline molecule is structurally similar to serotonin and acts on the serotonin $\left(5-\mathrm{HT}_{2 \mathrm{~A}}\right)$ receptor. 5- $\mathrm{HT}_{2 \mathrm{~A}}$ receptors activation increases cortical glutamate levels apparently through a presynaptic receptor-mediated release from thalamic afferents (Nichols, 2004; Gibbons and Arunotayanun, 2013).

1. Decrease of gastrointestinal absorption of alcohol and reducing of blood alcohol concentration (Xu et al., 2005).

2. Effective in enhancing ALDH activity than ADH activity, blocks lipid peroxidation, and eradicates unwarranted free radicals produced by alcohol (Yoshikawa et al., 1996b; Hase and Basnet, 1997; Xu et al., 2004).

1. Excess alcohol consumption hinders the metabolism of GLA, which is a precursor of prostaglandins. As a result, prostaglandins E1 (PGE1) levels are reduced in alcohol addicts, often leading to depressive states that increase patients' inclination to drink. The need to drink is thus indirectly lowered by a reduction in the depression symptoms (Tomczyk et al., 2012).

2. Protects liver and kidney damage caused by alcohol intake by counteracting the enzyme inhibition (Glen et al., 1987; Abenavoli et al., 2009; Tomczyk et al., 2012) 

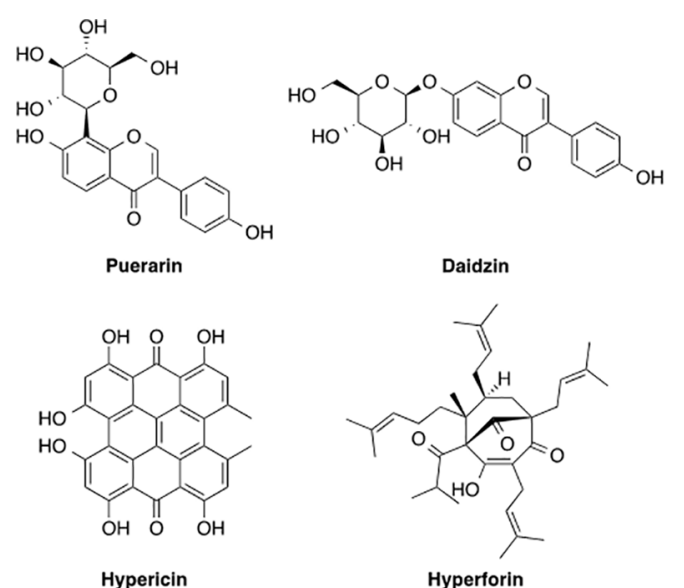

Hypericin
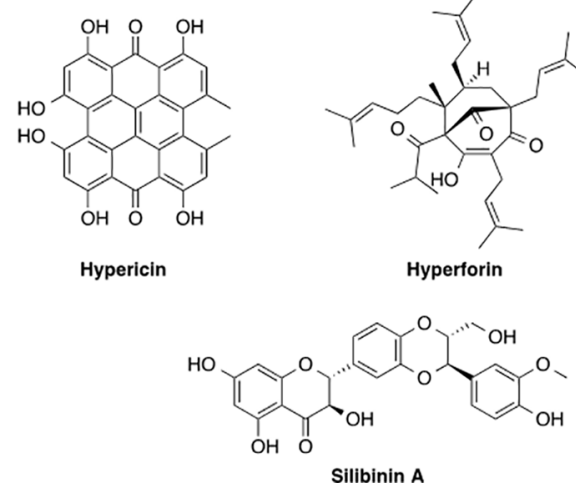
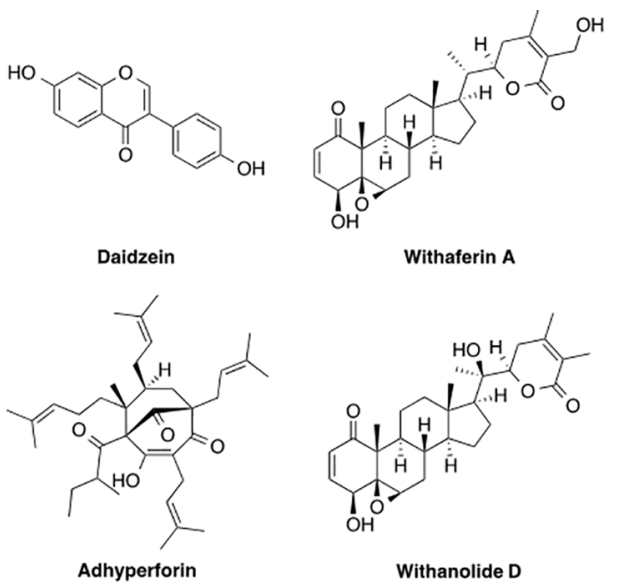

Withaferin A
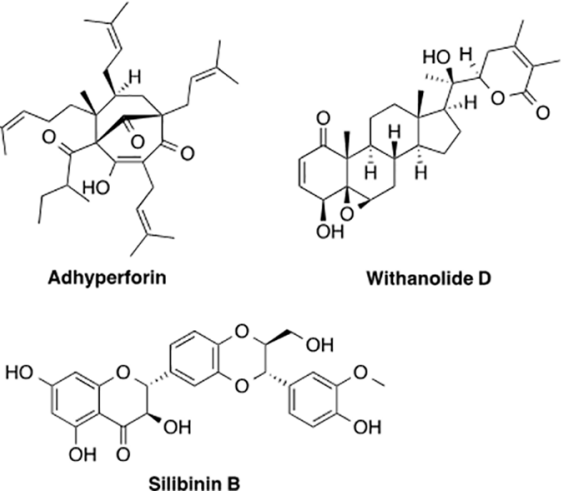

FIGURE 1 | Chemical structures of some important natural products.

contribution, review article or key editorial note), were taken into consideration. An outline of the various plants species used for prevention and management against alcohol abuse is presented in Table 1.

\section{PROMINENT MEDICINAL PLANTS/ EXTRACTS FOR MANAGEMENT OF ALCOHOL DEPENDENCE AND ABUSE}

\section{Pueraria montana var. lobata (Willd.) Maesen \& S.M.Almeida ex Sanjappa \& Predeep}

P. montana var. lobata (Willd.) Maesen \& S.M.Almeida ex Sanjappa \& Predeep (syn. Pueraria lobata (Lour.) Merr.) (Fabaceae), commonly known as kudzu, is a perennial climbing plant distributed throughout Asia (including Japan, Korea, China), as well as in some regions of North and South America. Kudzu is a noxious weed in the United States and it has been used for several centuries as Puerariae radix in traditional Chinese medicine. The plant has been known since the Pharmacopeia of Shen Nong (about 200 BC) in China and used as antidiarrheal, antiemetic, diaphoretic, and antipyretic agent (Zhu et al., 2017). Apart from this, the species finds its utility in treatment of fevers, muscle aches, gastrointestinal disorders, skin problems, allergies, high blood pressure, and chronic alcoholism (Lee et al., 1999; Abascal and Yarnell, 2007).

Chinese Pharmacopeia of $600 \mathrm{AD}$ describes its application in treatment of alcohol intoxication (Sun Simiao, about $600 \mathrm{AD}$ ) and as an anti-dipsotropic agent (Li Dongyuan, about 1200 AD). Crude extract of the species is a significant source of physiologically valuable isoflavones including puerarin, daidzin, and daidzein (Ohshima et al., 1988), compounds notably reported to be useful in suppressing free-choice ethanol intake in Golden Syrian hamsters (Keung and Vallee, 1993a), Wistar rats (Heyman et al., 1996), Fawn Hooded rats (Overstreet et al., 1996), and alcoholpreferring (P) rats (Lin et al., 1996; Benlhabib et al., 2004a).

The probable neurological pathway acting against ethanol intake is said to be mainly due to daidzin, a selective and reversible mitochondrial ALDH-2 inhibitor. It is crucial for acetaldehyde oxidation, which is a resultant of ethanol metabolism by suppression of reactive intermediates 5-hydroxyindole-3-acetic acid (5-HIAAA) and 3,4-dihydroxyphenylacetic acid (DOPAL) formation from serotonin and dopamine (Keung and Vallee, 1998), as a result of which there is an increase in levels of 5hydroxyindole 3-acetaldehyde (5-HIAL) and DOPAL. Thus, daidzin appears to stifle alcohol intake through aggregating 5HIAL and inhibiting ALDH-2 (Keung, 2003).

Shen et al. (1996) studied the pharmacological effects of daidzin and puerarin on ethanol via GABA/BDZ-chloride channel complex. BDZ tranquilizers are known to modulate the efficiency of inhibitory neurotransmitter GABA at the GABA/BDZ-chloride channel complex in the brain (Harris, 1990; Lin et al., 1993).

The in vitro use of daidzin and puerarin showed a mixed competitive and non-competitive inhibition of $\left[{ }^{3} \mathrm{H}\right]$ flunitrazepam binding to cortical, cerebellar, and hippocampal membranes in the brain. Alcohol is known to modulate the brain's mechanism to inhibit neurotransmitter GABA by chloride channel complex. Hence, kudzu extract can be used as an agent for treating alcohol dependence by virtue of its actions on $\mathrm{BDZ}$ receptors and role in modification in monoamine metabolism. 
In a recent study, Penetar and colleagues administered kudzu extract after an episode of acute drinking, in order to check the rate/level of ethanol concentration in blood (Penetar et al., 2011). Similarly, Shen and co-workers, using rats as the experimental animal, demonstrated that dihydromyricetin (DHM) [(2R,3R)-3,5,7-trihydroxy-2-(3,4,5-trihydroxyphenyl)2,3-dihydrochromen-4-one], a flavonoid component of kudzu extract, is effective against acute ethanol intoxication, thereby increasing alcohol withdrawal symptoms possibly by $\mathrm{GABA}_{\mathrm{A}}$ receptor-mediated mechanism. The increased hippocampal expression of $\mathrm{GABA}_{\mathrm{A}}$ receptor and interaction of $\mathrm{DHM}$ with the $\mathrm{BDZ}$ site on the $\mathrm{GABA}_{\mathrm{A}}$ receptor were held responsible for the above-mentioned actions of DHM (Shen et al., 2012).

The extract of kudzu has an excellent ability to change the effects of alcohol or reduce alcohol consumption in animals used in laboratories (Heyman et al., 1996; Keung and Vallee, 1993a; Overstreet et al., 1996; Keung, 2003). The extract can decrease the alcohol intake by up to $50 \%$ and the effect develops within only 1 to 2 days. It is an accepted fact that the isoflavones of kudzu extract have an ability to decrease alcohol consumption in a variety of mammalian species, regardless of the mechanism of action (Lukas et al., 2013).

There are several advantages of kudzu extract treatment over other medicines; for instance, it has minimal adverse effects when compared to its synthetic counterparts (Lukas et al., 2013).

\section{Salvia miltiorrhiza Bunge}

Salvia miltiorrhiza Bunge (Lamiaceae), commonly named as Danshen or Red Sage root, is a perennial medicinal herb that is extensively used across Asia. The name "salvia" is derived from a Latin word "salvere" meaning "to heal," which is in line with the folkloric belief regarding it as a plant with "magical" healing properties (Kasimu et al., 1998). The species is highly valued for its root and is classified as "super grade herb (herbs without observable toxicity)" in Shennong's Herbal Classic of Materia Medica (Shennong Bencao Jing about 221 BC to 220 AD) and has been utilized for over 2000 (Wang et al., 2017). It is listed in the Chinese Pharmacopoeia for treatment of menostasis, menstrual disorder, insomnia, menorrhalgia, and blood circulation diseases (China Pharmacopoeia Committee 2005). Recent investigation advocated its utility in different substance abuse, such as abuse of tobacco, alcohol, and various other drugs (Mah et al., 1998). The extract of the species is reported to be useful in the treatment of liver diseases, acquired immunodeficiency syndrome (AIDS), diabetic nephropathy, etc. (Abd-Elazem et al., 2002; Peng et al., 2018).

The major chemical constituents of $S$. miltiorrhiza roots are diterpene pigments, of orange-red color, with a phenanthrenequinone structure, such as tanshinones I, II, cryptotanshinone, and miltirone (Serra et al., 2003). Other biologically active constituents include danshensu, protocatechualdehyde, rosmarinic acid, and salvianolic acid A (Luo et al., 2015). Over 30 tashinone compounds are isolated from S. miltiorrhiza and that have antioxidant, antitumor, antiplatelet, and antiviral properties (Zhang and Wang, 2006). Pharmacological properties of some of these molecules have been well explored. Compounds such as tanshinones I and II, miltirone, and cryptotanshinone are known to play a key role in reducing alcohol intake in model animals (Carai et al., 2000; Serra et al., 2003), thus promoting antirelapse in alcoholpreferring rats (Colombo et al., 2006).

Lee et al. (1991) reported militirone as a low-affinity ligand for central $\mathrm{GABA}_{\mathrm{A}}-\mathrm{BDZ}$-binding site responsible for many behavioral consequences of alcohol, and hence acting as a partial agonist and having an anxiolytic effect (Lee et al., 1991). Similarly, IDN 5082 (standardized extract of Danshen) inhibited discriminative stimulus effects of ethanol in Sardinian alcoholpreferring ( $\mathrm{sP}$ ) rats (trained to distinguish ethanol from water) (Colombo et al., 1999) and substantially suppressing ethanol acquisition (Serra et al., 2003), an indication of its antirelapse properties (Serra et al., 2003). Likewise, Koo et al. (2004) reported that Danshen crude water extracts stimulated potassium-dependent release of dopamine from striatal slices of rats comparable to amphetamine (a stimulant drug) suggesting a probable mechanism of action that might be useful for substance abuse pharmacotherapy. Similarly, tanshinone II, an active constituent of the root extract, is reported to ameliorate ALD activity by reducing lipopolysaccharide and ethanol-induced Kupffer cell sensitization (Yin et al., 2008), while cryptotanshinone is reported to inhibit ALD by blocking hepatic cell death and fatty acid synthesis (Yin et al., 2009). Likewise, salvianolic acid B relieved acute ethanol-induced hepatocyte apoptosis through sirtuin 1-mediated deacetylation of the p53 transcription factor pathway (Li et al., 2014).

\section{Hypericum perforatum L.}

Hypericum perforatum L. (Clusiaceae) commonly named as St. John's wort (SJW) is an herbaceous perennial plant, with extensive creeping rhizome. The word hypericum derives from Greek "hyper" (over) and "eikon" (image or apparition), which reflects the herb's use against evil spirits. The species is native to Europe (Klemow et al., 2011), and widely distributed across the temperate areas of North Africa, Asia, Australia, and America (Gleason and Cronquist, 1963). Due to putative medicinal property it was recommended against various disorders from the first century onwards by various Greek physicians (such as Dioscorides, Galen, Hippocrates, and Pliny). Ever since then it has endured as a popular remedy for intestinal worms, anxiety, cuts, burns, depression, snakebites, and menstrual disorders (Castleman, 2001; Redvers et al., 2001). The species is also known to possess hypotensive, antibacterial, spasmolytic, stimulating (Chopra and Nayar, 1956), diuretic, (Solujic et al., 1997), analgesic, anti-inflammatory (Bukhari et al., 2004), anticancer, antitumor, antioxidant, antischizophrenic, anticonvulsant, and antidiabetic properties (Birt et al., 2009; Caraci et al., 2011; Can and Ozkay, 2012).

The species has been widely studied for its chemical composition and pharmacological properties. As a result, many representatives of bioactive compound groups have been isolated and described, including hypericin and pseudohypericin (naphtodianthrones), hyperforin, adhyperforin (phloroglucinol derivatives), several flavonol glycosides, proanthocyanidins, phenylpropanes, biflavones, xanthones, tannins, and some amino acids (Bombardelli and Morazzoni, 1995; Barnes et al., 2001). 
SJW's use is popular as an herbal remedy due to its efficacy against many diseases, especially depression and alcohol dependence. Recent experimental and clinical studies have identified hyperforin as an active biological compound with antidepressant qualities (Abenavoli et al., 2009), also being a good signature agent for reducing alcohol intake and desire to drink (Perfumi et al., 2001).

In-depth study on alcoholism and depression led to the identification of a common neurochemical substrate for both disorders (Markou et al., 1998), whereby coexistence of two or more neurochemical events was traced amid high alcohol intake and a depression-like condition in experimental alcoholpreferring rats. Ballenger et al. (1979) thought that depression and alcoholism might result from low serotonin levels that are augmented transiently by alcohol intake (Ballenger et al., 1979). Serotonin-targeting compounds reduced pathological drinking in experimental animals (Murphy et al., 1988; Rezvani et al., 1991; Rezvani and Grady, 1994). Notably, other preclinical studies have suggested that SJW has a role in reducing voluntary intake of alcohol. These works base their assertion on the tests carried out on selectively bred alcohol-preferring rats (De Vry et al., 1999; Panocka et al., 2000), Fawn-Hooded (FH) rats (Overstreet et al., 1992; Rezvani et al., 2002), high alcoholdrinking (Had) rats, Marchigian Sardinian (msP), and sP rats (Ciccocioppo et al., 1999).

Likewise, from other clinical and experimental studies, hyperforin, a lipophilic constituent of SJW, was found to inhibit aminergic transmitter's uptake of serotonin and noradrenaline into synaptic nerve endings (Kumar et al., 2006). It was also known to increase the level of norepinephrine, dopamine, serotonin, and GABA in the brain.

Other than this, the probable anticraving and antidepressant effects of SJW have been suggested to be as a result of increase in the levels of serotonin, dopamine, norepinephrine, or by sigma and opioid receptors stimulation in the CNS (Butterweck et al., 1997; Müller et al., 1997).

\section{Panax ginseng C.A. Mey}

Panax ginseng C.A. Mey (Araliaceae) is a well-known perennial herb, documented as ginseng in the traditional Chinese system of medicine. Its name is derived from the Greek words "pan" (all) and "axos" (cure) meaning possess of an inherent property to "cure all diseases." The species is widely distributed in northeastern regions of the Korean peninsula (Park et al., 2005). For 5000 years the species has been used in certain parts of the world especially in Korea, China, and Japan. It is both a nourishing and tonifying agent and a potent therapeutic agent for many diseases like liver diseases, immune diseases, cancer, depression, fatigue, diabetes, internal degeneration, tumors, inflammation, nausea, dyspepsia, vomiting, nervousness, pulmonary problems, stress, and ulcers (Lee et al., 2005).

The pharmacological effects of ginseng are due to various bioactive molecules like ginsenosides, fatty acids, polysaccharides, peptides, peptidoglycans, phytosterols, triterpene saponins, and phenolic compounds. It is also known to contain essential oils, i.e., polyacetylenes and sesquiterpenes (Kim et al., 2017). Ginsenosides represent the unique and major pharmacological active constituents of ginseng that are said to be present as triterpene glycosides (Rastogi et al., 2015). Over 100 ginsenosides have been isolated from Panax, out of which 40 are found in P. ginseng alone (Christensen, 2009), mainly Rb1, Rb2, Rc, Rd, Rg1, Rg2, Rh1, and Re (Attele et al., 1999). Most pharmacological studies of ginsenosides were done for their immunostimulatory, anticancer, anti-inflammatory, antioxidative, prevention of opioid, and psychostimulant abuse and dependence (Tokuyama and Takahashi, 2001). However, little attention has been paid to alcohol intoxication.

Joo et al. (1982) proposed that ginseng saponins increased alcohol metabolism and lowered BALs by increasing $\mathrm{ADH}$ activity and plasma clearance (Joo et al., 1982). A few authors have reported on ginseng extract decreasing alcohol consumption, which was later confirmed by Lee et al. (1987). Clinical studies on volunteers demonstrated that in 10 out of 14 cases, ginseng extract accelerated alcohol clearance by $31-51 \%$. Moreover, a recent study demonstrated that administration of red ginseng extract to alcohol-intoxicated rats altered alcohol absorption from the gastrointestinal tract (Carai et al., 2000) and prevented memory failure and excitation (Bao and Saito, 1984). It is also known to stimulate the microsomal ethanol-oxidizing system and the $\mathrm{ADH}$ enzyme action as a result of which there is a faster oxidation and removal of acetaldehyde with rapid shunting of excess hydrogen into lipid biosynthesis (Kwak and Joo, 1980). Thorough investigations are still needed concerning the value of ginseng in the treatment of alcoholism and associated problems, e.g., memory loss and nervous reactions.

\section{Tabernanthe iboga Baill}

Tabernanthe iboga Baill (Apocynaceae), commonly named as Iboga, is a perennial rainforest shrub native to Western Central Africa. Its principal psychoactive compound ibogaine is making up $80 \%$ of the psychoactive compounds, and it represents indole alkaloid, which can be isolated from the roots of the plant. Some of the other compounds include ibogaline, which constitutes about $15 \%$, ibogamine - up to $5 \%$ and-to a lesser extenttabernanthine and vocangine (Kontrimaviciute et al., 2006; Maciulaitis et al., 2008).

Ibogaine, a psychoactive compound used for preclinical and anecdotal studies, has proved its prominent role in drug addiction therapy. Scrapings of iboga root bark with potent hallucinogenic and therapeutic properties have been used for centuries in various medicinal formulations, i.e., in small doses to combat hunger, fatigue, sleep, and thirst; in high doses it was used for spiritual experiences (Alper et al., 2008). Boiled leaves are applied in the treatment of toothache, latex-in the treatment of anthelmintic turmoil, and the roots as anesthetic and febrifuge agents (Pope, 1969). In the early 1960s, the psychotherapeutic effects of ibogaine were studied by a Chilean psychiatrist, Dr. Claudio Naranjo. He observed that ibogaine administration led to an active period of visualizing of past events often described as a "waking dream state" (Gallo et al., 2009). The exact mechanism by which this psycho-pharmacological drug affects the brain is poorly understood. Iboga alkaloids [i.e., ibogaine, noribogaine and 18-methoxycoronaridine (18-MC)] are reported to have multiple and complex mechanisms of action within the CNS (Alper et al., 2008). Ibogaine at low micromolar concentrations is 
reported to possess a binding affinity for several receptors present within the CNS, including glutamate, kappa, muopioid, and sigma 2 receptors, $N$-methyl-D-aspartate (NMDA), sodium channels, and the serotonin reuptake transporter (Brown, 2013; Gallo et al., 2009; Mash et al., 2018).

Ibogaine has been effective in the treatment of different drugs abuse, including of morphine, cocaine, heroin, alcohol, and nicotine (Overstreet et al., 2003; Rezvani et al., 2003; Abenavoli et al., 2009). Ibogaine administration is known to cause a substantial reduction in drug withdrawal symptoms, a marked drop in the desire to use drugs; however, it can only be regarded as a simple initial element in the complete rehabilitation strategy. The preclinical studies support the use of the plant, whereby iboga alkaloids induced a significant reduction of opioid withdrawal signs in rats (Dzoljic et al., 1988; Maisonneuve et al., 1991; Parker et al., 2002; Panchal et al., 2005), in mice (Frances et al., 1992; Popik et al., 1995; Layer et al., 1996), and in primate (Leal et al., 2003). Iboga alkaloids are reported to decrease the self-administration of morphine (Pace et al., 2004), cocaine (Glick et al., 1994), amphetamine (Maisonneuve and Glick, 1992), methamphetamine (Glick et al., 2000; Pace et al., 2004), alcohol (Rezvani et al., 1995b; Rezvani et al., 1997), and nicotine (Glick and Maisonneuve, 1998; Glick et al., 2000).

Ibogaine is also said to be effective in treating alcohol dependence and abuse and was found to expressively reduce volitional alcohol consumption desire in alcohol-preferring $\mathrm{FH}$, $\mathrm{P}$, and AA rats. The anticraving effects of ibogaine are thought to be due to its ability to interact with the CNS and its ability to stimulate the dopamine and serotonin systems (Glick et al., 1991). Other than this, an analogue of ibogaine, i.e., 18-methoxycoronaridine (18$\mathrm{MC})$, displays the anticraving property in the same fashion as ibogaine by regulating dopamine and serotonin systems (Rezvani et al., 2003). In order to trace out the possible mode of actions or events happenings inside the brains, ibogaine and its analogue were tested. On systematic administration of iboga in alcohol-fed rats, the results showed that it significantly altered the level of dopamine and its metabolites within nucleus accumbens, striatum, and prefrontal cortex within the rat's brain (Sloviter et al., 1980; Maisonneuve et al., 1991), thus highlighting the anticraving property possessed. Similarly, on systemic administration of 18-MC it also resulted into decrease in extracellular levels of dopamine in nucleus accumbens of rats brain, thereby intimating its probable role in suppressing alcohol intake as off ibogaine. Other than this, the other possible mode of action of analogue 18-MC against alcohol intake includes its ability to associate and regulate the functional entity of opioids receptor, in the same fashion as ibogaine, which in turn interacts with k-opiate receptor (Deecher et al., 1992) and inhibits dopamine release (Reid et al., 1994). Thus, a possible suppressant effect on altering the endogenous opioid system is believed to counteract alcohol intake.

\section{Withania somnifera (L.) Dunal}

Withania somnifera (L.) Dunal (Solanaceae) is commonly known as "Ashwagandha" or "Indian winter cherry." It is regarded as a "Medhya rasayan" (Nootropic herb) in classical Ayurvedic system (Bhattacharya and Kumar, 1997; Maurya, 2010). Ashwagandha has been traditionally used as an herbal or metallic admixture that acts as rejuvenating and revitalizing agent. The species is distributed in Southeast Asia and also from the Mediterranean region to South Africa. Extracts from different plant parts like leaves, bark, stems, roots, and the entire plant are used for various therapeutic purposes including neurological, cardiovascular, gastric immunological conditions, and metabolic disorders such as diabetes (Mishra et al., 2000; Dar et al., 2017). The pharmacological effects of the species that have been thoroughly investigated over the years, chief phytoconstituents such as withanolide D and withaferin A, a group of steroidal lactones (Sharma et al., 2011) embarking much of the medicinal property. The other phytochemical constituents include steroidal lactones (glucosides-sitoinosides VII/VIII), cuscohygrine, tropine, alkaloids (withanine, somniferine, withananine, sominone, somnine, etc.), and saponins (Mishra et al., 2000).

Therapeutically Ashwagandha extract is used as an adaptogen, memory enhancer, aphrodisiac, energy tonic, and in the treatment of depression, hypertension, general debility, as anxiolytic, astringent, diuretic, narcotic, thermogenic, depurative, and stimulant, anthelmintic, anti-stress, antiinflammatory, anti-carbuncle, in rheumatism, constipation, insomnia, leucoderma, nervous breakdown, goiter, leucorrhea, piles, and oligospermia (Agarwal et al., 1999; Machiah et al., 2006; Machiah and Gowda, 2006).

Ashwagandha extract is reported as a potent enhancer of cellular antioxidant mechanisms (Parihar et al., 2004) and exhibits a free radical scavenging activity. It is also reported to strengthen morphine-induced analgesia, averts the progress of morphine-induced rebound hyperalgesia (Orrù et al., 2014) and attenuates the development of tolerance to morphine's analgesic effects. The most likely mechanism involves multiple roles on neurotransmitters acting synergistically; it might block the GABA binding to its receptors as a result of an increase in chloride influx in the absence of GABA (Ruiu et al., 2013). Keeping that in mind, Gupta and Rana (2008) hypothesized that formulations of Ashwagandha extract might help in reducing ethanol withdrawal-induced anxiety and potentiate ethanolinduced anxiolysis (Gupta and Rana, 2008).

\section{Silybum marianum (L.) Gaertn}

Silybum marianum (L.) Gaertn. (Asteraceae), commonly known as milk thistle, is an important annual/biannual plant growing to a height of $1.5 \mathrm{~m}$ long (Rambaldi et al., 2005). The species is native to the Mediterranean region; however, nowadays it is grown and cultivated around the world (Abenavoli et al., 2010). Traditionally, the plant was used as "galactogogue" (Ross, 2008). For more than 2000 years the plant has been used in the treatment of liver, kidney, spleen, headache, dyspepsia, eczema, migraine, psoriasis, and digestion disorders and gallbladder diseases (Gupta and Gupta, 2017; Tewari et al., 2017b). The species has antioxidant, antidiabetic, antihypertensive, antiatherosclerotic, and hypolipidemic properties that are useful in the treatment of liver and gallbladder disorders, including hepatitis, liver cirrhosis, and jaundice, and play a preventative role in cancer, neurodegenerative disorders such as Parkinson's and Alzheimer's diseases (Kren and Walterova, 2005; Bahmani et al., 2015; Tajmohammadi et al., 2018). Its 
herbal formulations are used against food poisoning, seasonal allergies, and several chemical and environmental toxins consumptions, i.e., alcohol intoxication and Amanita phalloides mushroom poisoning, acetaminophen, carbon tetrachloride, iron overload, phenylhydrazine, or bites and stings by snakes and insects (Abenavoli et al., 2010; Corchete; Kren and Walterova, 2005; Gupta and Gupta, 2017).

The above-mentioned pharmacological effects of milk thistle are derived from multiple bioactive compounds with potent biological properties. 'Silymarin' that is basically a composite mixture of flavonolignans (flavanone derivative) obtained from fruits and seeds (achenes) of the plant, accounts for nearly $70-80 \%$ of the pharmacopeia and represents nearly $1.5-3 \%$ of the dry weight (Abenavoli et al., 2010; Tajmohammadi et al., 2018). The important major constituent present in silymarin is silybin (silibinin) that is a mixture of diastereoisomers, silybin A and B, accounting for nearly $50 \%$ of the extract. Other bioactive components present in silymarin are silychristin (about 20\%), silydianin (about 10\%), as well as isosilybin A and B (both approx. 5\%). For several centuries milk thistle has been used as a natural remedy for a number of disorders of which a prominent one is ALD. A report of WHO (2012) states that of the total number of deaths globally due to liver cirrhosis, approximately 50\% was caused by excessive and prolonged intake of alcohol (Hao et al., 2017). Out of the total cases of death globally alcohol leads to $1 \%$ of them (Masarone et al., 2016). A chronological series of events towards the progression of ALD includes alcoholic steatosis and steatohepatitis, fibrosis, and cirrhosis and lastly the development of hepatocyte carcinoma (Bataller and Brenner, 2005). ALD is a major cause of chronic liver injury, which results in liver fibrosis and cirrhosis, which is associated with the development of proinflammatory and profibrogenic cytokines, liver peroxidation, and ROS. Though, the pathogenesis of alcohol-induced organ damage is known, current therapies are not adequate and effective. Silymarin has gained in importance due to its cytoprotective property (Das and Mukherjee, 2012) and to the fact that upon intake, it concentrates within or near hepatocytes cells (Flora et al., 1998). Silymarin is also known to show competitive behavior with several biological toxins resulting into its blockade and thus preventing toxins penetration inside the hepatocyte cell, ultimately resulting into its protection. Apart from this, as ethanol metabolism is associated with amplified production of harmful ROS, silymarin by virtue of its potent antioxidant and scavenging property is known to effectively counteract these ROS species, including inhibiting lipid peroxidation and so it can be used as a supplement in the therapy of alcoholic liver cirrhosis (Saller et al., 2001; Corchete, 2008). Likewise, silymarin is also reported to stimulate nucleolar polymerase, an enzyme system controlling synthesis of ribosomal protein that in turn stimulates liver regeneration capability and new hepatocytes formation, therefore enhancing liver regenerative capacity (Boerth and Strong, 2002).

Despite these beneficial effects of silymarin, few clinical studies have been conducted over the years. Ferenci et al. (1989) studied effects of silymarin on 170 patients diagnosed with liver cirrhosis; out of these 92 patients were specifically diagnosed with alcoholic liver cirrhosis. Two groups of patients were delineated; one received oral administration of silymarin (i.e., $140 \mathrm{mg} /$ day) three times a day while the control group was given placebo treatment for 2 years. It turned out that of the total number of deaths that occurred during the experiment the number in the placebo group was by twice higher (Ferenci et al., 1989). In another set of experiments, Vailati et al. (1993) studied alcoholic and viral chronic hepatitis patients using different doses of silymarin for 2 weeks. The doses of $160 \mathrm{mg} /$ day were administered to 19 patients, of $240 \mathrm{mg} /$ day to 17 patients and of $360 \mathrm{mg} /$ day to 18 patients. The results highlight a significant decrease in hepatic biochemical profile of both ALT and gamma-glutamyl transferase (GLT) levels as observed in the groups treated with 240 or $360 \mathrm{mg}$ of silybin/day (Vailati et al., 1993). Feher et al. (1989) performed a 6month double-blind liver functional test, involving serum, procollagen III and liver histology in 36 patients suffering from ALD. Liver functionality tests of the 17 ALD patients that were given 140 $\mathrm{mg}$ /day of silymarin for 6 months showed normalized functional behavior of serum bilirubin, AST and ALT, while a significant decrease in gamma-glutamyl transferase (GGT) and procollagen III was reported in the treated group as compared to the placebo group where only a decrease in GGT was observed, which was smaller than the treated group. Positive effects of silymarin were also reported on lymphocyte proliferation and lipid peroxidation as compared to the placebo group (Saller et al., 2001).

Das and Mukherjee (2012) studied the effectiveness of silymarin against ethanol-induced oxidative damage in the experimental mice. BALB/c 2-3 months mice with a body weight of 20-30 g were divided into four different groups. Group one was given $1.6 \mathrm{~g} /$ $\mathrm{kg}$ of ethanol, group two was exposed to $1.6 \mathrm{~g} / \mathrm{kg}$ of ethanol plus 250 $\mathrm{mg} / \mathrm{kg}$ of silybin, while the third group was fed with $250 \mathrm{mg} / \mathrm{kg}$ ethanol and $250 \mathrm{mg} / \mathrm{kg}$ ascorbic acid per day for 3 months, whereas the controlled group received isocaloric glucose solution. On histological and enzymatic analysis it was found that the levels of thiobarbituric acid and glutathione-S-transferase (GST) were significantly elevated in the blood hemolyzate biochemical profile analysis of the mice fed with ethanol. A noteworthy reduction in GSH and in several biochemical activities such as superoxide dismutase (SOD), catalase (CAT), glutathione reductase (GR), and glutathione peroxidase (GPx) was observed, while groups fed with silymarin counterchecked all the elevated parameters as seen in the ethanol group. Furthermore, silymarin drastically prevented the changes of molecular docks associated with ethanol consumption leading into several diseases such as interleukin (IL-4 \& IL-10), TNF- $\alpha$, vascular endothelial growth factor (VEGF-A), TGF- $\beta 1$, and gamma interferon (IFN- $\gamma$ ) (Das and Mukherjee, 2012).

\section{PRECLINICAL AND CLINICAL RESEARCH BASED ON ETHNOPHARMACOLOGICAL APPLICATIONS TARGETING ALCOHOL ABUSE}

A number of preclinical and clinical studies with natural products-based medicines have been performed to treat drug 
dependence, including alcoholism. Reports from some of the preclinical studies have shown that NR-ANX-C (standardized polyherbal formulation) consisting of extracts of Ocimum tenuiflorum L. (syn. Ocimum sanctum L.), Withania somnifera (L.) Dunal, Camellia sinensis (L.) Kuntze, Zanthoxylum rhetsa (Roxb.) DC., triphala (Terminalia chebula Retz., Terminalia belerica (Gaertn.) Roxb., and Phyllanthus emblica L. (syn. Emblica officinalis), and shilajit withdrawals ethanol induced anxiety behavior in rats (Nair et al., 2011), heightened ethanolinduced anxiolysis (Gupta and Rana, 2008), and weaken acquisition of oral ethanol administration under fixed and systemic increase in ratios (Peana et al., 2014). In addition to this, it decreased the deprivation effects and did promote the reinstatement state in ethanol-seeking behaviors in experimental rat model (de Wit and Stewart, 1981; Spina et al., 2015). Notably, the acquisition of ethanol-elicited mechanisms has been attributed to a number of cumulative neurological events involving receptors such as $\mathrm{GABA}_{\mathrm{A}}$ (Chester and Cunningham, 1999) and $\mathrm{GABA}_{\mathrm{B}}$ (Agabio and Colombo, 2014; Peana et al., 2014), dopamine (Spina et al., 2010), serotonin (Sellers et al., 1992; Koob, 2003), endogenous opioid receptor (Gianoulakis, 2009), and adenosine transmission (López-Cruz et al., 2013). Further, Gupta and Rana (2008) posited that the downregulation of $\mathrm{GABA}_{\mathrm{A}}$ receptors or decrease in the GABAergic transmission may have been connected to alcohol withdrawal symptoms (Gupta and Rana, 2008). This in turn suggests that GABA mimetic and adaptogenic effect of Ashwagandha may further decrease the regulation of $\mathrm{GABA}_{\mathrm{A}}$ receptor. The possible mechanisms of action of some phytoconstituents are presented in Figure 2.
The use of medicines based on natural products fits well with new trends in the treatment of drug dependence, such as alcoholism. Tables 2 and 3 review the effects of a wide variety of extracts and some active plant constituents in animal models and clinical trials, respectively, in relation to alcohol dependence and abuse.

Apart from the above studies, numerous plants are utilized in folklore medicine and as such are thoroughly investigated for their use in prevention or treatment of ethanol-induced liver injury. Some of these natural products like taraxasterol exhibit their protective potential against ethanol-induced liver damage because they regulate different signaling pathways like NF- $\kappa \mathrm{B}$ and CYP2E1/Nrf2/HO-1 in mice models (Xu et al., 2018). Studies also showed that Monolluma quadrangula (Forssk.) Plowes, Geranium schiedeanum Schltdl., and Phyllanthus emblica L. are also effective in this respect (Ibrahim et al., 2015; Madrigal-Santillán et al., 2015; Chaphalkar et al., 2017). Recently a number of reviews have been published on the topic (Guan et al., 2018; Singh et al., 2018).

\section{CONCLUSIONS AND OUTLOOK}

Alcohol abuse and dependence is one of the most important public health problems worldwide. Over time, regular usage of substances such as alcohol, opioids, cigarettes, and tobacco has resulted in a habitual behavioral intake. Rehabilitation and discontinuation of these substance addictions remain a challenging task of research. At present efforts are focusing on the development of low-toxicity and high-efficiency natural

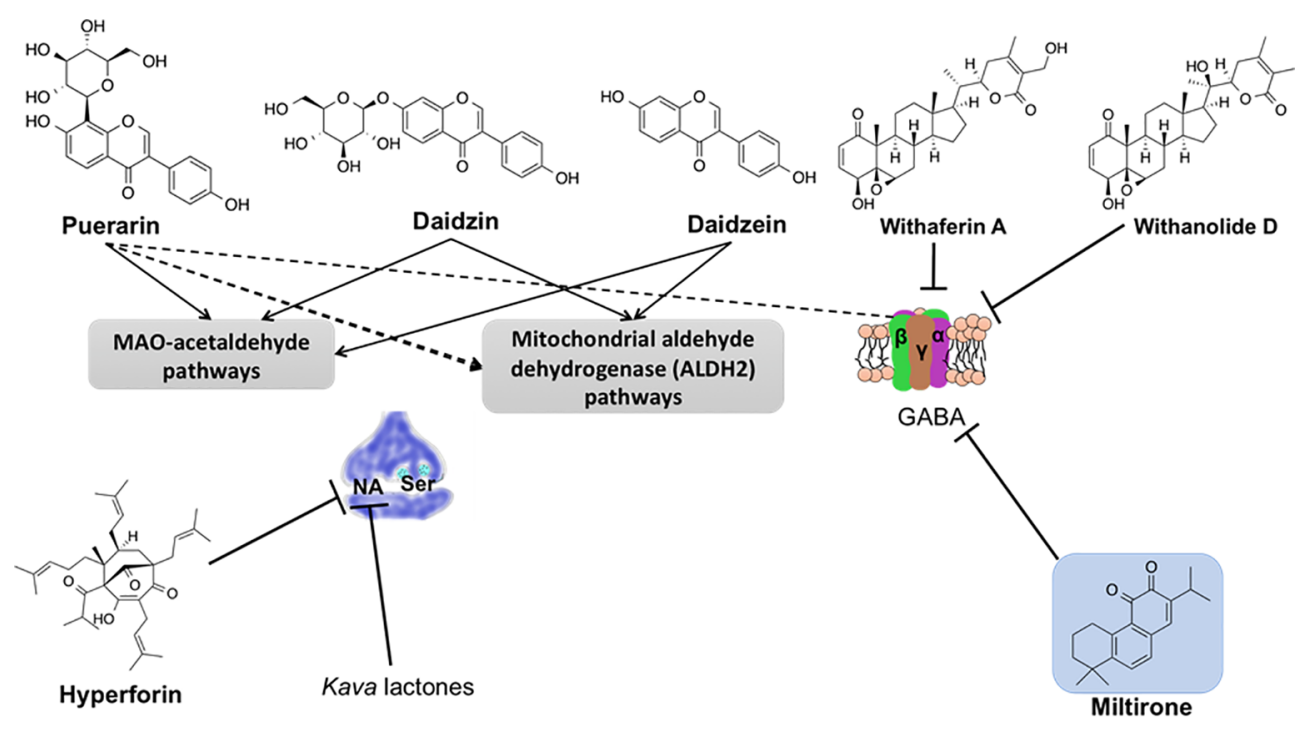

FIGURE 2 | Possible mechanism of action of some of phytoconstituents in the context of counteracting alcohol abuse. Puerarin, daidzein, and daidzin decrease alcohol consumption by alterations in MAO-acetaldehyde pathways or mitochondrial ALDH2 pathways (Keung, 2003; Lukas et al., 2013); Withaferin A and withanolide D block GABA receptors binding and upsurges chloride influx in absence of GABA (Gupta and Rana, 2008; Lu et al., 2009; Ruiu et al., 2013); Kava lactones bind to multiple locations in the brain and interact with different neurotransmitters and significantly inhibit the uptake of noradrenaline, but not serotonin (Sällström Baum et al., 1998); Militirone is low-affinity ligand for central GABAA-BDZ-binding site, thus acting as a partial agonist and implying an anxiolytic effect (Lee et al., 1991). 
TABLE 2 | Preclinical research based on ethnopharmacological applications targeting alcohol abuse.

\begin{tabular}{|c|c|c|c|c|c|}
\hline Species & Common name & $\begin{array}{l}\text { Plant extract or } \\
\text { compound }\end{array}$ & Test model & Results & Reference \\
\hline $\begin{array}{l}\text { Aesculus } \\
\text { hippocastanum } \\
\text { L. }\end{array}$ & Horse Chestnut & $\begin{array}{l}\text { Escins la, lb, Ila, Ilb, } \\
\text { and IIla }\end{array}$ & Male Wistar rats & $\begin{array}{l}\text { Escins la, lb, Ila, and Ilb inhibit ethanol } \\
\text { absorption. }\end{array}$ & $\begin{array}{l}\text { (Yoshikawa et al., } \\
\text { 1996b) }\end{array}$ \\
\hline \multirow[t]{2}{*}{$\begin{array}{l}\text { Aralia elata } \\
\text { (Miq.) Seem. }\end{array}$} & $\begin{array}{l}\text { Chinese angelica-tree, } \\
\text { Japanese angelica-tree, } \\
\text { and Korean angelica-tree }\end{array}$ & $\begin{array}{l}\text { Oleanolic acid, 28-O- } \\
\text { bisdesmosides, and } \\
\text { oleanolic acid 3-O- } \\
\text { monodesmosides }\end{array}$ & Male Wistar rats & Inhibitory effect on ethanol absorption. & $\begin{array}{l}\text { (Yoshikawa et al., } \\
\text { 1996a) }\end{array}$ \\
\hline & $\begin{array}{l}\text { Chinese angelica-tree, } \\
\text { Japanese angelica-tree, } \\
\text { and Korean angelica-tree }\end{array}$ & $\begin{array}{l}\text { 3-O- } \\
\text { monodesmosides }\end{array}$ & Male Wistar rats & $\begin{array}{l}\text { Elatoside A showed potent inhibitory activity } \\
\text { on ethanol absorption. }\end{array}$ & $\begin{array}{l}\text { (Yoshikawa et al., } \\
\text { 1993) }\end{array}$ \\
\hline Buzui & Buzui & $\begin{array}{l}\text { Fruit of Schisandra } \\
\text { chinensis (Turcz.) } \\
\text { Baill., Terminalia } \\
\text { chebula Retz., Dark } \\
\text { plum fruit and } \\
\text { Crataegus pinnatifda } \\
\text { Bunge, Chicken's } \\
\text { gizzard membrane } \\
\text { and Silkworm } \\
\text { excrement }\end{array}$ & $\begin{array}{l}\text { Male pathogen-free (SPF) } \\
\text { Kunming mice }\end{array}$ & $\begin{array}{l}\text { Induces wakefulness and prevents acute } \\
\text { alcohol intoxication, accelerates alcohol } \\
\text { metabolism and thereby reduces oxidative } \\
\text { damage. }\end{array}$ & (Chen et al., 2016) \\
\hline $\begin{array}{l}\text { Camellia } \\
\text { japonica L. }\end{array}$ & $\begin{array}{l}\text { Common camellia, } \\
\text { Japanese camellia, Rose } \\
\text { of Winter }\end{array}$ & $\begin{array}{l}\text { Camellia saponins } \\
\text { A1, A2, B1, B2, C1, } \\
\text { and C2 }\end{array}$ & Male Wistar rats & $\begin{array}{l}\text { Camellia saponins B1, B2, C1, and C2 } \\
\text { exhibit inhibitory ethanol absorption activity. }\end{array}$ & $\begin{array}{l}\text { (Yoshikawa et al., } \\
\text { 1996) }\end{array}$ \\
\hline $\begin{array}{l}\text { Galanthus nivalis } \\
\text { L. and Peganum } \\
\text { harmala L. }\end{array}$ & Snowdrop and Syrian rue & Galanthamine & $\begin{array}{l}\text { Female Alko alcohol (AA) } \\
\text { rats }\end{array}$ & $\begin{array}{l}\text { Desoxypeganine- } \mathrm{HCl} \text { reduces ethanol } \\
\text { preference and intake while systemically } \\
\text { increasing the dose concentration ( } 10 \text { and } \\
30 \mathrm{mg} / \mathrm{kg} \text { of the body weight). } \\
\text { Desoxypeganine- } \mathrm{HCl} \text { when applied in } \\
\text { subcutaneous and intraperitoneal regions of } \\
\text { the body leads to prominent reduction in } \\
\text { ethanol preference and intake. }\end{array}$ & $\begin{array}{l}\text { (Doetkotte et al., } \\
\text { 2005) }\end{array}$ \\
\hline $\begin{array}{l}\text { Ginkgo biloba } \\
\text { L., Mentha } \\
\text { arvensis L. var. } \\
\text { piperascens, } \\
\text { Citrus deliciosa } \\
\text { Ten. (syn. Citrus } \\
\text { unshiu) Blanco, } \\
\text { and Pueraria } \\
\text { montana var. } \\
\text { lobata (Willd.) } \\
\text { Maesen \& } \\
\text { S.M.Almeida ex } \\
\text { Sanjappa \& } \\
\text { Predeep }\end{array}$ & - & $\begin{array}{l}\text { Combined aqueous } \\
\text { extracts (BHR) }\end{array}$ & Male Sprague-Dawley rats & $\begin{array}{l}\text { BHR extract significantly reduces BALs and } \\
\text { reduces area under curve (AUC) and } C_{\max } \\
\text { values in } \mathrm{BHR} \text { treated rats at a dose } \\
\text { concentration of } 1 \text { and } 3 \mathrm{~g} / \mathrm{kg} \text {. }\end{array}$ & $\begin{array}{l}\text { (Soo Shin et al., } \\
\text { 2005) }\end{array}$ \\
\hline $\begin{array}{l}\text { Glycine max } \\
\text { (L.) Merr. }\end{array}$ & Soybean & Milk & Male Sprague-Dawley rats & $\begin{array}{l}\text { Demonstrates that soymilk products inhibit } \\
\text { ethanol absorption and enhance ethanol } \\
\text { metabolism in rats. }\end{array}$ & $\begin{array}{l}\text { (Kano et al., 2002; } \\
\text { Kano and Kubota, } \\
\text { 2013) }\end{array}$ \\
\hline \multirow[t]{3}{*}{$\begin{array}{l}\text { Hovenia dulcis } \\
\text { Thunb. }\end{array}$} & Korean raisin tree & Fruit extract & Mice & $\begin{array}{l}\text { Reduces blood alcohol concentration by } \\
\text { increasing the efficiency of ADH and } \\
\text { glutathione-S-transferase (GST) activity and } \\
\text { thus increases detoxification. }\end{array}$ & (An et al., 1999) \\
\hline & & $\begin{array}{l}\text { Seed extract from } \\
\text { China and Korea }\end{array}$ & Rats & $\begin{array}{l}\text { Both extracts (crude and partitioned) } \\
\text { accelerate the reducing rate of blood alcohol } \\
\text { concentrations down to } 1-2 \mathrm{~h} \text {, compared to } \\
\text { that of control. }\end{array}$ & (Kim et al., 2000) \\
\hline & & $\begin{array}{l}\text { Ethanol and aqueous } \\
\text { fruit extract }\end{array}$ & Rats & $\begin{array}{l}\text { Reduces blood alcohol concentration by } \\
\text { increasing the activity of ADH, ALDH, and } \\
\text { GST activity and thus increases } \\
\text { detoxification. }\end{array}$ & (Cha et al., 2004) \\
\hline
\end{tabular}


TABLE 2 | Continued

\begin{tabular}{|c|c|c|c|c|c|}
\hline Species & Common name & $\begin{array}{l}\text { Plant extract or } \\
\text { compound }\end{array}$ & Test model & Results & Reference \\
\hline & & Fruit water extract & Rats & $\begin{array}{l}\text { Shows significant alcohol decrease in blood } \\
\text { and hepatoprotective activity against } \mathrm{CCl}_{4^{-}} \\
\text {toxicity. }\end{array}$ & (Kim et al., 2006) \\
\hline & & Fruit water extract & Rats & $\begin{array}{l}\text { The fruit extract (methanol and hot water } \\
\text { extract) reduces acute alcohol toxicity and } \\
\text { shows potent hepatoprotective activity } \\
\text { against chemically, i.e., } \mathrm{CCl}_{4} \text {, induced liver } \\
\text { injury model. }\end{array}$ & (Kim et al., 2008) \\
\hline & & $\begin{array}{l}\text { Dihydromyricetin } \\
\text { (DHM) }\end{array}$ & Sprague-Dawley rats & $\begin{array}{l}\text { Determines anti-alcoholic effects of DHM on } \\
\text { animal models and put forward a major } \\
\text { molecular target and cellular mechanism of } \\
\text { DHM against alcohol dependence and } \\
\text { intoxication. }\end{array}$ & (Shen et al., 2012) \\
\hline \multirow[t]{8}{*}{$\begin{array}{l}\text { Hypericum } \\
\text { perforatum L. }\end{array}$} & \multirow[t]{8}{*}{ St John's wort (SJW) } & $\begin{array}{l}\text { Hypericum } \\
\text { perforatum extract } \\
\text { (HPE) }\end{array}$ & cAA rats & $\begin{array}{l}\text { Hypericum extract } \\
\text { Ze } 117\left(\text { Remotiv }{ }^{\circledR}\right) \text { reduces } \mathrm{EtOH} \text { intake in a } \\
\text { selective manner thus revealing that the } \\
\text { extract may be an interesting adjunct for the } \\
\text { treatment of alcoholism. }\end{array}$ & (De Vry et al., 1999) \\
\hline & & $\begin{array}{l}\text { Hypericum } \\
\text { perforatum extract } \\
\text { (HPE) }\end{array}$ & $\begin{array}{l}\text { Marchigian Sardinian } \\
\text { alcohol-preferring (msP) } \\
\text { rats }\end{array}$ & $\begin{array}{l}\text { Antidepressant-like effect of HPE extract in } \\
\text { the force swimming test (FST) may be } \\
\text { mediated by interaction of sigma receptors } \\
\text { and to some extent by increased } \\
\text { serotonergic neurotransmission. }\end{array}$ & (Panocka et al., 2000) \\
\hline & & $\begin{array}{l}\text { Hypericum } \\
\text { perforatum extracts } \\
\text { (HPE) }\end{array}$ & $\begin{array}{l}\text { Marchigian Sardinian } \\
\text { alcohol-preferring (msP) } \\
\text { rats }\end{array}$ & $\begin{array}{l}\text { HPE noticeably reduces ethanol intake in } \\
\text { msP rats, without affecting food intake. }\end{array}$ & (Perfumi et al., 1999) \\
\hline & & $\begin{array}{l}\text { Methanolic extract } \\
\text { (with } 0.3 \% \text { hypericin } \\
\text { and } 3.8 \% \text { hyperforin) } \\
\text { (HPE1) and } \mathrm{CO}_{2} \\
\text { extract (HPE2) with } \\
24.33 \% \text { hyperforin } \\
\text { and very less } \\
\text { hypericin. }\end{array}$ & $\begin{array}{l}\text { Marchigian Sardinian } \\
\text { alcohol-preferring (msP) } \\
\text { rats }\end{array}$ & $\begin{array}{l}\text { HPE2 hinders ethanol intake more effectively } \\
\text { than HPE1; higher HPE2 potency parallels } \\
\text { the content of hyperforin, taking the role of } \\
\text { hyperforin in reducing ethanol intake. }\end{array}$ & (Perfumi et al., 2001) \\
\hline & & $\begin{array}{l}\text { Hypericum } \\
\text { perforatum extracts } \\
\text { (HPE) }\end{array}$ & $\begin{array}{l}\text { Marchigian Sardinian } \\
\text { alcohol-prefering (msP) } \\
\text { rats }\end{array}$ & $\begin{array}{l}\text { HPE inhibitory effects on ethanol intake are } \\
\text { not mediated by GABA agonist actions. }\end{array}$ & (Perfumi et al., 2002) \\
\hline & & $\begin{array}{l}\text { Hypericum } \\
\text { perforatum } \mathrm{CO}_{2} \\
\text { Extract }\end{array}$ & $\begin{array}{l}\text { Marchigian Sardinian } \\
\text { alcohol-prefering (msP) } \\
\text { rats }\end{array}$ & $\begin{array}{l}\mathrm{CO}_{2} \text { extract of } \mathrm{H} \text {. perforatum and opiate } \\
\text { receptor } \\
\text { antagonists synergistically act to induce } \\
\text { selective reduction of voluntary consumption } \\
\text { of ethanol in alcohol-preferring rats. }\end{array}$ & (Perfumi et al., 2003) \\
\hline & & $\begin{array}{l}\text { Hypericum } \\
\text { perforatum extracts } \\
\text { (HPE) }\end{array}$ & $\begin{array}{l}\text { Fawn-hooded }(\mathrm{FH}) \text { and } \\
\text { high-alcohol drinking } \\
\text { (HAD) rats }\end{array}$ & $\begin{array}{l}\text { Demonstrates that acute or repeated oral } \\
\text { administration of HPE produce dose- } \\
\text { dependent reduction in alcohol intake in rats. }\end{array}$ & (Rezvani et al., 1999) \\
\hline & & $\begin{array}{l}\text { Hypericum } \\
\text { perforatum extracts } \\
\text { (HPE) }\end{array}$ & $\begin{array}{l}\text { Adult male C57BL/6J } \\
\text { mice }\end{array}$ & $\begin{array}{l}\text { Hyperforin contributes to observed reduction } \\
\text { in alcohol intake. }\end{array}$ & (Wright et al., 2003) \\
\hline $\begin{array}{l}\text { Jodina } \\
\text { rhombifolia } \\
\text { (Hook. \& Arn.) } \\
\text { Reissek }\end{array}$ & Sombra de toro & $\begin{array}{l}\text { Lyophilized aqueous } \\
\text { extract (JRLE) }\end{array}$ & Male Wistar rats & $\begin{array}{l}\text { Repeated administration of JRLE extract, } \\
\text { noticeably reduce voluntary ethanol intake in } \\
\text { male Wistar rats. This reduction in terms of } \\
\text { consumption was of notable magnitude and } \\
\text { remained stable during the 10-days of } \\
\text { treatment. }\end{array}$ & (Teves et al., 2015) \\
\hline NPI-028 & NPI-028 & $\begin{array}{l}\text { Chinese herbal } \\
\text { mixture: Pueraria } \\
\text { montana var. lobata } \\
\text { (Willd.) Maesen \& } \\
\text { S.M.Almeida ex } \\
\text { Sanjappa \& Predeep } \\
\text { (syn. Pueraria lobata) } \\
\text { (roots and leaves) }\end{array}$ & Rats and monkeys & $\begin{array}{l}\text { Significantly reduces alcohol intake in } \\
\text { alcohol-preferring }(\mathrm{P}) \text { rats deprived of } \\
\text { alcohol, suggesting that it might reduce } \\
\text { desire for alcohol intake. However, NPI-028 } \\
\text { did not produce a taste aversion to a novel } \\
\text { saccharin solution, so it does not have a } \\
\text { similar mechanism of action as that of } \\
\text { naltrexone, the opiate antagonist. NPI-028 }\end{array}$ & $\begin{array}{l}\text { (Overstreet et al., } \\
\text { 1997) }\end{array}$ \\
\hline
\end{tabular}


TABLE 2 | Continued

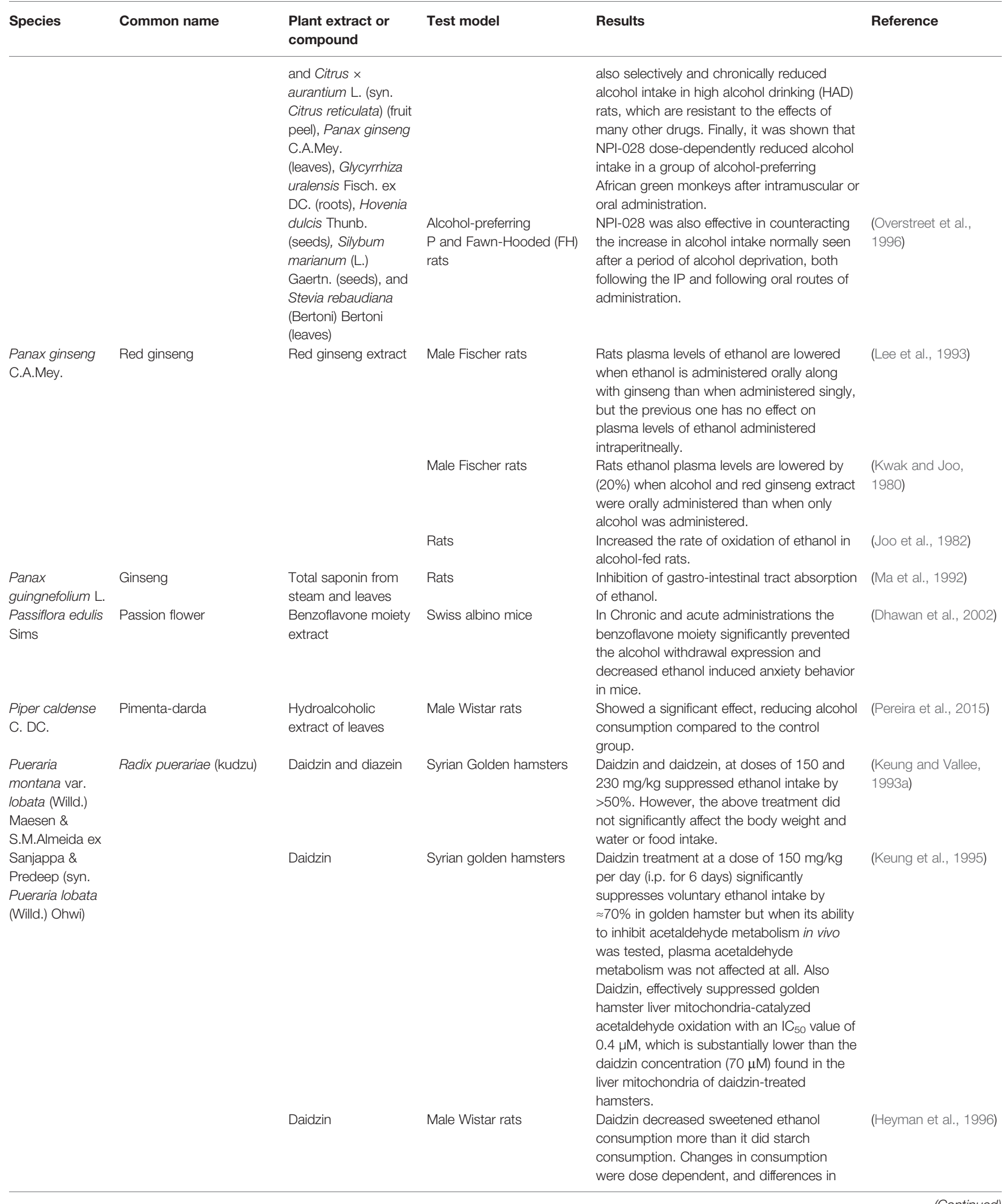


TABLE 2 | Continued

\begin{tabular}{|c|c|c|c|}
\hline Species & Common name & $\begin{array}{l}\text { Plant extract or } \\
\text { compound }\end{array}$ & Test model \\
\hline & & $\begin{array}{l}\text { Kudzu Root Extract } \\
\text { (KRE) }\end{array}$ & $\begin{array}{l}\text { Adult male Sprague- } \\
\text { Dawley (SD) rats }\end{array}$ \\
\hline
\end{tabular}

Kudzu Root Extract Alcohol-preferring $(P)$ rats (KRE)

Kudzu Root Extract Alcohol preferring $(P)$ rats (KRE)

Ethanol extract

Male Wistar rats

Flos puerariae lobatae water extract (FPE)

Puerariae Flos mice isoflavonoid fraction (PF-IF)

daidzin, daidzein and Alcohol preferring $(P)$ rats puerarin

Pyrus pyrifolia Korean Pear Korean Pear extract

Burm.f.) Nakai

(syn. Pyrus

pyrifolia CV.

Shingo) and deficient (ALDH2 -/-) male mice
Sedum rosea Rhodiola (golden root) Salidroside Male Wistar rats
(L.) Scop.
Results

Reference

ethanol and food consumption increased slightly (but significantly) as dose increased. Daidzin inhibits ALDH-2 and suppresses heavy drinking in rodents. Decreased drinking due to ALDH-2 inhibition is attributed to aversive properties of acetaldehyde accumulated during alcohol consumption.

A daily $50 \mathrm{mg} / \mathrm{kg}$ dose of puerarin (PU) caused approximately 50\% suppression in alcohol intake, but did not affect body weight and food and total fluid intake in $\mathrm{P}$ rats receiving "free choice" of water and $15 \%$ ethanol. PU feeding transiently suppressed alcohol intake and abolished withdrawal symptoms at a time when alcohol intake had returned to the control level.

A daily dose of $50 \mathrm{mg} / \mathrm{kg}$ of puerarin (PU) caused approximately 50\% suppression in alcohol intake, but did not affect body weight and food and total fluid intake in $\mathrm{P}$ rats receiving "free choice" of water and $15 \%$ ethanol. PU feeding transiently suppressed alcohol intake and abolished withdrawal symptoms at a time when alcohol intake had returned to the control level.

Daidzin delayed and decreased peak blood alcohol concentration (BAC) level after ethanol intake. When ethanol (40\% solution, $3 \mathrm{~g} / \mathrm{kg}$ of body weight) was given to fasted rats intragastrically, BAC peaked at $30 \mathrm{~min}$ after alcohol ingestion and reached $1.77 \pm$ $0.14 \mathrm{mg} / \mathrm{mL}$. But when daidzin (30 mg/kg) was mixed with the ethanol solution and given to animals intragastrically, BAC was found to peak at $90 \mathrm{~min}$ after alcohol ingestion and reached only $1.20 \pm 0.30 \mathrm{mg} / \mathrm{ml}$.

Male Sprague-Dawley rats FPE and its active ingredient puerarin have preventive effects on alcoholism-related disorders. Puerarin pretreatment, but not post-treatment, can reverse the changes of $\mathrm{GABA}_{A} \mathrm{R}$ subunit expression and increase $\mathrm{ADH}$ activity in alcoholism models.

blood alcohol and acetaldehyde

(Benlhabib et al., 2004b)

(Arolfo et al., 2009)

(1)

(Benlhabib et al.,

2004a)

(Xie et al., 1994) concentrations decreased more after the treatment

suppressing the appetite for alcohol when taken orally

ALDH2 normal (C57BL/6) Pear extract stimulated both ADH and ALDH (Lee et al., 2012)

activities by $2 \sim 3$ in vivo and 1.3 fold in in vitro studies. The pharmacokinetic data (i.e., $\mathrm{A} \cup \mathrm{C} \alpha$ and $\mathrm{C}_{\max }$ ) showed that the pear extract decreased the alcohol level in blood regardless of ALDH2 genotype and increased the acetaldehyde level in blood in Aldh2 deficient mice but not in ALDH2 normal mice.

Indicates that salidroside at a dose of $45 \quad$ (Szulc et al., 2018) $\mathrm{mg} / \mathrm{kg}$ inhibited the development of tolerance to the hypothermic effect of
(Zhang et al., 2010)

(Niiho et al., 1989)

(Lin et al., 1996)

. 
TABLE 2 | Continued

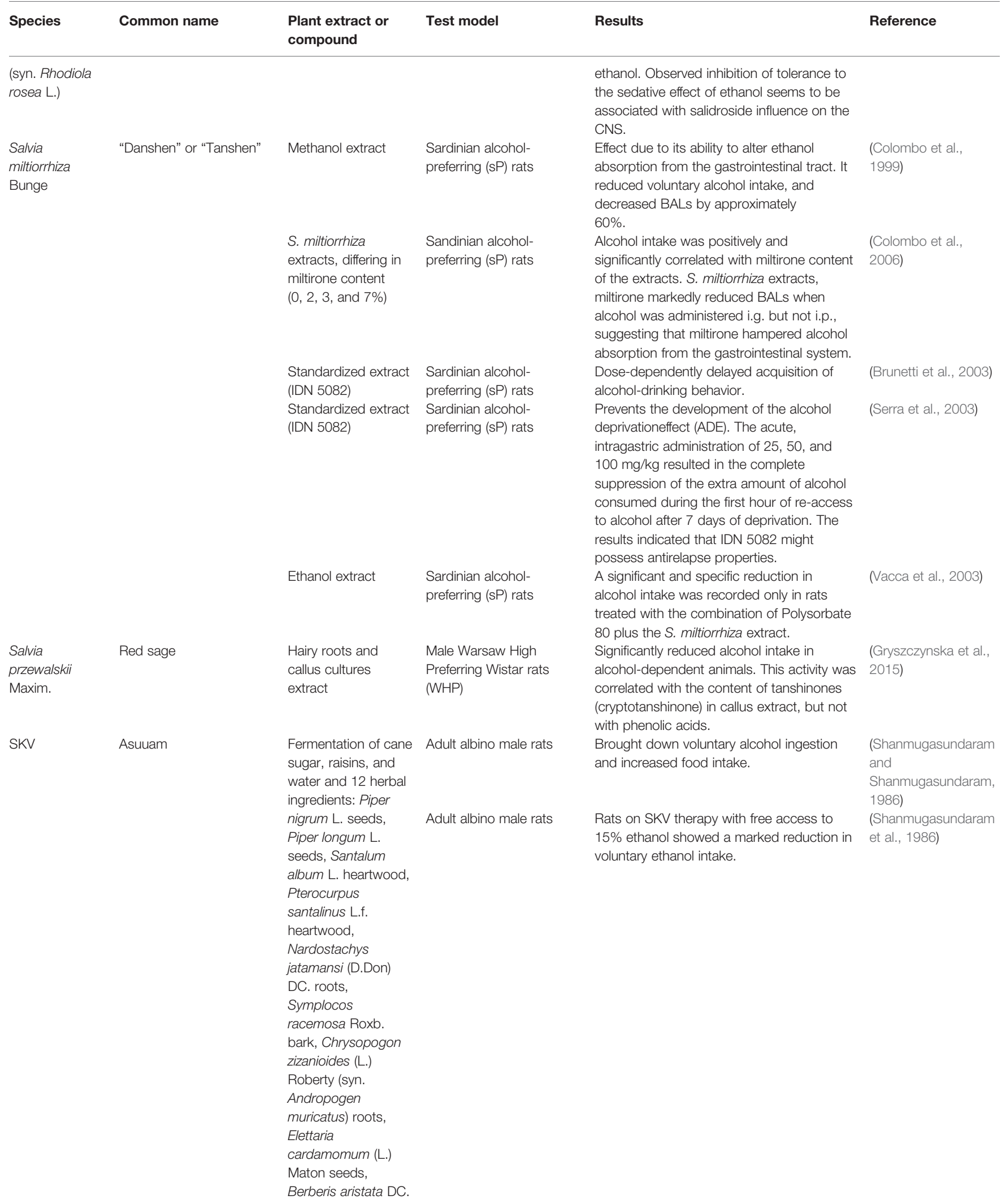


TABLE 2 | Continued

\begin{tabular}{|c|c|c|c|c|c|}
\hline Species & Common name & $\begin{array}{l}\text { Plant extract or } \\
\text { compound }\end{array}$ & Test model & Results & Reference \\
\hline \multirow[b]{2}{*}{$\begin{array}{l}\text { Strychnos nux- } \\
\text { vomica L. }\end{array}$} & & $\begin{array}{l}\text { root/bark/- } \\
\text { stem, Plumbago } \\
\text { zeylanica L. roots } \\
\text { and Cyprus rotundus } \\
\text { L. tubers, } \\
\text { Woodfordia fruticosa } \\
\text { (L.) Kurz (syn. } \\
\text { Woodfordia } \\
\text { floribunda) flowers. }\end{array}$ & & & \\
\hline & Nux vomica & $\begin{array}{l}\text { Mother tincture (MT), } \\
\text { Nux 30c, and its } \\
\text { principal alkaloid, } \\
\text { strychnine }\end{array}$ & $\begin{array}{l}\text { Albino rats of the Charles } \\
\text { Foster strain }\end{array}$ & $\begin{array}{l}\text { Nux MT and Nux 30c could reduce ethanol } \\
\text { intake in rats. The altered solution structure } \\
\text { of Nux 30c is thought to mimic Nux MT and } \\
\text { produce ethanol aversion in rats. }\end{array}$ & (Sukul et al., 2001) \\
\hline \multirow[t]{4}{*}{$\begin{array}{l}\text { Tabernathe } \\
\text { iboga Baill. }\end{array}$} & lboga & lbogaine & Sprague-Dawley rats & $\begin{array}{l}\text { Reduces volitional alcohol consumption in } \\
\text { alcohol-preferring rats. Exerted its anti- } \\
\text { craving effects on voluntary alcohol intake by } \\
\text { interacting with the brain parts involved in } \\
\text { stimulating dopaminergic and serotonergic } \\
\text { systems. }\end{array}$ & (Glick et al., 1991) \\
\hline & & & Fawn-Hooded rats & $\begin{array}{l}\text { lbogaine when injected into different regions } \\
\text { of the body, i.e., intraperitoneal or } \\
\text { intragastric but not subcutaneous, can } \\
\text { significantly reduce alcohol intake without an } \\
\text { effect on blood alcohol concentrations or } \\
\text { food intake. }\end{array}$ & $\begin{array}{l}\text { (Rezvani et al., } \\
\text { 1995b) }\end{array}$ \\
\hline & & Noribogaine & $\mathrm{P}$ and Fawn-Hooded rats & $\begin{array}{l}\text { Significantly suppressed alcohol intake in } \\
\text { alcohol preferring rats. }\end{array}$ & (Rezvani et al., 1995a) \\
\hline & & $\begin{array}{l}18- \\
\text { Methoxycoronaridine } \\
\text { (18-MC) }\end{array}$ & $\begin{array}{l}\text { Adult male alcohol- } \\
\text { preferring rats }\end{array}$ & $\begin{array}{l}\text { Significantly and dose-dependently } \\
\text { attenuated alcohol consumption and } \\
\text { preference and commensurately increased } \\
\text { water intake. }\end{array}$ & (Rezvani et al., 1997) \\
\hline $\begin{array}{l}\text { Thymus vulgaris } \\
\text { L. }\end{array}$ & Thyme & Water extract & Male Albino mice & Detoxifying and antioxidant effects. & $\begin{array}{l}\text { (Shati and Elsaid, } \\
\text { 2009) }\end{array}$ \\
\hline $\begin{array}{l}\text { Withania } \\
\text { somnifera (L.) } \\
\text { Dunal }\end{array}$ & Indian ginseng & Roots extract (WSE) & Adult male Wistar rats & $\begin{array}{l}\text { WSE reduced the acquisition, maintenance } \\
\text { breakpoint of ethanol self-administration and } \\
\text { reinstatement of ethanol-seeking behaviors. } \\
\text { The GABA } \text { B }_{\mathrm{B}} \text { receptor antagonist, phaclofen, } \\
\text { counteracted the ability of WSE to impair the } \\
\text { maintenance of ethanol self-administration. }\end{array}$ & (Peana et al., 2014) \\
\hline $\begin{array}{l}\text { Zingiber } \\
\text { officinale } \\
\text { Roscoe }\end{array}$ & Ginger & Water extract & Male Albino mice & $\begin{array}{l}\text { Significant increase in } \mathrm{NO} \text { and } \\
\text { malondialdehyde level in liver and brain and } \\
\text { a decrease in the total antioxidant capacity } \\
\text { and GPx activity in alcoholic group. } \\
\text { The extract has potent detoxifying and } \\
\text { antioxidant effects. }\end{array}$ & $\begin{array}{l}\text { (Shati and Elsaid, } \\
\text { 2009) }\end{array}$ \\
\hline
\end{tabular}

remedies. Although the modern pharmacological approaches are known to play a key role in achieving complete alcohol abstinence and preventing relapse, their efficacy is still limited, accompanied with a great deal of side effects, tolerance development, and sensitization or dependence to such drugs (Addolorato et al., 2005a; Addolorato et al. 2005b; Uzbay, 2008). Taking this into account, search for an alternative and new psychotherapeutic medication from natural sources was emphasized for antiaddiction therapies. The extracts from Hypericum perforatum, Puereria montana var. lobata, Withania somnifera, Panax ginseng, Macropiper methysticum, Salvia miltiorrhiza, Thunbergia laurifolia, Tabernanthe iboga, etc., have demonstrated potent antidipsotropic effects in alcohol preferring or alcohol-fed rats (Lin et al., 1996; Lin and Li, 1998; Overstreet et al., 2003; Rezvani et al., 2003). Similarly extracts from P. tenuifolia, T. laurifolia, and Simplocos racemosa have been found to inhibit cocaine-craving behavior in rats (Chung et al., 2002, Thongsaard and Marsden, 2002). Extracts from P. ginseng and Corydalis yanhusuo may be clinically useful for the prevention of opioids abuse and to prevent relapse to chronic drug dependence. Sinomenine, an alkaloid from Sinomenium acutum (Thunb.) Rehder \& E.H.Wilson, has been shown to have preventive and curative effects of opioid dependence. Rhynchophylline an alkaloid from Uncaria rhynchophylla (Miq.) Miq. ex Havil. is reported to have positive effects on methamphetamine and ketamine addiction. Likewise, LStepholidine, an alkaloid extract of the Chinese herb Stephania intermedia H.S. Lo, helps to control morphine-preference and induces reinstatement (Zhu et al., 2017). 
TABLE 3 | Clinical research based on ethnopharmacological applications targeting alcohol abuse.

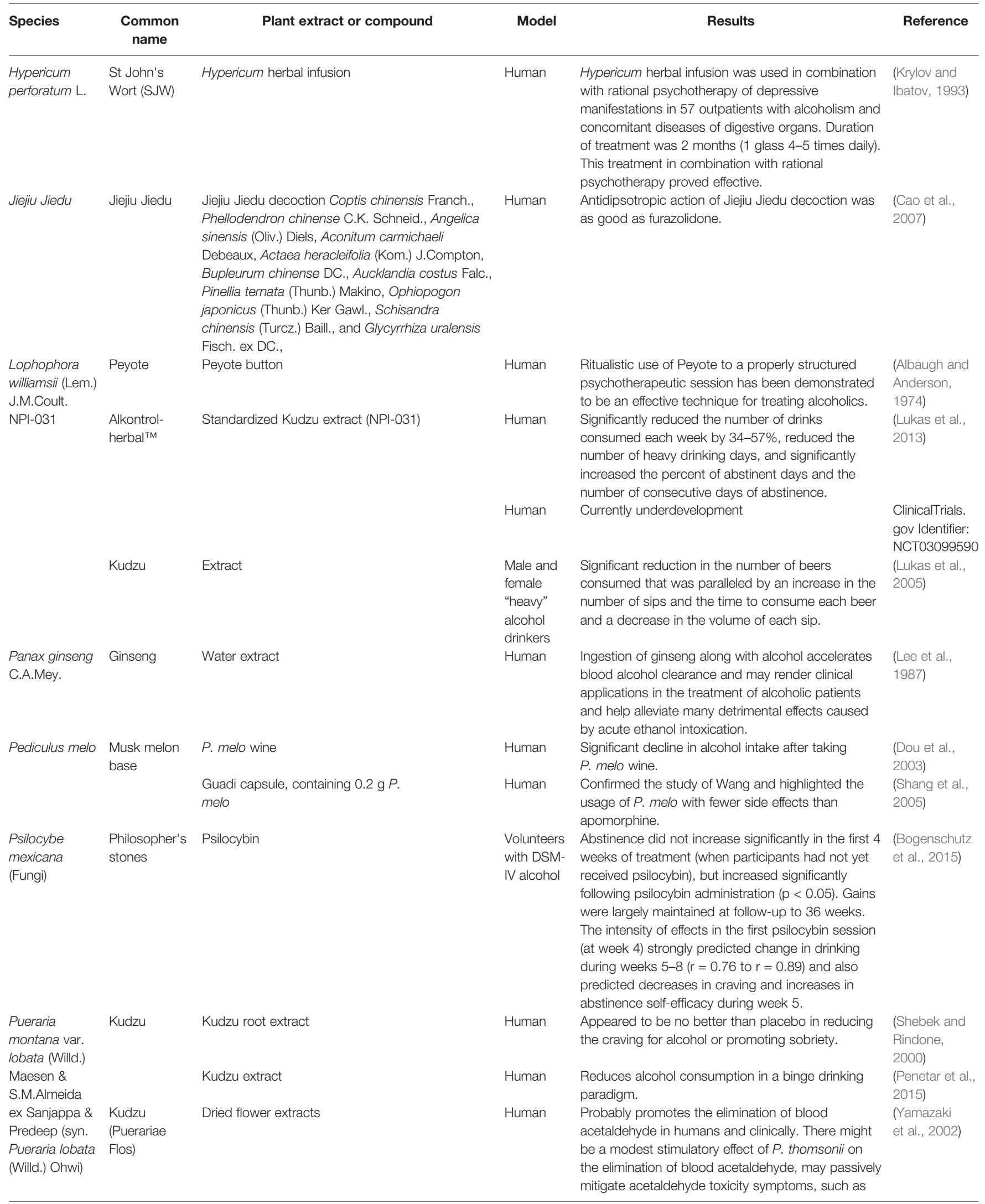


TABLE 3 | Continued

\begin{tabular}{|c|c|c|c|c|c|}
\hline Species & $\begin{array}{l}\text { Common } \\
\text { name }\end{array}$ & Plant extract or compound & Model & Results & Reference \\
\hline & & & & $\begin{array}{l}\text { flushing, palpitation, headache, etc., associated with } \\
\text { excessive alcohol intake. }\end{array}$ & \\
\hline $\begin{array}{l}\text { Wendan } \\
\text { decoction }\end{array}$ & $\begin{array}{l}\text { Wendan } \\
\text { decoction } \\
\text { (WDD) }\end{array}$ & $\begin{array}{l}\text { WDD is typically composed of Pinellia ternata } \\
\text { (Thunb.) Makino, Phyllostachys nigra var. henonis } \\
\text { (Mitford) Rendle, Citrus } \times \text { aurantium L., Wolfiporia } \\
\text { extensa, Zingiber officinale Roscoe, Ziziphus jujuba } \\
\text { Mill. and Glycyrrhiza uralensis Fisch. ex DC. }\end{array}$ & Human & $\begin{array}{l}\text { Wendan decoction ( } 500 \mathrm{ml} \text {, bid) was effective in } \\
\text { treating alcohol dependence patients (overall } \\
\text { effective rate: } 83.3 \% \text { ). }\end{array}$ & $\begin{array}{l}\text { (Qu and } \\
\text { Wang, 2008) }\end{array}$ \\
\hline
\end{tabular}

Considering the limitations of the available pharmacotherapeutic agents, herbal remedies may provide an alternative. Herbal extracts and constituents with demonstrable psychotherapeutic effects in animal models deserve further clinical trials and evaluation. Further, the use of such natural formulations is still in its infancy stage. Further clinical and behavioral studies of herbal remedies might provide a unique opportunity for the development of new pharmacotherapies for alcohol withdrawal symptoms and prevention of relapse.

\section{AUTHOR CONTRIBUTIONS}

LS, TJ, DT, JE, AM, and AA drafted and conceived the manuscript. All authors revised and approved the final version.

\section{REFERENCES}

Abascal, K., and Yarnell, E. (2007). Kudzu-The miracle vine. Altern. Complement. Ther. 13, 78-85. doi: 10.1089/act.2007.13207

Abd-Elazem, I. S., Chen, H. S., Bates, R. B., and Huang, R. C. C. (2002). Isolation of two highly potent and non-toxic inhibitors of human immunodeficiency virus type 1 (HIV-1) integrase from Salvia miltiorrhiza. Antiviral Res. 55, 91-106. doi: 10.1016/s0166-3542(02)00011-6

Abenavoli, L., Capasso, F., and Addolorato, G. (2009). Phytotherapeutic approach to alcohol dependence: new old way? Phytomedicine 16, 638-644. doi: 10.1016/ j.phymed.2008.12.013

Abenavoli, L., Capasso, R., Milic, N., and Capasso, F. (2010). Milk thistle in liver diseases: past, present, future. Phytother. Res. 24, 1423-1432. doi: 10.1002/ptr.3207

Achaya, K. T. (1991). (01) Alcoholic Fermentation and ITs Products in Ancient India. Indian J. Hist. Sci. 26, 123-129.

Adams, J. W., Bryant, K. J., Edelman, J. E., Fiellin, D. A., Gaither, J. R., Gordon, A. J., et al. (2018). Association of cannabis, stimulant, and alcohol use with mortality prognosis among HIV-infected men. AIDS Behav. 22, 1341-1351. doi: 10.1007/s10461-017-1905-4

Addolorato, G., Castelli, E., Stefanini, G. F., Casella, G., Caputo, F., Marsigli, L., et al. (1996). An open multicentric study evaluating 4-hydroxybutyric acid sodium salt in the medium-term treatment of 179 alcohol dependent subjects. GHB Study Group. Alcohol Alcohol 31, 341-345. doi: 10.1093/ oxfordjournals.alcalc.a008160

Addolorato, G., Caputo, F., Stefanini, G. F., and Gasbarrini, G. (1997). GammaHydroxybutyric acid in the treatment of alcohol dependence: possible craving development for the drug. Addiction 92, 1035-1036. doi: 10.1016/S0741-8329 (99)00084-1

Addolorato, G., Balducci, G., Capristo, E., Attilia, M. L., Taggi, F., Gasbarrini, G., et al. (1999). Gamma-hydroxybutyric acid (GHB) in the treatment of alcohol withdrawal syndrome: a randomized comparative study versus benzodiazepine. Alcohol. Clin. Exp. Res. 23, 1596-1604. doi: 10.1111/j.15300277.1999.tb04049.x

\section{ACKNOWLEDGMENTS}

JE is grateful for support from Fondo Nacional de Desarrollo Científico y Tecnológico (FONDECYT) postdoctoral grant FONDECYT $\mathrm{N}^{\circ} 3130327$ and project CONICYT PAI/ ACADEMIA project $\mathrm{N}^{\circ} 79160109$. AJ, DT, and AA acknowledge the support by the Polish KNOW (Leading National Research Centre) Scientific Consortium "Healthy Animal-Safe Food," decision of the Ministry of Science and Higher Education No. 051/KNOW2/2015 and the European Union under the European Regional Development Fund (Homing/2017-4/41). DT acknowledges the support provided by Lovely Professional University, Phagwara, Punjab, India. JFK is grateful for the financial support given from the Polish Ministry of Science and Higher Education by subvention activity for the Faculty of Chemistry of Wrocław University of Science and Technology.

Addolorato, G., Caputo, F., Capristo, E., Colombo, G., Gessa, G. L., and Gasbarrini, G. (2000). Ability of baclofen in reducing alcohol craving and intake: II-Preliminary clinical evidence. Alcohol. Clin. Exp. Res. 24, 67-71. doi: 10.1111/j.1530-0277.2000.tb04555.x

Addolorato, G., Armuzzi, A., Gasbarrini, G., De Lorenzi, G., Ancona, C., Abenavoli, L., et al. (2002). Pharmacological approaches to the management of alcohol addiction. Eur. Rev. Med. Pharmacol. Sci. 6, 89-98.

Addolorato, G., Abenavoli, L., Leggio, L., and Gasbarrini, G. (2005a). How many cravings? Pharmacological aspects of craving treatment in alcohol addiction: a review. Neuropsychobiology 51, 59-66. doi: 10.1159/000084161

Addolorato, G., Leggio, L., Abenavoli, L., Gasbarrini, G. and Alcoholism Treatment Study Group. (2005b). Neurobiochemical and clinical aspects of craving in alcohol addiction: a review. Addict. Behav. 30, 1209-1224.

Agabio, R., and Colombo, G. (2014). GABABreceptor ligands for the treatment of alcohol use disorder: preclinical and clinical evidence. Front. Neurosci. 8, 140. doi: $10.3389 /$ fnins.2014.00140

Agarwal, R., Diwanay, S., Patki, P., and Patwardhan, B. (1999). Studies on immunomodulatory activity of Withania somnifera (Ashwagandha) extracts in experimental immune inflammation. J. Ethnopharmacol. 67, 27-35. doi: 10.1016/S0378-8741(99)00065-3

Ajmera, V. H., Terrault, N. A., and Harrison, S. A. (2017). Is moderate alcohol use in nonalcoholic fatty liver disease good or bad? A critical review. Hepatology 65, 2090-2099. doi: 10.1002/hep.29055

Albaugh, B. J., and Anderson, P. O. (1974). Peyote in the treatment of alcoholism among American Indians. Am. J. Psychiatry 131, 1247-1250. doi: 10.1176/ ajp.131.11.1247

Alper, K. R., Lotsof, H. S., and Kaplan, C. D. (2008). The ibogaine medical subculture. J. Ethnopharmacol. 115, 9-24. doi: 10.1016/j.jep.2007.08.034

American Psychiatric Association. (2013). Diagnostic and statistical manual of mental disorders (DSM-5), 5th Ed. Washington DC, USA: American Psychiatric Pub. doi: 10.1176/appi.books.9780890425596

An, S.-W., Kim, Y.-G., Kim, M.-H., Lee, B.-I., Lee, S.-H., Kwon, H.-I., et al. (1999). Comparison of Hepatic Detoxification activity and reducing Serum Alcohol 
concentration of Hovenia dulsis Thunb. and Alnus japonica Steud. Korean J. Med. Crop Sci. 7, 263-268.

Angamuthu, V., Shanmugavadivu, M., Nagarajan, G., and Velmurugan, B. K. (2019). Pharmacological activities of antroquinonol- Mini review. Chem. Biol. Interact. 297, 8-15. doi: 10.1016/j.cbi.2018.10.009

Ao, Z.-H., Xu, Z.-H., Lu, Z.-M., Xu, H.-Y., Zhang, X.-M., and Dou, W.-F. (2009). Niuchangchih (Antrodia camphorata) and its potential in treating liver diseases. J. Ethnopharmacol. 121, 194-212. doi: 10.1016/j.jep.2008.10.039

Arnsten, J. H., Demas, P. A., Grant, R. W., Gourevitch, M. N., Farzadegan, H., Howard, A. A., et al. (2002). Impact of active drug use on antiretroviral therapy adherence and viral suppression in HIV-infected drug users. J. Gen. Intern. Med. 17, 377-381. doi: 10.1046/j.1525-1497.2002.10644.x

Arolfo, M. P., Overstreet, D. H., Yao, L., Fan, P., Lawrence, A. J., Tao, G., et al. (2009). Suppression of heavy drinking and alcohol seeking by a selective ALDH-2 inhibitor. Alcohol. Clin. Exp. Res. 33, 1935-1944. doi: 10.1111/j.15300277.2009.01031.x

Atanasov, A. G., Waltenberger, B., Pferschy-Wenzig, E.-M., Linder, T., Wawrosch, C., Uhrin, P., et al. (2015). Discovery and resupply of pharmacologically active plantderived natural products: a review. Biotechnol. Adv. 33, 1582-1614. doi: 10.1016/ J.BIOTECHADV.2015.08.001

Attele, A. S., Wu, J. A., and Yuan, C. S. (1999). Ginseng pharmacology: multiple constituents and multiple actions. Biochem. Pharmacol. 58, 1685-1693. doi: 10.1016/s0006-2952(99)00212-9

Bahmani, M., Shirzad, H., Rafieian, S., and Rafieian-Kopaei, M. (2015). Silybum marianum: beyond hepatoprotection. J. Evid. Based. Complement. Altern. Med. 20, 292-301. doi: 10.1177/2156587215571116

Baldassarre, M., Caputo, F., Pavarin, R. M., Bossi, M. M., Bonavita, M. E., Caraceni, P., et al. (2018). Accesses for alcohol intoxication to the emergency department and the risk of re-hospitalization: an observational retrospective study. Addict. Behav. 77, 1-6. doi: 10.1016/j.addbeh.2017.08.031

Ballenger, J. C., Goodwin, F. K., Major, L. F., and Brown, G. L. (1979). Alcohol and central serotonin metabolism in man. Arch. Gen. Psychiatry 36, 224-227. doi: 10.1001/archpsyc. 1979.01780020114013

Bao, T., and Saito, H. (1984). Effects of red ginseng, vitamins and their preparations (IV). Effect on sex cycle in stressed female mice. Yakuri to Chiryo 12, 1477-1481.

Barnes, J., Anderson, L. A., and Phillipson, J. D. (2001). St John's wort (Hypericum perforatum L.): a review of its chemistry, pharmacology and clinical properties. J. Pharm. Pharmacol. 53, 583-600. doi: 10.1211/0022357011775910

Barrett, S. P., Tichauer, M., Leyton, M., and Pihl, R. O. (2006). Nicotine increases alcohol self-administration in non-dependent male smokers. Drug Alcohol Depend. 81, 197-204. doi: 10.1016/j.drugalcdep.2005.06.009

Bataller, R., and Brenner, D. A. (2005). Liver fibrosis. J. Clin. Invest. 115, 209-218. doi: $10.1172 /$ JCI24282

Benegal, V. (2005). India: alcohol and public health. Addiction 100, 1051-1056.

Benlhabib, E., Baker, J. I., Keyler, D. E., and Singh, A. K. (2004a). Effects of purified puerarin on voluntary alcohol intake and alcohol withdrawal symptoms in $\mathrm{P}$ rats receiving free access to water and alcohol. J. Med. Food 7, 180-186. doi: $10.1089 / 1096620041224102$

Benlhabib, E., Baker, J. I., Keyler, D. E., and Singh, A. K. (2004b). Kudzu root extract suppresses voluntary alcohol intake and alcohol withdrawal symptoms in $\mathrm{P}$ rats receiving free access to water and alcohol. J. Med. Food 7, 168-179. doi: 10.1089/1096620041224210

Bessembinders, K., Wielders, J., and van de Wiel, A. (2011). Severe hypertriglyceridemia influenced by alcohol (SHIBA). Alcohol Alcohol 46, 113-116. doi: $10.1093 /$ alcalc/agq088

Beulens, J. W. J., van Beers, R. M., Stolk, R. P., Schaafsma, G., and Hendriks, H. F. J. (2006). The effect of moderate alcohol consumption on fat distribution and adipocytokines. Obesity (Silver Spring) 14, 60-66. doi: 10.1038/oby.2006.8

Beulens, J. W. J., de Zoete, E. C., Kok, F. J., Schaafsma, G., and Hendriks, H. F. J. (2008). Effect of moderate alcohol consumption on adipokines and insulin sensitivity in lean and overweight men: a diet intervention study. Eur. J. Clin. Nutr. 62, 1098-1105. doi: 10.1038/sj.ejcn.1602821

Bhattacharya, S. K., and Kumar, A. (1997). Effect of Trasina, an ayurvedic herbal formulation, on experimental models of Alzheimer's disease and central cholinergic markers in rats. J. Altern. Complement. Med. 3, 327-336. doi: 10.1089/acm.1997.3.327
Birt, D. F., Widrlechner, M. P., Hammer, K. D. P., Hillwig, M. L., Wei, J., Kraus, G. A., et al. (2009). "Hypericum in infection: identification of anti-viral and anti-inflammatory constituents," Pharmaceutical Biology. 47, 774-782. doi: $10.1080 / 13880200902988645$

Bito-Onon, J. J., Simms, J. A., Chatterjee, S., Holgate, J., and Bartlett, S. E. (2011). Varenicline, a partial agonist at neuronal nicotinic acetylcholine receptors, reduces nicotine-induced increases in $20 \%$ ethanol operant self-administration in Sprague-Dawley rats. Addict. Biol. 16, 440-449. doi: 10.1111/j.13691600.2010.00309.x

Blachier, M., Leleu, H., Peck-Radosavljevic, M., Valla, D.-C., and RoudotThoraval, F. (2013). The burden of liver disease in Europe: a review of available epidemiological data. J. Hepatol. 58, 593-608. doi: 10.1016/ j.jhep.2012.12.005

Blomqvist, O., Ericson, M., Johnson, D. H., Engel, J. A., and Soderpalm, B. (1996). Voluntary ethanol intake in the rat: effects of nicotinic acetylcholine receptor blockade or subchronic nicotine treatment. Eur. J. Pharmacol. 314, 257-267. doi: 10.1016/s0014-2999(96)00583-3

Boerth, J., and Strong, K. M. (2002). The clinical utility of milk thistle (Silybum marianum) in cirrhosis of the liver. J. Herb. Pharmacother. 2, 11-17. doi: 10.1080/J157v02n02_02

Boesche, R. (2002). The first great political realist: Kautilya and his Arthashastra (Lexington Books).

Bogenschutz, M. P., Forcehimes, A. A., Pommy, J. A., Wilcox, C. E., Barbosa, P. C. R., and Strassman, R. J. (2015). Psilocybin-assisted treatment for alcohol dependence: a proof-of-concept study. J. Psychopharmacol. 29, 289-299. doi: $10.1177 / 0269881114565144$

Bombardelli, E., and Morazzoni, P. (1995). Hypericum perforatum. Fitoterapia 66, 43-68.

Bono, G., Sinforiani, E., Merlo, P., Belloni, G., Soldati, M., and Gelso, E. (1991). Alcoholic abstinence syndrome: short-term treatment with metadoxine. Int. J. Clin. Pharmacol. Res. 11, 35-40.

Borges, G., Monteiro, M., Cherpitel, C. J., Orozco, R., Ye, Y., Poznyak, V., et al. (2017). Alcohol and road traffic injuries in Latin America and the Caribbean: a case-crossover study. Alcohol. Clin. Exp. Res. 41, 1731-1737. doi: 10.1111/ acer. 13467

Briasoulis, A., Agarwal, V., and Messerli, F. H. (2012). Alcohol consumption and the risk of hypertension in men and women: a systematic review and metaanalysis. J. Clin. Hypertens. (Greenwich) 14, 792-798. doi: 10.1111/jch.12008

Brien, S. E., Ronksley, P. E., Turner, B. J., Mukamal, K. J., and Ghali, W. A. (2011). Effect of alcohol consumption on biological markers associated with risk of coronary heart disease: systematic review and meta-analysis of interventional studies. BMJ 342, d636. doi: 10.1136/bmj.d636

Brown, T. (2013). Ibogaine in the treatment of substance dependence. Curr. Drug Abuse Rev. doi: 10.2174/15672050113109990001

Bukhari, I. A., Dar, A., and Khan, R. A. (2004). Antinociceptive activity of methanolic extracts of St. John's Wort (Hypericum perforatum) preparation. Pak J. Pharm. Sci. 6, 3-16.

Butterweck, V., Wall, A., Lieflander-Wulf, U., Winterhoff, H., and Nahrstedt, A. (1997). Effects of the total extract and fractions of Hypericum perforatum in animal assays for antidepressant activity. Pharmacopsychiatry 30, 117-124. doi: $10.1055 / \mathrm{s}-2007-979531$

Caballeria, J., Pares, A., Bru, C., Mercader, J., Garcia Plaza, A., Caballeria, L., et al. (1998). Metadoxine accelerates fatty liver recovery in alcoholic patients: results of a randomized double-blind, placebo-control trial. Spanish group for the study of alcoholic fatty liver. J. Hepatol. 28, 54-60. doi: 10.1016/s0168-8278(98) 80202-x

Campbell, M. L., Bozec, L. J., McGrath, D., and Barrett, S. P. (2012). Alcohol and tobacco co-use in nondaily smokers: an inevitable phenomenon? Drug Alcohol Rev. 31, 447-450. doi: 10.1111/j.1465-3362.2011.00328.x

Can, O. D., and Ozkay, U. D. (2012). Effects of Hypericum montbretti extract on the central nervous system and involvement of GABA (A)/Benzodiazepine receptors in its pharmacological activity. Phytother. Res. 26, 1695-1700. doi: $10.1002 /$ ptr.4629

Cao, G. Y., Zhang, J. Y., Zhang, G. Q., Zhou, H. S., and Deng, C. J. (2007). A control study comparing herbal Jiejiu decotion and furazolidone in the treatment of alcohol dependence. Hebei Med. (Hebei Yiyao) 28, 1196-1197.

Caraci, F., Crupi, R., Drago, F., and Spina, E. (2011). Metabolic drug interactions between antidepressants and anticancer drugs: focus on selective serotonin 
reuptake inhibitors and hypericum extract. Curr. Drug Metab 12, 570-577. doi: 10.2174/138920011795713706

Carai, M. A., Agabio, R., Bombardelli, E., Bourov, I., Gessa, G. L., Lobina, C., et al. (2000). Potential use of medicinal plants in the treatment of alcoholism. Fitoterapia 71, S38-S42.

Castleman, M. (2001). The New Healing Herbs: The Classic Guide to Nature's Best Medicines Featuring the Top 100 Time-Tested Herbs. 2nd ed. (Emmaus, Pennsylvania: Rodale Press). doi: 10.1016/s0367-326x(00)00178-7

Cha, B. C., Lee, E. H., Lee, E., and Park, H. H. (2004). Activity of glutathione Stransferase and effect of alcohol decomposition on the fruit of Hovenia dulcis Thunb. Yakhak Hoeji 48, 213-217.

Chander, G., Himelhoch, S., and Moore, R. D. (2006). Substance abuse and psychiatric disorders in HIV-positive patients: epidemiology and impact on antiretroviral therapy. Drugs 66, 769-789. doi: 10.2165/00003495-20066606000004

Chandra, P. S., Krishna, V. A. S., Benegal, V., and Ramakrishna, J. (2003). Highrisk sexual behaviour \& sensation seeking among heavy alcohol users. Indian J. Med. Res. 117, 88-92.

Chaphalkar, R., Apte, K. G., Talekar, Y., Ojha, S. K., and Nandave, M. (2017). Antioxidants of Phyllanthus emblica L. Bark extract provide hepatoprotection against ethanol-induced hepatic damage: a comparison with silymarin. Oxid. Med. Cell. Longev. 2017, 3876040. doi: 10.1155/2017/3876040

Chen, X., Unger, J. B., Palmer, P., Weiner, M. D., Johnson, C. A., Wong, M. M., et al. (2002). Prior cigarette smoking initiation predicting current alcohol use: evidence for a gateway drug effect among California adolescents from eleven ethnic groups. Addict. Behav. 27, 799-817. doi: 10.1016/S0306-4603(01)00211-8

Chen, C., Wen, D.-C., Gao, S., Hu, X., and Yi, C. (2016). The protective effects of Buzui on acute alcoholism in mice. Evidence-Based Complement. Altern. Med. 2016, 3539748. doi: 10.1155/2016/3539748

Chester, J. A., and Cunningham, C. L. (1999). GABA(A) receptors modulate ethanol-induced conditioned place preference and taste aversion in mice. Psychopharmacol. 144, 363-372. doi: 10.1007/s002130051019

Choi, W.-J., Shin, J.-W., Son, J.-Y., Seo, D.-S., Park, H.-S., Han, S.-H., et al. (2006). Toxicological study of the hepatotherapeutic herbal formula, chunggan extract, in beagle dogs. World J. Gastroenterol. 12, 7497-7502. doi: 10.3748/ wjg.v12.i46.7497

Chopra, R. N., Nayar, S. L., and Chopra, I. C. (1956). Glossary of Indian medicinal plants. New Delhi: Council of Scientific And Industrial Research

Christensen, L. P. (2009). Ginsenosides chemistry, biosynthesis, analysis, and potential health effects. Adv. Food Nutr. Res. 55, 1-99. doi: 10.1016/S1043-4526 (08)00401-4

Chung, I. W., Moore, N. A., Oh, W. K., O’Neill, M. F., Ahn, J. S., Park, J. B., et al. (2002). Behavioural pharmacology of polygalasaponins indicates potential antipsychotic efficacy. Pharmacol. Biochem. Behav. 71, 191-195. doi: 10.1016/S0091-3057(01)00648-7

Ciccocioppo, R., Panocka, I., Froldi, R., Colombo, G., Gessa, G. L., and Massi, M. (1999). Antidepressant-like effect of ethanol revealed in the forced swimming test in Sardinian alcohol-preferring rats. Psychopharmacol. 144, 151-157. doi: $10.1007 / \mathrm{s} 002130050988$

Colombo, G., Agabio, R., Lobina, C., Reali, R., Morazzoni, P., Bombardelli, E., et al. (1999). Salvia miltiorrhiza extract inhibits alcohol absorption, preference, and discrimination in sP rats. Alcohol 18, 65-70. doi: 10.1016/s0741-8329(98) 00069-x

Colombo, G., Agabio, R., Carai, M. A., Lobina, C., Pani, M., Reali, R., et al. (2000). Ability of baclofen in reducing alcohol intake and withdrawal severity: IPreclinical evidence. Alcohol. Clin. Exp. Res. 24, 58-66. doi: 10.1111/j.15300277.2000.tb04554.x

Colombo, G., Serra, S., Vacca, G., Orrù, A., Maccioni, P., Morazzoni, P., et al. (2006). Identification of miltirone as active ingredient of Salvia miltiorrhiza responsible for the reducing effect of root extracts on alcohol intake in rats. Alcohol. Clin. Exp. Res. 30, 754-762. doi: 10.1111/j.15300277.2006.00088.x

Corchete, P. (2008). Silybum marianum (L.) Gaertn: the source of silymarin. In Bioactive Molecules and Medicinal Plants (pp. 123-148). Springer, Berlin, Heidelberg. doi: 10.1007/978-3-540-74603-4_6

Costanzo, S., Di Castelnuovo, A., Donati, M. B., Iacoviello, L., and de Gaetano, G. (2010). Alcohol consumption and mortality in patients with cardiovascular disease: a meta-analysis. J. Am. Coll. Cardiol. 55, 1339-1347. doi: 10.1016/ j.jacc.2010.01.006

Croop, R. S., Faulkner, E. B., and Labriola, D. F. (1997). The safety profile of naltrexone in the treatment of alcoholism. Results from a multicenter usage study. The naltrexone usage study group. Arch. Gen. Psychiatry 54, 1130-1135. doi: 10.1001/archpsyc.1997.01830240090013

Dani, J. A., and Bertrand, D. (2007). Nicotinic acetylcholine receptors and nicotinic cholinergic mechanisms of the central nervous system. Annu. Rev. Pharmacol. Toxicol. 47, 699-729. doi: 10.1146/annurev.pharmtox.47. 120505.105214

Dani, J. A., and Harris, R. A. (2005). Nicotine addiction and comorbidity with alcohol abuse and mental illness. Nat. Neurosci. 8, 1465-1470. doi: 10.1038/ nn1580

Dar, N. J., Bhat, J. A., Satti, N. K., Sharma, P. R., Hamid, A., and Ahmad, M. (2017). Withanone, an active constituent from withania somnifera, affords protection against NMDA-induced excitotoxicity in neuron-like cells. Mol. Neurobiol. 54, 5061-5073. doi: 10.1007/s12035-016-0044-7

Dart, R. C., and Bailey, E. (2007). Does therapeutic use of acetaminophen cause acute liver failure? Pharmacotherapy 27, 1219-1230. doi: 10.1592/ phco.27.9.1219

Das, S. K., and Mukherjee, S. (2012). Biochemical and immunological basis of silymarin effect, a milk thistle (Silybum marianum) against ethanol-induced oxidative damage. Toxicol. Mech. Methods 22, 409-413. doi: 10.3109/ 15376516.2012 .673090

Das, S. K., and Vasudevan, D. M. (2007). Alcohol-induced oxidative stress. Life Sci. 81, 177-187. doi: 10.1016/j.lfs.2007.05.005

De, B. K., Gangopadhyay, S., Dutta, D., Baksi, S. Das, Pani, A., and Ghosh, P. (2009). Pentoxifylline versus prednisolone for severe alcoholic hepatitis: a randomized controlled trial. World J. Gastroenterol. 15, 1613-1619. doi: 10.3748/wjg.15.1613

De Vry, J., Maurel, S., Schreiber, R., De Beun, R., and Jentzsch, K. R. (1999). Comparison of hypericum extracts with imipramine and fluoxetine in animal models of depression and alcoholism. Eur. Neuropsychopharmacol. 9, 461-468. doi: $10.1016 /$ s0924-977x(99)00005-x

de Wit, H., and Stewart, J. (1981). Reinstatement of cocaine-reinforced responding in the rat. Psychopharmacol. 75, 134-143. doi: 10.1007/BF00432175

Dedert, E. A., McDuffie, J. R., Stein, R., McNiel, J. M., Kosinski, A. S., Freiermuth, C. E., et al. (2015). Electronic interventions for alcohol misuse and alcohol use disorders: a systematic review. Ann. Intern. Med. 163, 205-214. doi: 10.7326/ M15-0285

Deecher, D. C., Teitler, M., Soderlund, D. M., Bornmann, W. G., Kuehne, M. E., and Glick, S. D. (1992). Mechanisms of action of ibogaine and harmaline congeners based on radioligand binding studies. Brain Res. 571, 242-247. doi: 10.1016/0006-8993(92)90661-r

Dhawan, K., Kumar, S., and Sharma, A. (2002). Suppression of alcohol-cessationoriented hyper-anxiety by the benzoflavone moiety of Passiflora incarnata Linneaus in mice. J. Ethnopharmacol. 81, 239-244. doi: 10.1016/s0378-8741 (02)00086-7

DiFranza, J. R., and Guerrera, M. P. (1990). Alcoholism and smoking. J. Stud. Alcohol 51, 130-135. doi: 10.15288/jsa.1990.51.130

Doetkotte, R., Opitz, K., Kiianmaa, K., and Winterhoff, H. (2005). Reduction of voluntary ethanol consumption in alcohol-preferring Alko alcohol (AA) rats by desoxypeganine and galanthamine. Eur. J. Pharmacol. 522, 72-77. doi: 10.1016/j.ejphar.2005.08.038

Dopico, A. M., and Lovinger, D. M. (2009). Acute alcohol action and desensitization of ligand-gated ion channels. Pharmacol. Rev. 61, 98-114. doi: $10.1124 /$ pr.108.000430

Dou, J. J., Gao, H. J., and Liu, B. S. (2003). The effect of Guadi wine in the treatment of alcohol dependence. Chin. J. Med. (Zhongguo Yikang) 2, 48.

Doyon, W. M., Dong, Y., Ostroumov, A., Thomas, A. M., Zhang, T. A., and Dani, J. A. (2013a). Nicotine decreases ethanol-induced dopamine signaling and increases self-administration via stress hormones. Neuron 79, 530-540. doi: 10.1016/j.neuron.2013.06.006

Doyon, W. M., Thomas, A. M., Ostroumov, A., Dong, Y., and Dani, J. A. (2013b). Potential substrates for nicotine and alcohol interactions: a focus on the mesocorticolimbic dopamine system. Biochem. Pharmacol. 86, 1181-1193. doi: 10.1016/j.bcp.2013.07.007 
Dyr, W., Koros, E., Bienkowski, P., and Kostowski, W. (1999). Involvement of nicotinic acetylcholine receptors in the regulation of alcohol drinking in Wistar rats. Alcohol Alcohol 34, 43-47. doi: 10.1093/alcalc/34.1.43

Dzoljic, E. D., Kaplan, C. D., and Dzoljic, M. R. (1988). Effect of ibogaine on naloxone-precipitated withdrawal syndrome in chronic morphine-dependent rats. Arch. Int. Pharmacodyn. Thér. 294, 64-70.

Fan, A. Z., Russell, M., Dorn, J., Freudenheim, J. L., Nochajski, T., Hovey, K., et al. (2006). Lifetime alcohol drinking pattern is related to the prevalence of metabolic syndrome. The Western New York Health Study (WNYHS). Eur. J. Epidemiol. 21, 129-138. doi: 10.1007/s10654-005-5457-y

Feher, J., Deák, G., Müzes, G., Lang, I., Niederland, V., Nekam, K., et al. (1989). Liver-protective action of silymarin therapy in chronic alcoholic liver diseases. Orv. Hetil. 130, 2723-2727.

Ferenci, P., Dragosics, B., Dittrich, H., Frank, H., Benda, L., Lochs, H., et al. (1989). Randomized controlled trial of silymarin treatment in patients with cirrhosis of the liver. J. Hepatol. 9, 105-113. doi: 10.1016/0168-8278(89)90083-4

Flora, K., Hahn, M., Rosen, H., and Benner, K. (1998). Milk thistle (Silybum marianum) for the therapy of liver disease. Am. J. Gastroenterol. 93, 139-143. doi: 10.1111/j.1572-0241.1998.00139.x

Frances, B., Gout, R., Cros, J., and Zajac, J. M. (1992). Effects of ibogaine on naloxone-precipitated withdrawal in morphine-dependent mice. Fundam. Clin. Pharmacol. 6, 327-332. doi: 10.1111/j.1472-8206.1992.tb00127.x

Friedman, S. L. (2003). Liver fibrosis - from bench to bedside. J. Hepatol. 38 (Suppl 1), S38-S53. doi: 10.1016/s0168-8278(02)00429-4

Funk, D., Marinelli, P. W., and Le, A. D. (2006). Biological processes underlying co-use of alcohol and nicotine: neuronal mechanisms, cross-tolerance, and genetic factors. Alcohol Res. Health 29, 186-192.

Gallimberti, L., Spella, M. R., Soncini, C. A., and Gessa, G. L. (2000). Gammahydroxybutyric acid in the treatment of alcohol and heroin dependence. Alcohol 20, 257-262. doi: 10.1016/s0741-8329(99)00089-0

Gallo, C., Renzi, P., Loizzo, S., Loizzo, A., and Capasso, A. (2009). Tabernanthe iboga: a Comprehensive Review. Pharmacologyonline. 3, 906-920.

Gately, I. (2008). Drink: A cultural history of alcohol. New York, USA: Penguin.

Gessa, G. L., Agabio, R., Carai, M. A., Lobina, C., Pani, M., Reali, R., et al. (2000). Mechanism of the antialcohol effect of gamma-hydroxybutyric acid. Alcohol 20, 271-276. doi: 10.1016/s0741-8329(99)00091-9

Gianoulakis, C. (2009). Endogenous opioids and addiction to alcohol and other drugs of abuse. Curr. Top. Med. Chem. 4, 39-50. doi: 10.2174/156802609789 630956

Gibbons, S., and Arunotayanun, W. (2013). Natural Product (Fungal and Herbal) Novel Psychoactive Substances, in Novel Psychoactive Substances: Classification, Pharmacology and Toxicology (Academic Press: Elsevier), 345362. doi: 10.1016/B978-0-12-415816-0.00014-6

Glautier, S., Clements, K., White, J. A. W., Taylor, C., and Stolerman, I. P. (1996). Alcohol and the reward value of cigarette smoking. Behav. Pharmacol. 7, 144154. doi: 10.1097/00008877-199603000-00005

Gleason, H. A., and Cronquist, A. (1963). Manual of vascular plants of northeastern United States and adjacent Canada (New York: Van Nostrand).

Glen, L., Skinner, F., Glen, E., and MacDonell, L. (1987). The role of essential fatty acids in alcohol dependence and tissue damage. Alcohol. Clin. Exp. Res. 11, 37-41. doi: 10.1111/j.1530-0277.1987.tb01257.x

Glick, S. D., and Maisonneuve, I. S. (1998). Mechanisms of antiaddictive actions of ibogaine. Ann. N. Y. Acad. Sci. 844, 214-226. doi: 10.1111/j.17496632.1998.tb08237.x

Glick, S. D., Rossman, K., Steindorf, S., Maisonneuve, I. M., and Carlson, J. N. (1991). Effects and aftereffects of ibogaine on morphine self-administration in rats. Eur. J. Pharmacol. 195, 341-345. doi: 10.1016/0014-2999(91)90474-5

Glick, S. D., Kuehne, M. E., Raucci, J., Wilson, T. E., Larson, D., Keller, R. W., et al. (1994). Effects of iboga alkaloids on morphine and cocaine self-administration in rats: relationship to tremorigenic effects and to effects on dopamine release in nucleus accumbens and striatum. Brain Res. 657, 14-22. doi: 10.1016/00068993(94)90948-2

Glick, S. D., Maisonneuve, I. M., and Szumlinski, K. K. (2000). 18Methoxycoronaridine (18-MC) and ibogaine: comparison of antiaddictive efficacy, toxicity, and mechanisms of action. Ann. N. Y. Acad. Sci. 914, 369386. doi: 10.1111/j.1749-6632.2000.tb05211.x
Global Burden of Disease Collaborative Network. Global Burden of Disease Study 2016 (GBD 2016) Alcohol Use Estimates 1990-2016. Seattle, United States: Institute for Health Metrics and Evaluation.

Gorelick, D. A., and Paredes, A. (1992). Effect of fluoxetine on alcohol consumption in male alcoholics. Alcohol. Clin. Exp. Res. 16, 261-265. doi: 10.1111/j.1530-0277.1992.tb01373.x

Grant, B. F. (1998). Age at smoking onset and its association with alcohol consumption and DSM-IV alcohol abuse and dependence: results from the National Longitudinal Alcohol Epidemiologic Survey. J. Subst. Abuse 10, 59-73. doi: 10.1016/s0899-3289(99)80141-2

Grant, B. F., Goldstein, R. B., Saha, T. D., Chou, S. P., Jung, J., Zhang, H., et al. (2015). Epidemiology of dsm-5 alcohol use disorder: results from the national epidemiologic survey on alcohol and related conditions iii. JAMA Psychiatry 72, 757-766. doi: doi: 10.1001/jamapsychiatry.2015.0584

Gryszczynska, A., Opala, B., Lowicki, Z., Dreger, M., Gorska-Paukszta, M., Szulc, M., et al. (2015). Bioactive compounds determination in the callus and hydroalcoholic extracts from Salvia miltiorrhiza and Salvia przewalskiiPreliminary study on their anti-alcoholic activity effects. Phytochem. Lett. 11, 399-403. doi: 10.1016/j.phytol.2014.11.009

Guan, M.-J., Zhao, N., Xie, K.-Q., and Zeng, T. (2018). Hepatoprotective effects of garlic against ethanol-induced liver injury: a mini-review. Food Chem. Toxicol. 111, 467-473. doi: 10.1016/j.fct.2017.11.059

Guidot, D. M., and Mehta, A. J. (2014). “A Brief History of Alcohol Use and Abuse in Human History," in Alcohol Use Disorders and the Lung (New York: Springer), 3-6.

Gupta, S., and Gupta, Y. K. (2017). Combination of Zizyphus jujuba and silymarin showed better neuroprotective effect as compared to single agent in MCAoinduced focal cerebral ischemia in rats. J. Ethnopharmacol. 197, 118-127. doi: 10.1016/j.jep.2016.07.060

Gupta, G. L., and Rana, A. C. (2008). Effect of Withania somnifera Dunal in ethanol-induced anxiolysis and withdrawal anxiety in rats. Indian J. Exp. Biol. 46, 470-475.

Gutierrez-Ruiz, M. C., Quiroz, S. C., Souza, V., Bucio, L., Hernandez, E., Olivares, I. P., et al. (1999). Cytokines, growth factors, and oxidative stress in HepG2 cells treated with ethanol, acetaldehyde, and LPS. Toxicology 134, 197-207. doi: 10.1016/S0300-483X(99)00044-X

Hanson, D. (2013). Historical evolution of alcohol consumption in society. Alcohol Sci. Policy Public Heal. 2013, 4-14.

Hao, F., Cubero, F. J., Ramadori, P., Liao, L., Haas, U., Lambertz, D., et al. (2017). Inhibition of Caspase- 8 does not protect from alcohol-induced liver apoptosis but alleviates alcoholic hepatic steatosis in mice. Cell Death Dis. 8, e3152. doi: 10.1038 /cddis. 2017.532

Harris, R. A. (1990). Distinct actions of alcohols, barbiturates and benzodiazepines on GABA-activated chloride channels. Alcohol 7, 273-275. doi: 10.1016/07418329(90)90017-7

Harrison, E. L. R., Desai, R. A., and McKee, S. A. (2008). Nondaily smoking and alcohol use, hazardous drinking, and alcohol diagnoses among young adults: findings from the NESARC. Alcohol. Clin. Exp. Res. 32, 2081-2087. doi: 10.1111/j.1530-0277.2008.00796.x

Hase, K., and Basnet, P. (1997). Effect of Hovenia dulcis on lipopolysaccharideinduced liver injury in chronic alcohol-fed rats. J. Trad. Med. 14, 28-33.

Heyman, G. M., Keung, W., and Vallee, B. L. (1996). Daidzin decreases ethanol consumption in rats. Alcohol. Clin. Exp. Res. 20, 1083-1087. doi: 10.1111/ j.1530-0277.1996.tb01950.x

Hillemacher, T., Weinland, C., Heberlein, A., Groschl, M., Schanze, A., Frieling, H., et al. (2009). Increased levels of adiponectin and resistin in alcohol dependencepossible link to craving. Drug Alcohol Depend. 99, 333-337. doi: 10.1016/ j.drugalcdep.2008.07.019

Hinkin, C. H., Barclay, T. R., Castellon, S. A., Levine, A. J., Durvasula, R. S., Marion, S. D., et al. (2007). Drug use and medication adherence among HIV-1 infected individuals. AIDS Behav. 11, 185-194. doi: 10.1007/s10461-006-9152-0

Huang, H. T. (2000). Science and civilisation in China. Volume 6: Biology and biological technology. Part V: fermentations and food science. by J. Needham Cambridge Univ. Press Cambridge.

Hyams, E. (1965). Dionysus; a social history of the wine vine. (New York: Macmillan). Ibrahim, I. A. A., Abdulla, M. A., Hajrezaie, M., Bader, A., Shahzad, N., Al-Ghamdi, S. S., et al. (2015). The gastroprotective effects of hydroalcoholic extract of 
Monolluma quadrangula against ethanol-induced gastric mucosal injuries in Sprague Dawley rats. Drug Des. Devel. Ther. 10, 93-105. doi: 10.2147/ DDDT.S91247

Jang, M.-H., Shin, M.-C., Lee, T.-H., Bahn, G.-H., Shin, H.-S., Lim, S., et al. (2003). Effect of Puerariae radix on c-Fos expression in hippocampus of alcoholintoxicated juvenile rats. Biol. Pharm. Bull. 26, 37-40. doi: 10.1248/bpb.26.37

Jensen, M. K., Sorensen, T. I. A., Andersen, A. T., Thorsen, T., Tolstrup, J. S., Godtfredsen, N. S., et al. (2003). A prospective study of the association between smoking and later alcohol drinking in the general population. Addiction 98, 355-363. doi: 10.1046/j.1360-0443.2003.00304.x

Jin, G.-Z. (1987). (-)-Tetrahydropalmatine and its analogues as new dopamine receptor antagonists. Trends Pharmacol. Sci. 8, 81-82. doi: 10.1016/0165-6147 (87) $90076-9$

Joo, C. N., Koo, J. H., Lee, H. B., Yoon, J. B., and Byun, Y. S. (1982). Biochemical studies on the absorption of ginseng saponin and its effect on metabolism in the animal body. Korean Biochem. J. 15, 189-199.

Kalichman, S. C., Kalichman, M. O., Cherry, C., Hoyt, G., Washington, C., Grebler, T., et al. (2015). Intentional medication nonadherence because of interactive toxicity beliefs among HIV-positive active drug users. J. Acquir. Immune Defic. Syndr. 70, 503-509. doi: 10.1097/QAI.0000000000000776

Kano, M., and Kubota, N. (2013). "Soy products affecting alcohol absorption and metabolism," in Alcohol, Nutrition, and Health Consequences (Springer, NY: Humana Press), 203-214. doi: 10.1201/9780203507636-16

Kano, M., Ishikawa, F., Matsubara, S., Kikuchi-Hayakawa, H., and Shimakawa, Y. (2002). Soymilk products affect ethanol absorption and metabolism in rats during acute and chronic ethanol intake. J. Nutr. 132, 238-244. doi: 10.1093/jn/ 132.2.238

Kapadia, F., Vlahov, D., Donahoe, R. M., and Friedland, G. (2005). The role of substance abuse in HIV disease progression: reconciling differences from laboratory and epidemiologic investigations. Clin. Infect. Dis. 41, 1027-1034. doi: $10.1086 / 433175$

Kaser, S., Moschen, A., Kaser, A., Ludwiczek, O., Ebenbichler, C. F., Vogel, W., et al. (2005). Circulating adiponectin reflects severity of liver disease but not insulin sensitivity in liver cirrhosis. J. Intern. Med. 258, 274-280. doi: 10.1111/ j.1365-2796.2005.01543.x

Kasimu, R., Tanaka, K., Tezuka, Y., Gong, Z. N., Li, J. X., Basnet, P., et al. (1998). Comparative study of seventeen Salvia plants: aldose reductase inhibitory activity of water and $\mathrm{MeOH}$ extracts and liquid chromatography-mass spectrometry (LC-MS) analysis of water extracts. Chem. Pharm. Bull. (Tokyo) 46, 500-504. doi: 10.1248/cpb.46.500

Kasztelan-Szczerbinska, B., Surdacka, A., Slomka, M., Rolinski, J., Celinski, K., Smolen, A., et al. (2013). Association of serum adiponectin, leptin, and resistin concentrations with the severity of liver dysfunction and the disease complications in alcoholic liver disease. Mediators Inflamm. 2013, 148526. doi: $10.1155 / 2013 / 148526$

Kaur, G., Meena, C., Veeranjaneyulu, A., and Agrawal, S. S. (2009). Evaluation of hepatoprotective activity of Ocimum scantum in HepG2 cell line. Arch. Pharm. Sci. Res. 1, 25-30.

Keung, W.-M., and Vallee, B. L. (1993a). Daidzin and daidzein suppress freechoice ethanol intake by Syrian golden hamsters. Proc. Natl. Acad. Sci. 90, 10008-10012. doi: 10.1073/pnas.90.21.10008

Keung, W. M., and Vallee, B. L. (1993b). Daidzin: a potent, selective inhibitor of human mitochondrial aldehyde dehydrogenase. Proc. Natl. Acad. Sci. U. S. A. 90, 1247-1251. doi: 10.1073/pnas.90.4.1247

Keung, W. M., and Vallee, B. L. (1998). Daidzin and its antidipsotropic analogs inhibit serotonin and dopamine metabolism in isolated mitochondria. Proc. Natl. Acad. Sci. U. S. A. 95, 2198-2203. doi: 10.1073/pnas.95.5.2198

Keung, W.-M., Lazo, O., Kunze, L., and Vallee, B. L. (1995). Daidzin suppresses ethanol consumption by Syrian golden hamsters without blocking acetaldehyde metabolism. Proc. Natl. Acad. Sci. 92, 8990-8993. doi: 10.1073/pnas.92.19.8990

Keung, W. M. (2003). Anti-dipsotropic isoflavones: the potential therapeutic agents for alcohol dependence. Med. Res. Rev. 23, 669-696. doi: 10.1002/med.10049

Kim, M.-H., Chung, Y.-T., Lee, J.-H., Park, Y.-S., Shin, M.-K., Kim, H.-S., et al. (2000). Hepatic detoxification activity and reduction of serum alcohol concentration of Hovenia dulcis $\$ T_{-}\{$HUNB $\}$\$ from Korea and China. Korean J. Med. Crop Sci. 8, 225-233.

Kim, S.-M., Kang, S.-H., Ma, J.-Y., and Kim, J.-H. (2006). A study on the extraction and efficacy of bioactive compound from Hovenia dulcis. KSBB J. 21, 11-15.
Kim, S. H., Chung, H. G., and Han, J. (2008). Hepatoprotective and blood alcohol lowering effects of Korean Raisin Tree (Hovenia dulcis var. Koreana Nakai) polar extracts. Planta Med. 74, PA286. doi: 10.1055/s-0028-1084284

Kim, H.-G., Kim, J.-M., Han, J.-M., Lee, J.-S., Choi, M.-K., Lee, D.-S., et al. (2014). Chunggan extract, a traditional herbal formula, ameliorated alcohol-induced hepatic injury in rat model. World J. Gastroenterol. 20, 15703-15714. doi: 10.3748/wjg.v20.i42.15703

Kim, J. H., Yi, Y.-S., Kim, M.-Y., and Cho, J. Y. (2017). Role of ginsenosides, the main active components of Panax ginseng, in inflammatory responses and diseases. J. Ginseng Res. 41, 435-443. doi: 10.1016/j.jgr.2016.08.004

Klemow, K. M., Bartlow, A., Crawford, J., Kocher, N., Shah, J., and Ritsick, M. (2011). 11 medical attributes of St. John's Wort (Hypericum perforatum). Lester Packer Ph. D. 211.

Kontrimaviciute, V., Mathieu, O., Mathieu-Daude, J.-C., Vainauskas, P., Casper, T., Baccino, E., et al. (2006). Distribution of ibogaine and noribogaine in a man following a poisoning involving root bark of the Tabernanthe iboga shrub. J. Anal. Toxicol. 30, 434-440. doi: 10.1093/jat/30.7.434

Koo, B. S., Kwon, T. S., and Kim, C. H. (2004). Salviae miltiorrhizae radix inhibits superoxide generation by activated rat microglias and mimics the action of amphetamine on in vitro rat striatal dopamine release. Neurochem. Res. 29, 1837-1845. doi: 10.1023/B:NERE.0000042210.72927.ec

Koob, G. F. (2003). Alcoholism: allostasis and beyond. Alcohol. Clin. Exp. Res. 27, 232-243. doi: 10.1097/01.ALC.0000057122.36127.C2

Kouri, E. M., McCarthy, E. M., Faust, A. H., and Lukas, S. E. (2004). Pretreatment with transdermal nicotine enhances some of ethanol's acute effects in men. Drug Alcohol Depend. 75, 55-65. doi: 10.1016/j.drugalcdep.2004.01.011

Kranzler, H. R., Burleson, J. A., Korner, P., Del Boca, F. K., Bohn, M. J., Brown, J., et al. (1995). Placebo-controlled trial of fluoxetine as an adjunct to relapse prevention in alcoholics. Am. J. Psychiatry 152, 391-397. doi: 10.1176/ajp.152.3.391

Kren, V., and Walterova, D. (2005). Silybin and silymarin-new effects and applications. Biomed. Pap. Med. Fac. Univ. Palacky. Olomouc. Czech. Repub. $149,29-41$.

Krylov, A. A., and Ibatov, A. N. (1993). Experience with hypericum herbal infusion in complex treatment of patients with alcoholism in association with ulcer disease and chronic gastritis. Lik Sprav. 2, 146-148.

Kumar, V., Mdzinarishvili, A., Kiewert, C., Abbruscato, T., Bickel, U., van der Schyf, C. J., et al. (2006). NMDA receptor-antagonistic properties of hyperforin, a constituent of St. John's Wort. J. Pharmacol. Sci. 102, 47-54. doi: $10.1254 /$ jphs.fp0060378

Kumar, K. J. S., Chu, F.-H., Hsieh, H.-W., Liao, J.-W., Li, W.-H., Lin, J. C.-C., et al. (2011). Antroquinonol from ethanolic extract of mycelium of Antrodia cinnamomea protects hepatic cells from ethanol-induced oxidative stress through Nrf-2 activation. J. Ethnopharmacol. 136, 168-177. doi: 10.1016/ j.jep.2011.04.030

Kwak, H. S., and Joo, C. N. (1980). Effect of ginseng saponin fraction on ethanol metabolism in rat liver. Korean J. Ginseng Sci. 12, 76-81.

Langebeek, N., Gisolf, E. H., Reiss, P., Vervoort, S. C., Hafsteinsdottir, T. B., Richter, C., et al. (2014). Predictors and correlates of adherence to combination antiretroviral therapy (ART) for chronic HIV infection: a meta-analysis. $B M C$ Med. 12, 142. doi: 10.1186/s12916-014-0142-1

Larson, A. M., Polson, J., Fontana, R. J., Davern, T. J., Lalani, E., Hynan, L. S., et al. (2005). Acetaminophen-induced acute liver failure: results of a United States multicenter, prospective study. Hepatology 42, 1364-1372. doi: 10.1002/ hep. 20948

Larsson, A., and Engel, J. A. (2004). Neurochemical and behavioral studies on ethanol and nicotine interactions. Neurosci. Biobehav. Rev. 27, 713-720. doi: 10.1016/j.neubiorev.2003.11.010

Layer, R. T., Skolnick, P., Bertha, C. M., Bandarage, U. K., Kuehne, M. E., and Popik, P. (1996). Structurally modified ibogaine analogs exhibit differing affinities for NMDA receptors. Eur. J. Pharmacol. 309, 159-165. doi: 10.1016/0014-2999(96)00304-4

Le, A. D., Wang, A., Harding, S., Juzytsch, W., and Shaham, Y. (2003). Nicotine increases alcohol self-administration and reinstates alcohol seeking in rats. Psychopharmacol. 168, 216-221. doi: 10.1007/s00213-002-1330-9

Leal, M. B., Michelin, K., Souza, D. O., and Elisabetsky, E. (2003). Ibogaine attenuation of morphine withdrawal in mice: role of glutamate N-methyl-Daspartate receptors. Prog. Neuropsychopharmacol. Biol. Psychiatry. 27, 781785. doi: 10.1016/S0278-5846(03)00109-X 
Leao, R. M., Cruz, F. C., Vendruscolo, L. F., de Guglielmo, G., Logrip, M. L., Planeta, C. S., et al. (2015). Chronic nicotine activates stress/reward-related brain regions and facilitates the transition to compulsive alcohol drinking. J. Neurosci. 35, 6241-6253. doi: 10.1523/JNEUROSCI.3302-14.2015

Lee, F. C., Ko, J. H., Park, J. K., and Lee, J. S. (1987). Effects of Panax ginseng on blood alcohol clearance in man. Clin. Exp. Pharmacol. Physiol. 14, 543-546. doi: 10.1111/j.1440-1681.1987.tb01510.x

Lee, C. M., Wong, H. N., Chui, K. Y., Choang, T. F., Hon, P. M., and Chang, H. M. (1991). Miltirone, a central benzodiazepine receptor partial agonist from a Chinese medicinal herb Salvia miltiorrhiza. Neurosci. Lett. 127, 237-241. doi: 10.1016/0304-3940(91)90802-z

Lee, Y. J., Pantuck, C. B., and Pantuck, E. J. (1993). Effect of ginseng on plasma levels of ethanol in the rat. Planta Med. 59, 17-19. doi: 10.1055/s-2006-959595

Lee, J. S., Lee, K. H., and Jeong, J. H. (1999). Effects of extract of Pueraria radix on lipid metabolism in rats fed high fat diet. J. Korean Soc. Food Sci. Nutr. 28, 218224. doi: $10.1186 / 1472-6882-2-12$

Lee, T.-K., Johnke, R. M., Allison, R. R., O'Brien, K. F., and Dobbs, L. J. J. (2005). Radioprotective potential of ginseng. Mutagenesis 20, 237-243. doi: 10.1093/ mutage/gei041

Lee, H., Isse, T., Kawamoto, T., Woo, H., Kim, A. K., Park, J. Y., et al. (2012). Effects and action mechanisms of Korean pear (Pyrus pyrifolia cv. Shingo) on alcohol detoxification. Phyther. Res. 26, 1753-1758. doi: 10.1002/ptr.4630

Li, M., Lu, Y., Hu, Y., Zhai, X., Xu, W., Jing, H., et al. (2014). Salvianolic acid B protects against acute ethanol-induced liver injury through SIRT1-mediated deacetylation of p53 in rats. Toxicol. Lett. 228 (2), 67-74. doi: 10.1016/ j.toxlet.2014.04.011

Li, Y. (1962). Dui woguo niangjiu qiyuan de tantao (The origin of alcoholic beverages in China). Kaogu 1, 41-44.

Lin, L. H., Whiting, P., and Harris, R. A. (1993). Molecular determinants of general anesthetic action: role of GABAA receptor structure. J. Neurochem. 60, 15481553. doi: 10.1111/j.1471-4159.1993.tb03320.x

Lin, R. C., Guthrie, S., Xie, C. Y., Mai, K., Lee, D. Y., Lumeng, L., et al. (1996). Isoflavonoid compounds extracted from Pueraria lobata suppress alcohol preference in a pharmacogenetic rat model of alcoholism. Alcohol. Clin. Exp. Res 20, 659-663. doi: 10.1111/j.1530-0277.1996.tb01668.x

Lin, R. C., and Li, T. K. (1998). Effects of isoflavones on alcohol pharmacokinetics and alcohol-drinking behavior in rats. Am. J. Clin. Nutr. 68, 1512S-1515S. doi: 10.1093/ajcn/68.6.1512S

Liu, S., Zhou, W., Liu, H., Yang, G., and Zhao, W. (2005). Electroacupuncture attenuates morphine withdrawal signs and c-Fos expression in the central nucleus of the amygdala in freely moving rats. Brain Res. 1044, 155-163. doi: 10.1016/j.brainres.2005.02.075

Liu, L. (2005). The Chinese Neolithic: trajectories to early states (Cambridge: University Press).

López-Cruz, L., Salamone, J. D., and Correa, M. (2013). The impact of caffeine on the behavioral effects of ethanol related to abuse and addiction: a review of animal studies. J. Caffeine Res. 3, 9-21. doi: 10.1089/jcr.2013.0003

$\mathrm{Lu}, \mathrm{Y}$., and Cederbaum, A. I. (2008). CYP2E1 and oxidative liver injury by alcohol. Free Radic. Biol. Med. 44, 723-738. doi: 10.1016/j.freeradbiomed.2007.11.004

Lu, L., Liu, Y., Zhu, W., Shi, J., Liu, Y., Ling, W., et al. (2009). Traditional medicine in the treatment of drug addiction. Am. J. Drug Alcohol Abuse 35, 1-11. doi: $10.1080 / 00952990802455469$

Lucia, S. P. (1963). A history of wine as therapy (Philadelphia: JB Lippincott).

Lukas, S. E., Penetar, D., Berko, J., Vicens, L., Palmer, C., Mallya, G., et al. (2005). An extract of the Chinese herbal root kudzu reduces alcohol drinking by heavy drinkers in a naturalistic setting. Alcohol. Clin. Exp. Res. 29, 756-762. doi: 10.1097/01.alc.0000163499.64347.92

Lukas, S. E., Penetar, D., Su, Z., Geaghan, T., Maywalt, M., Tracy, M., et al. (2013). A standardized kudzu extract (NPI-031) reduces alcohol consumption in nontreatment-seeking male heavy drinkers. Psychopharmacol. 226, 65-73. doi: $10.1007 / \mathrm{s} 00213-012-2884-9$

Luo, H., Kong, W., Hu, Y., Chen, P., Wu, X., Wan, L., et al. (2015). Quality evaluation of Salvia miltiorrhiza Bge. by ultra high performance liquid chromatography with photodiode array detection and chemical fingerprinting coupled with chemometric analysis. J. Sep. Sci. 38, 1544-1551. doi: 10.1002/jssc.201401430

Luscher, C., and Malenka, R. C. (2011). Drug-evoked synaptic plasticity in addiction: from molecular changes to circuit remodeling. Neuron 69, 650663. doi: 10.1016/j.neuron.2011.01.017
Müller, W., Rolli, M., Schäfer, C., and Hafner, U. (1997). Effects of hypericum extract (LI 160) in biochemical models of antidepressant activity. Pharmacopsychiatry. 30, 102-107. doi: 10.1055/s-2007-979528

Ma, C., Li, F., and Zhao, Y. (1992). Effect of total saponin from stems and leaves of Panax guingnefolium L. on acute alcohol toxicity in rats. Heilongjiang Med. Pharm. 5, 18-19.

Machiah, D. K., and Gowda, T. V. (2006). Purification of a post-synaptic neurotoxic phospholipase A2from Naja naja venom and its inhibition by a glycoprotein from Withania somnifera. Biochimie. 88, 701-710. doi: 10.1016/ j.biochi.2005.12.006

Machiah, D. K., Girish, K. S., and Gowda, T. V. (2006). A glycoprotein from a folk medicinal plant, Withania somnifera, inhibits hyaluronidase activity of snake venoms. Comp. Biochem. Physiol. - C Toxicol. Pharmacol. 143, 158-161. doi: 10.1016/j.cbpc.2006.01.006

Maciulaitis, R., Kontrimaviciute, V., Bressolle, F. M. M., and Briedis, V. (2008). Ibogaine, an anti-addictive drug: pharmacology and time to go further in development. A narrative review. Hum. Exp. Toxicol. 27, 181-194. doi: $10.1177 / 0960327107087802$

Madrigal-Santillán, E., Bautista, M., Gayosso-De-Lucio, J. A., Reyes-Rosales, Y., Posadas-Mondragón, A., Morales-González, Á., et al. (2015). Hepatoprotective effect of Geranium schiedeanum against ethanol toxicity during liver regeneration. World J. Gastroenterol. 21, 7718-7729. doi: 10.3748/ wjg.v21.i25.7718

Mah, S. J., Tang, Y., Liauw, P. E., Nagel, J. E., and Schneider, A. S. (1998). Ibogaine acts at the nicotinic acetylcholine receptor to inhibit catecholamine release. Brain Res. doi: 10.1016/S0006-8993(98)00207-8

Maisonneuve, I. M., and Glick, S. D. (1992). Interactions between ibogaine and cocaine in rats: in vivo microdialysis and motor behavior. Eur. J. Pharmacol. 212, 263-266. doi: 10.1016/0014-2999(92)90340-A

Maisonneuve, I. M., Keller, R. W., and Glick, S. D. (1991). Interactions between ibogaine, a potential anti-addictive agent, and morphine: an in vivo microdialysis study. Eur. J. Pharmacol. 199, 35-42. doi: 10.1016/0014-2999(91)90634-3

Malec, T. S., Malec, E. A., and Dongier, M. (1996). Efficacy of buspirone in alcohol dependence: a review. Alcohol. Clin. Exp. Res. 20, 853858. doi: 10.1111/j.15300277.1996.tb05263.x

Marcenac, F., Jin, G. Z., and Gonon, F. (1986). Effect of 1-tetrahydropalmatine on dopamine release and metabolism in the rat striatum. Psychopharmacol. 89, 89-93. doi: 10.1111/j.1530-0277.1996.tb05263.x

Markou, A., Kosten, T. R., and Koob, G. F. (1998). Neurobiological similarities in depression and drug dependence: a self-medication hypothesis. Neuropsychopharmacology 18, 135-174. doi: 10.1016/S0893-133X(97)00113-9

Martinez, D., Gil, R., Slifstein, M., Hwang, D.-R., Huang, Y., Perez, A., et al. (2005). Alcohol dependence is associated with blunted dopamine transmission in the ventral striatum. Biol. Psychiatry 58, 779-786. doi: 10.1016/ j.biopsych.2005.04.044

Masarone, M., Rosato, V., Dallio, M., Abenavoli, L., Federico, A., Loguercio, C., et al. (2016). Epidemiology and natural history of alcoholic liver disease. Rev. Recent Clin. Trials 11, 167-174. doi: 10.2174/1574887111666160810101202

Mash, D. C., Duque, L., Page, B., and Allen-Ferdinand, K. (2018). Ibogaine detoxification transitions opioid and cocaine abusers between dependence and abstinence: clinical observations and treatment outcomes. Front. Pharmacol. 9, 529. doi: 10.3389/fphar.2018.00529

Maurya, R. (2010). Chemistry and pharmacology of Withania coagulans: an Ayurvedic remedy. J. Pharm. Pharmacol. 62, 153-160. doi: 10.1211/ jpp.62.02.0001

Mayo-Smith, M. F. (1997). Pharmacological management of alcohol withdrawal. A meta-analysis and evidence-based practice guideline. American Society of Addiction Medicine Working Group on Pharmacological Management of Alcohol Withdrawal. JAMA 278, 144-151. doi: 10.1001/jama.278.2.144

McGovern, P. E. (2013). Ancient wine: the search for the origins of viniculture (Princeton: Princeton University Press).

Michalak, A., and Biala, G. (2016). Alcohol dependence-neurobiology and treatment. Acta Pol. Pharm. 73, 3-12.

Miller, N. S., and Gold, M. S. (1998). Comorbid cigarette and alcohol addiction: epidemiology and treatment. J. Addict. Dis. 17, 55-66. doi: 10.1300/ J069v17n01_06

Mimiaga, M. J., Reisner, S. L., Grasso, C., Crane, H. M., Safren, S. A., Kitahata, M. M., et al. (2013). Substance use among HIV-infected patients engaged in primary 
care in the United States: findings from the centers for AIDS research network of integrated clinical systems cohort. Am. J. Public Health 103, 1457-1467. doi: 10.2105/AJPH.2012.301162

Mishra, L. C., Singh, B. B., and Dagenais, S. (2000). Scientific basis for the therapeutic use of Withania somnifera (ashwagandha): a review. Altern. Med. Rev. 5, 334-346.

Morris, M., Johnson, D., and Morrison, D. S. (2012). Opportunities for prevention of alcohol-related death in primary care: results from a population-based cross-sectional study. Alcohol 46, 703-707. doi: 10.1016/ j.alcohol.2011.12.006

Mostallino, M. C., Mascia, M. P., Pisu, M. G., Busonero, F., Talani, G., and Biggio, G. (2004). Inhibition by miltirone of up-regulation of GABAA receptor alpha4 subunit mRNA by ethanol withdrawal in hippocampal neurons. Eur. J. Pharmacol. 494, 83-90. doi: 10.1016/j.ejphar.2004.04.021

Murphy, J. M., McBride, W. J., Lumeng, L., and Li, T. K. (1988). "Effects of serotonin and dopamine agents on ethanol intake of alcohol-preferring P-rats," in Alcoholism-Clinical and Experimental Research (351 West Camden St, Baltimore, MD 21201-2436: Williams \& Wilkins), 306.

Nadal, R., and Samson, H. H. (1999). Operant ethanol self-administration after nicotine treatment and withdrawal. Alcohol 17, 139-147. doi: 10.1016/s07418329(98)00045-7

Nah, H. Y., Lee, W. S., Joo, Y. E., Kim, H. S., Choi, S. K., Rew, J. S., et al. (2005). Resveratrol protects HepG2 and chang liver cells from oxidative stress. Chonnam Med. J. 41, 243-252.

Naimi, T. S., Brewer, R. D., Mokdad, A., Denny, C., Serdula, M. K., and Marks, J. S. (2003). Binge drinking among US adults. JAMA 289, 70-75. doi: 10.1001/ jama.289.1.70

Nair, V., Mohan, L., Rao, U. S. C., and Gopalakrishna, H. N. (2011). Evaluation of the anxiolytic activity of NR-ANX-C (a Polyherbal Formulation) in ethanol withdrawal-induced anxiety behavior in rats. Evidence-Based Complement. Altern. Med. 327160. doi: 10.1155/2011/327160

Nestler, E. J. (2004). Molecular mechanisms of drug addiction. Neuropharmacology 47, 24-32. doi: 10.1016/j.neuropharm.2004.06.031

Nichols, D. E. (2004). Hallucinogens. Pharmacol. Ther. 101, 131-181. doi: 10.1016/j.pharmthera.2003.11.002

Niiho, Y., Yamazaki, T., Nakajima, Y., Itoh, H., Takeshita, T., Kinjo, J., et al. (1989). Pharmacological studies on Puerariae Flos. I. The effects of Puerariae Flos on alcoholic metabolism and spontaneous movement in mice. Yakugaku Zasshi J. Pharm. Soc Jpn. 109, 424-431. doi: 10.1248/yakushi1947.109.6_424

O'Shea, R. S., Dasarathy, S., and McCullough, A. J. (2010). Alcoholic liver disease. Hepatology 51, 307-328. doi: 10.1002/hep.23258

Ogony, J., Matthews, R., Anni, H., Shannon, K., and Ercal, N. (2008). The mechanism of elevated toxicity in HepG2 cells due to combined exposure to ethanol and ionizing radiation. J. Appl. Toxicol. 28, 345-355. doi: 10.1002/jat.1285

Ohshima, Y., Okuyama, T., Takahashi, K., Takizawa, T., and Shibata, S. (1988). Isolation and high performance liquid chromatography (HPLC) of isoflavonoids from the Pueraria root. Planta Med. 54, 250-254. doi: 10.1055/ s-2006-962420

Organization, W. H., and Unit, W. H. O. M. of S. A. (2014). Global status report on alcohol and health, 2014 (World Health Organization).

Orrù, A., Marchese, G., Casu, G., Casu, M. A., Kasture, S., Cottiglia, F., et al. (2014). Withania somnifera root extract prolongs analgesia and suppresses hyperalgesia in mice treated with morphine. Phytomedicine. 21, 745-752. doi: 10.1016/j.phymed.2013.10.021

Ostroumov, A., Thomas, A. M., Dani, J. A., and Doyon, W. M. (2015). Cigarettes and alcohol: The influence of nicotine on operant alcohol self-administration and the mesolimbic dopamine system. Biochem. Pharmacol. 97, 550-557. doi: 10.1016/j.bcp.2015.07.038

Overstreet, D. H., Rezvani, A. H., and Janowsky, D. S. (1992). Genetic animal models of depression and ethanol preference provide support for cholinergic and serotonergic involvement in depression and alcoholism. Biol. Psychiatry 31, 919-936. doi: 10.1016/0006-3223(92)90118-j

Overstreet, D. H., Lee, Y., Rezvani, A. H., Pei, Y., Criswell, H. E., and Janowsky, D. S. (1996). Suppression of alcohol intake after administration of the Chinese herbal medicine, NPI-028, and its derivatives. Alcohol. Clin. Exp. Res. 20, 221-227. doi: 10.1111/j.1530-0277.1996.tb01633.x

Overstreet, D. H., Lee, D., and Rezvani, A. H. (1997). The Chinese herbal medicine NPI-028 suppresses alcohol intake in alcohol-preferring rats and monkeys without inducing taste aversion. Focus Altern. Complement. Ther. 2, 194. doi: 10.1111/j.2042-7166.1997.tb00734.x

Overstreet, D. H., Keung, W., Rezvani, A. H., Massi, M., and Lee, D. Y. W. (2003). Herbal remedies for alcoholism: promises and possible pitfalls. Alcohol. Clin. Exp. Res. 27, 177-185. doi: 10.1097/01.ALC.0000051022.26489.CF

Pace, C. J., Glick, S. D., Maisonneuve, I. M., He, L. W., Jokiel, P. A., Kuehne, M. E., et al. (2004). Novel iboga alkaloid congeners block nicotinic receptors and reduce drug self-administration. Eur. J. Pharmacol. 492, 159-167. doi: 10.1016/ j.ejphar.2004.03.062

Paille, F. M., Guelfi, J. D., Perkins, A. C., Royer, R. J., Steru, L., and Parot, P. (1995). Double-blind randomized multicentre trial of acamprosate in maintaining abstinence from alcohol. Alcohol Alcohol 30, 239-247. doi: 10.1093/ oxfordjournals.alcalc.a045720

Panchal, V., Taraschenko, O. D., Maisonneuve, I. M., and Glick, S. D. (2005). Attenuation of morphine withdrawal signs by intracerebral administration of 18-methoxycoronaridine. Eur. J. Pharmacol. 525, 98-104. doi: 10.1016/ j.ejphar.2005.09.060

Panocka, I., Perfumi, M., Angeletti, S., Ciccocioppo, R., and Massi, M. (2000). Effects of Hypericum perforatum extract on ethanol intake, and on behavioral despair: a search for the neurochemical systems involved. Pharmacol. Biochem. Behav. 66, 105-111. doi: 10.1016/s0091-3057(00)00193-3

Parihar, M. S., Chaudhary, M., Shetty, R., and Hemnani, T. (2004). Susceptibility of hippocampus and cerebral cortex to oxidative damage in streptozotocin treated mice: prevention by extracts of Withania somnifera and Aloe vera. J. Clin. Neurosci. 11, 397-402. doi: 10.1016/j.jocn.2003.09.008

Park, J. D., Rhee, D. K., and Lee, Y. H. (2005). Biological activities and chemistry of saponins from panax ginseng C. A. Meyer. Phytochem. Rev. 4, 159-175. doi: 10.1007/s11101-005-2835-8

Parkar, S. R., Dawani, V. S., and Apte, J. S. (2001). History of psychiatry in India. J. Postgrad. Med. 47, 73-76.

Parker, L. A., Burton, P., McDonald, R. V., Kim, J. A., and Siegel, S. (2002). Ibogaine interferes with motivational and somatic effects of naloxone-precipitated withdrawal from acutely administered morphine. Prog. Neuropsychopharmacol. Biol. Psychiatry. 26, 293-297. doi: 10.1016/S0278-5846(01)00268-8

Parker, R., Kim, S.-J., and Gao, B. (2018). Alcohol, adipose tissue and liver disease: mechanistic links and clinical considerations. Nat. Rev. Gastroenterol. Hepatol. 15, 50-59. doi: 10.1038/nrgastro.2017.116

Parsons, C. J., Takashima, M., and Rippe, R. A. (2007). Molecular mechanisms of hepatic fibrogenesis. J. Gastroenterol. Hepatol. 22 (Suppl 1), S79-S84. doi: 10.1111/j.1440-1746.2006.04659.x

Peana, A. T., Muggironi, G., Spina, L., Rosas, M., Kasture, S. B., Cotti, E., et al. (2014). Effects of Withania somnifera on oral ethanol self-administration in rats. Behav. Pharmacol. 25, 618-628. doi: 10.1097/FBP.0000000000000078

Penetar, D. M., Maclean, R. R., McNeil, J. F., and Lukas, S. E. (2011). Kudzu extract treatment does not increase the intoxicating effects of acute alcohol in human volunteers. Alcohol. Clin. Exp. Res. 35, 726-734. doi: 10.1111/j.15300277.2010.01390.x

Penetar, D. M., Toto, L. H., Lee, D. Y.-W., and Lukas, S. E. (2015). A single dose of kudzu extract reduces alcohol consumption in a binge drinking paradigm. Drug Alcohol Depend. 153, 194-200. doi: 10.1016/j.drugalcdep.2015.05.025

Peng, Y., Yang, T., Huang, K., Shen, L., Tao, Y., and Liu, C. (2018). Salvia miltiorrhiza ameliorates liver fibrosis by activating hepatic natural killer cells in vivo and in vitro. Front. Pharmacol. 9, 762. doi: 10.3389/fphar.2018.00762

Pereira, R., Guedes, A., and Da Silva, G. E. (2015). The hydroalcoholic extract of leaves of Piper caldense C. DC. decreases alcohol consumption in rats. Rev. Bras. Plantas Med. 17, 157-163. doi: 10.1590/1983-084X/12_145

Perfumi, M., Ciccocioppo, R., Angeletti, S., Cucculelli, M., and Massi, M. (1999). Effects of Hypericum perforatum extract on alcohol intake in Marchigian Sardinian alcohol-preferring rats. Alcohol Alcohol. 34, 690-698. doi: 10.1093/ alcalc/34.5.690

Perfumi, M., Panocka, I., Ciccocioppo, R., Vitali, D., Froldi, R., and Massi, M. (2001). Effects of a methanolic extract and a hyperforin-enriched CO2 extract of Hypericum perforatum on alcohol intake in rats. Alcohol Alcohol. 36, 199206. doi: $10.1093 / \mathrm{alcalc} / 36.3 .199$

Perfumi, M., Santoni, M., Ciccocioppo, R., and Massi, M. (2002). Blockade of $\gamma$ aminobutyric acid receptors does not modify the inhibition of ethanol intake induced by Hypericum perforatum in rats. Alcohol Alcohol. 37, 540-546. doi: $10.1093 / \mathrm{alcalc} / 37.6 .540$ 
Perfumi, M., Santoni, M., Cippitelli, A., Ciccocioppo, R., Froldi, R., and Massi, M. (2003). Hypericum perforatum CO2 extract and opioid receptor antagonists act synergistically to reduce ethanol intake in alcohol-preferring rats. Alcohol. Clin. Exp. Res. 27, 1554-1562. doi: 10.1097/01.ALC.0000092062.60924.56

Pickens, R. W., and Svikis, D. S. (1998). Biological vulnerability to drug abuse (Vol. 88, No. 1590). US Department of Health and Human Services, Public Health Service, Alcohol, Drug Abuse, and Mental Health Administration, National Institute on Drug Abuse. 81, Rockville, Md. (5600 Fishers Lane, Rockville 20857).

Pinzani, M., and Marra, F. (2001). Cytokine receptors and signaling in hepatic stellate cells. Semin. Liver Dis. 21, 397-416. doi: 10.1055/s-2001-17554

Pohl, S., Zobel, J., and Moffat, A. (2010). "Extended Boolean Retrieval for Systematic Biomedical Reviews," in Proceedings of the Thirty-Third Australasian Conferenc on Computer Science - Volume 102 ACSC "10 (Darlinghurst, Australia, Australia: Australian Computer Society, Inc.), 117-126.

Pope, H. G. (1969). Tabernanthe iboga: an African narcotic plant of social importance. Econ. Bot. 23, 174-184. doi: 10.1007/BF02860623

Popik, P., Layer, R. T., and Skolnick, P. (1995). 100 years of ibogaine: neurochemical and pharmacological actions of a putative anti-addictive drug. Pharmacol. Rev. 47, 235-254.

Prakash, O. (1961). Food and drinks in ancient India. New Delhi: Munshi Ram Manohar Lal Publisher.

Pryor, L., and MacKillop, J. (2009). Delayed reward discounting in individuals with alcohol use disorders and other addictive disorders: a meta-analysis. Alcohol Clin. Exp. Res. 33, 104A.

Qu, J. H., and Wang, Z. P. (2008). Huanglianwendan plus-minus decoction in the treatment of alcohol dependence: 30 cases report. Shangxi J. TCM (Shangxi Zhongyi) 29, 8-9.

Rambaldi, A., Jacobs, B. P., Iaquinto, G., and Gluud, C. (2005). Milk thistle for alcoholic and/or hepatitis B or C liver diseases-a systematic cochrane hepatobiliary group review with meta-analyses of randomized clinical trials. Am. J. Gastroenterol. 100, 2583-2591. doi: 10.1111/j.1572-0241.2005.00262.x

Rastogi, V., Santiago-Moreno, J., and Dorã, S. (2015). Ginseng: a promising neuroprotective strategy in stroke. Front. Cell. Neurosci. 8, 457. doi: 10.3389/ fncel.2014.00457

Raynard, B., Balian, A., Fallik, D., Capron, F., Bedossa, P., Chaput, J.-C., et al. (2002). Risk factors of fibrosis in alcohol-induced liver disease. Hepatology 35, 635-638. doi: 10.1053/jhep.2002.31782

Redvers, A., Laugharne, R., Kanagaratnam, G., and Srinivasan, G. (2001). How many patients self-medicate with St John's wort? Psychiatr. Bull. 25, 254-256. doi: $10.1192 / \mathrm{pb} .25 .7 .254$

Rehm, J., Samokhvalov, A. V., and Shield, K. D. (2013). Global burden of alcoholic liver diseases. J. Hepatol. 59, 160-168. doi: 10.1016/j.jhep.2013.03.007

Reid, M., Hsu, K., Broderick, P., and Berger, S. P. (1994). Evidence that Ibogaine inhibits dopamine release via a kappa receptor mechanism. Abstr-Soc. Neurosci. 20, 1676.

Rezvani, A. H., and Grady, D. R. (1994). Suppression of alcohol consumption by fenfluramine in Fawn-Hooded rats with serotonin dysfunction. Pharmacol. Biochem. Behav. 48, 105-110. doi: 10.1016/0091-3057(94)90505-3

Rezvani, A. H., Overstreet, D. H., and Janowsky, D. S. (1991). Drug-induced reductions in ethanol intake in alcohol preferring and Fawn-Hooded rats. Alcohol Alcohol Suppl. 1, 433-437.

Rezvani, A. H., Mash, D. C., Hearn, W. L., Lee, Y. W., and Overstreet, D. H. (1995a). Noribogaine, a primary Ibogaine metabolite, reduces alcohol intake in P and fawn-hooded rats. Alcohol Clin. Exp. Res. 19, 15A.

Rezvani, A. H., Overstreet, D. H., and Leef, Y.-W. (1995b). Attenuation of alcohol intake by ibogaine in three strains of alcohol-preferring rats. Pharmacol. Biochem. Behav. 52, 615-620. doi: 10.1016/0091-3057(95)00152-m

Rezvani, A. H., Overstreet, D. H., Yang, Y., Maisonneuve, I. M., Bandarage, U. K., Kuehne, M. E., et al. (1997). Attenuation of alcohol consumption by a novel nontoxic ibogaine analogue (18-methoxycoronaridine) in alcohol-preferring rats. Pharmacol. Biochem. Behav. 58, 615-619. doi: 10.1016/s0091-3057(97)10003-x

Rezvani, A. H., Overstreet, D. H., Yang, Y., and Clark, E.Jr. (1999). Attenuation of alcohol intake by extract of Hypericum perforatum (St John's wort) in two different strains of alcohol-preferring rats. Alcohol Alcohol. 34, 699-705. doi: 10.1093/alcalc/34.5.699

Rezvani, A. H., Parsian, A., and Overstreet, D. H. (2002). The Fawn-Hooded (FH/ Wjd) rat: a genetic animal model of comorbid depression and alcoholism. Psychiatr. Genet. 12, 1-16. doi: 10.1097/00041444-200203000-00001
Rezvani, A. H., Overstreet, D. H., Perfumi, M., and Massi, M. (2003). Plant derivatives in the treatment of alcohol dependency. Pharmacol. Biochem. Behav. 75, 593-606. doi: 10.1016/s0091-3057(03)00124-2

Rhodes, R., Aggarwal, S., and Schiano, T. D. (2011). Overdose with suicidal intent: ethical considerations for liver transplant programs. Liver Transplant. Off. Publ. Am. Assoc. Study Liver Dis. Int. Liver Transplant. Soc 17, 1111-1116. doi: $10.1002 / \mathrm{lt} .22332$

Riala, K., Hakko, H., Isohanni, M., Jarvelin, M.-R., and Rasanen, P. (2004). Teenage smoking and substance use as predictors of severe alcohol problems in late adolescence and in young adulthood. J. Adolesc. Health 35, 245-254. doi: 10.1016/j.jadohealth.2003.08.016

Riper, H., Spek, V., Boon, B., Conijn, B., Kramer, J., Martin-Abello, K., et al. (2011). Effectiveness of E-self-help interventions for curbing adult problem drinking: a meta-analysis. J. Med. Internet Res. 13, e42. doi: 10.2196/jmir.1691

Riper, H., Blankers, M., Hadiwijaya, H., Cunningham, J., Clarke, S., Wiers, R., et al. (2014). Effectiveness of guided and unguided low-intensity internet interventions for adult alcohol misuse: a meta-analysis. PloS One 9, e99912. doi: 10.1371/journal.pone.0099912

Rose, J. E., Brauer, L. H., Behm, F. M., Cramblett, M., Calkins, K., and Lawhon, D. (2004). Psychopharmacological interactions between nicotine and ethanol. Nicotine Tob. Res. 6, 133-144. doi: 10.1080/14622200310001656957

Ross, S. M. (2008). Milk thistle (Silybum marianum): an ancient botanical medicine for modern times. Holist. Nurs. Pract. 22, 299-300. doi: 10.1097/ 01.HNP.0000334924.77174.6d

Ruiu, S., Longoni, R., Spina, L., Orrù, A., Cottiglia, F., Collu, M., et al. (2013). Withania somnifera prevents acquisition and expression of morphine-elicited conditioned place preference. Behav. Pharmacol. 24, 133-143. doi: 10.1097/ FBP.0b013e32835f3d15

Sacks, J. J., Gonzales, K. R., Bouchery, E. E., Tomedi, L. E., and Brewer, R. D. (2015). 2010 National and state costs of excessive alcohol consumption. Am. J. Prev. Med. 49, e73-e79. doi: 10.1016/j.amepre.2015.05.031

Saller, R., Meier, R., and Brignoli, R. (2001). The use of silymarin in the treatment of liver diseases. Drugs 61, 2035-2063. doi: 10.2165/00003495-200161140-00003

Sällström Baum, S., Hill, R., and Rommelspacher, H. (1998). Effect of kava extract and individual kavapyrones on neurotransmitter levels in the nucleus accumbens of rats. Prog. Neuropsychopharmacol. Biol. Psychiatry. 22, 11051120. doi: 10.1016/S0278-5846(98)00062-1

Samoylenko, V., Rahman, M. M., Tekwani, B. L., Tripathi, L. M., Wang, Y. H., Khan, S. I., et al. (2010). Banisteriopsis caapi, a unique combination of MAO inhibitory and antioxidative constituents for the activities relevant to neurodegenerative disorders and Parkinson's disease. J. Ethnopharmacol. 127, 357-367. doi: 10.1016/j.jep.2009.10.030

Sass, D. A., and Shakil, A. O. (2005). Fulminant hepatic failure. Liver Transplant. Off. Publ. Am. Assoc. Study Liver Dis. Int. Liver Transplant. Soc 11, 594-605. doi: $10.1002 / 1 \mathrm{t} .20435$

Sass, H., Soyka, M., Mann, K., and Zieglgansberger, W. (1996). Relapse prevention by acamprosate. Results from a placebo-controlled study on alcohol dependence. Arch. Gen. Psychiatry 53, 673-680. doi: 10.1001/archpsyc.1996.01830080023006

Saxena, S. (1999). Country profile on alcohol in India. Alcohol and public health in 8 developing countries. 8, 37-60.

Schaub, M. P., Blankers, M., Lehr, D., Boss, L., Riper, H., Dekker, J., et al. (2016). Efficacy of an internet-based self-help intervention to reduce co-occurring alcohol misuse and depression symptoms in adults: study protocol of a three-arm randomised controlled trial. BMJ Open 6, e011457. doi: 10.1136/bmjopen-2016-011457

Schaub, M. P., Tiburcio, M., Martinez, N., Ambekar, A., Balhara, Y. P. S., Wenger, A., et al. (2018). Alcohol e-Help: study protocol for a web-based self-help program to reduce alcohol use in adults with drinking patterns considered harmful, hazardous or suggestive of dependence in middle-income countries. Addiction 113, 346-352. doi: 10.1111/add.14034

Schiller, J. S., Lucas, J. W., Ward, B. W., and Peregoy, J. A. (2012). Summary health statistics for U.S. adults: National Health Interview Survey, 2010. Vital Health Stat. 10, 1-207.

Sellers, E. M., Higgins, G. A., and Sobell, M. B. (1992). 5-HT and alcohol abuse. Trends Pharmacol. Sci. 13, 69-75. doi: 10.1016/0165-6147(92)90026-3

Sellers, E. M., Toneatto, T., Romach, M. K., Somer, G. R., Sobell, L. C., and Sobell, M. B. (1994). Clinical efficacy of the 5-HT3 antagonist ondansetron in alcohol abuse and dependence. Alcohol. Clin. Exp. Res. 18, 879-885. doi: 10.1111/ j.1530-0277.1994.tb00054.x 
Serra, S., Vacca, G., Tumatis, S., Carrucciu, A., Morazzoni, P., Bombardelli, E., et al. (2003). Anti-relapse properties of IDN 5082, a standardized extract of Salvia miltiorrhiza, in alcohol-preferring rats. J. Ethnopharmacol. 88, 249-252. doi: 10.1111/j.1530-0277.1994.tb00054.X

Shang, Y. H., Zhao, Y. H., and Gao, S. H. (2005). A clinical control study on the effect of Guadi capsule in the treatment of alcohol abstinence. Chin. J. Psychiatry (Zhonghua Jingshenke Zazhi) 31, S195.

Shanmugasundaram, E. R. B., and Shanmugasundaram, K. R. (1986). An Indian herbal formula (SKV) for controlling voluntary ethanol intake in rats with chronic alcoholism. J. Ethnopharmacol. 17, 171-182. doi: 10.1016/0378-8741 (86)90056-5

Shanmugasundaram, E. R. B., Subramaniam, U., Santhini, R., and Shanmugasundaram, K. R. (1986). Studies on brain structure and neurological function in alcoholic rats controlled by an Indian medicinal formula (SKV). J. Ethnopharmacol. 17, 225-245. doi: 10.1016/0378-8741(86) 90111-x

Sharma, H. K., Tripathi, B. M., and Pelto, P. J. (2010). The evolution of alcohol use in India. AIDS Behav. 14, S8-17. doi: 10.1007/s10461-010-9727-7

Sharma, V., Sharma, S., and Pracheta, P. R. (2011). Withania somnifera: a rejuvenating ayurvedic medicinal herb for the treatment of various human ailments. Int. J. PharmTech Res. 3, 187-192.

Sharpe, A. L., and Samson, H. H. (2002). Repeated nicotine injections decrease operant ethanol self-administration. Alcohol 28, 1-7. doi: 10.1016/s0741-8329 (02)00238-0

Shati, A. A., and Elsaid, F. G. (2009). Effects of water extracts of thyme (Thymus vulgaris) and ginger (Zingiber officinale Roscoe) on alcohol abuse. Food Chem. Toxicol. 47, 1945-1949. doi: 10.1016/j.fct.2009.05.007

Shebek, J., and Rindone, J. P. (2000). A pilot study exploring the effect of kudzu root on the drinking habits of patients with chronic alcoholism. J. Altern. Complement. Med. 6, 45-48. doi: 10.1089/acm.2000.6.45

Shen, X. L., Witt, M. R., Nielsen, M., and Sterner, O. (1996). Inhibition of [3H] flunitrazepam binding to rat brain membranes in vitro by puerarin and daidzein. Yao Xue Xue Bao 31, 59-62.

Shen, Y., Lindemeyer, A. K., Gonzalez, C., Shao, X. M., Spigelman, I., Olsen, R. W., et al. (2012). Dihydromyricetin as a novel anti-alcohol intoxication medication. J. Neurosci. 32, 390-401. doi: 10.1523/JNEUROSCI.4639-11.2012

Shpilenya, L. S., Muzychenko, A. P., Gasbarrini, G., and Addolorato, G. (2002). Metadoxine in acute alcohol intoxication: a double-blind, randomized, placebo-controlled study. Alcohol. Clin. Exp. Res. 26, 340-346. doi: 10.1111/ j.1530-0277.2002.tb02543.x

Sierksma, A., Patel, H., Ouchi, N., Kihara, S., Funahashi, T., Heine, R. J., et al. (2004). Effect of moderate alcohol consumption on adiponectin, tumor necrosis factor-alpha, and insulin sensitivity. Diabetes Care 27, 184-189. doi: 10.2337/diacare.27.1.184

Singh, G., and Lal, B. (1979). Alcohol in India. Indian J. Psychiatry 21, 39-45.

Singh, K. K., and Bloom, S. S. (2004). Influence of alcohol use on male sexual behaviour leading to HIV/AIDS in Uttar Pradesh, India. International conference on AIDS Bangkok, Thailand.

Singh, M., Hussain, T., Firdous, H., Shaikh, S., Rizvi, S. M. D., Moin, A., et al. (2018). Preclinical Hepatoprotective effect of herbalism against ethanol induced hepatotoxicity: a Review. Curr. Drug Metab. 19, 1002-1011. doi: 10.2174/1389200219666180330125003

Sivaram, S., Srikrishnan, A. K., Latkin, C., Iriondo-Perez, J., Go, V. F., Solomon, S., and Celentano, D. D. (2008). Male alcohol use and unprotected sex with nonregular partners: evidence from wine shops in Chennai, India. Drug Alcohol Depen. 94, 133-141. doi: 10.1016/j.drugalcdep.2007.11.016

Sloviter, R. S., Drust, E. G., Damiano, B. P., and Connor, J. D. (1980). A common mechanism for lysergic acid, indolealkylamine and phenethylamine hallucinogens: serotonergic mediation of behavioral effects in rats. J. Pharmacol. Exp. Ther. 214, 231-238.

Smith, B. R., Horan, J. T., Gaskin, S., and Amit, Z. (1999). Exposure to nicotine enhances acquisition of ethanol drinking by laboratory rats in a limited access paradigm. Psychopharmacol. 142, 408-412. doi: 10.1007/s002130050906

Solujic, S., Sukdolak, S., Comic, L., and Krstic, L. J. (1997). Biochemical reactions in vitro of certain fungi to the presence of Hypericin. Acta Vet. 47, 331-344.

Soo Shin, B., Jun, H., Lee, D.-E., Ro Lee, K., Seok Park, E., and Dong Yoo, S. (2005). Altered oral absorption of alcohol by combined aqueous extracts of four herbal plants in rats. J. Toxicol. Environ. Heal. Part A 68, 2219-2226. doi: 10.1080/ 15287390500182081

Spina, L., Longoni, R., Vinci, S., Ibba, F., Peana, A. T., Muggironi, G., et al. (2010). Role of dopamine D1 receptors and extracellular signal regulated kinase in the motivational properties of acetaldehyde as assessed by place preference conditioning. Alcohol. Clin. Exp. Res. 34, 607-616. doi: 10.1111/j.15300277.2009.01129.x

Spina, L., Longoni, R., Rosas, M., Collu, M., Peana, A. T., Espa, E., et al. (2015). Withania somnifera Dunal (Indian ginseng) impairs acquisition and expression of ethanol-elicited conditioned place preference and conditioned place aversion. J. Psychopharmacol. 29, 1191-1199. doi: 10.1177/ 0269881115600132

Stefanini, G. F., Addolorato, G., Caputo, F., Bernardi, M., and Gasbarrini, G. (1999). Treatment of alcoholic fatty liver: is the metabolic effect of metadoxine the only reason for improved liver function? J. Hepatol. 30, 739-740. doi: 10.1016/s0168-8278(99)80209-8

Sukul, N. C., Ghosh, S., Sinhababu, S. P., and Sukul, A. (2001). Strychnos nuxvomica extract and its ultra-high dilution reduce voluntary ethanol intake in rats. J. Altern. Complement. Med. 7, 187-193. doi: 10.1089/10755530 1750164280

Sullivan, L. E., Goulet, J. L., Justice, A. C., and Fiellin, D. A. (2011). Alcohol consumption and depressive symptoms over time: a longitudinal study of patients with and without HIV infection. Drug Alcohol Depend. 117, 158-163. doi: 10.1016/j.drugalcdep.2011.01.014

Sulzer, D. (2011). How addictive drugs disrupt presynaptic dopamine neurotransmission. Neuron 69, 628-649. doi: 10.1016/j.neuron.2011.02.010

Sun, K., Ren, M., Liu, D., Wang, C., Yang, C., and Yan, L. (2014). Alcohol consumption and risk of metabolic syndrome: a meta-analysis of prospective studies. Clin. Nutr. 33, 596-602. doi: 10.1016/j.clnu.2013.10.003

Sundstrom, C., Blankers, M., and Khadjesari, Z. (2017). Computer-Based interventions for problematic alcohol use: a review of systematic reviews. Int. J. Behav. Med. 24, 646-658. doi: 10.1007/s12529-016-9601-8

Sweetnam, P. M., Lancaster, J., Snowman, A., Collins, J. L., Perschke, S., Bauer, C., et al. (1995). Receptor binding profile suggests multiple mechanisms of action are responsible for ibogaine's putative anti-addictive activity. Psychopharmacol. 118, 369-376. doi: 10.1007/BF02245936

Szulc, M., Mularczyk, P., Kujawski, R., Gryszczyńska, A., Kamińska, E., Geppert, B., et al. (2018). Influence of salidroside, a neuroactive compound of Rhodiola rosea L., on alcohol tolerance development in rats. Herba Pol. 64, 22-35. doi: 10.2478/ hepo-2018-0002

Tacke, F., Wustefeld, T., Horn, R., Luedde, T., Srinivas Rao, A., Manns, M. P., et al. (2005). High adiponectin in chronic liver disease and cholestasis suggests biliary route of adiponectin excretion in vivo. J. Hepatol. 42, 666-673. doi: 10.1016/j.jhep.2004.12.024

Tajmohammadi, A., Razavi, B. M., and Hosseinzadeh, H. (2018). Silybum marianum (milk thistle) and its main constituent, silymarin, as a potential therapeutic plant in metabolic syndrome: A review. Phytother. Res. 32, 1933 1949. doi: 10.1002/ptr.6153

Teves, M. R., Wendel, G. H., and Pelzer, L. E. (2015). Reduction in voluntary ethanol intake following repeated oral administration of Jodina rhombifolia lyophilized aqueous extract in male Wistar rats. J. Ethnopharmacol. 161, 170174. doi: 10.1016/j.jep.2014.12.019

Tewari, D., Mocan, A., Parvanov, E. D., Sah, A. N., Nabavi, S. M., Huminiecki, L., et al. (2017a). Ethnopharmacological approaches for therapy of jaundice: Part I. Front. Pharmacol. 8, 518. doi: 10.3389/fphar.2017.00518

Tewari, D., Mocan, A., Parvanov, E. D., Sah, A. N., Nabavi, S. M., Huminiecki, L. et al. (2017b). Ethnopharmacological approaches for therapy of jaundice: Part II. Highly used plant species from Acanthaceae, Euphorbiaceae, Asteraceae, Combretaceae, and Fabaceae families. Front. Pharmacol. 8, 519. doi: 10.3389/ fphar.2017.00519

Thongsaard, W., and Marsden, C. A. (2002). A herbal medicine used in the treatment of addiction mimics the action of amphetamine on in vitro rat striatal dopamine release. Neurosci. Lett. 329, 129-132. doi: 10.1016/S03043940(02)00658-4

Thongsaard, W., Marsden, C. A., Morris, P., Prior, M., and Shah, Y. B. (2005). Effect of Thunbergia laurifolia, a Thai natural product used to treat drug addiction, on cerebral activity detected by functional magnetic resonance 
imaging in the rat. Psychopharmacol. (Berl). 180, 1-9. doi: 10.1007/s00213-0050053-0

Tokuyama, S., and Takahashi, M. (2001). Pharmacological and physiological effects of ginseng on actions induced by opioids and psychostimulants. Nihon Yakurigaku Zasshi. 117, 195-201. doi: 10.1254/fpj.117.195

Tomczyk, M., Zovko-Koncic, M., and Chrostek, L. (2012). Phytotherapy of alcoholism. Nat. Prod. Commun. 7, 273-280. doi: 10.1177/1934578X1200 700243

Town, M., Naimi, T. S., Mokdad, A. H., and Brewer, R. D. (2006). Health care access among U.S. adults who drink alcohol excessively: missed opportunities for prevention. Prev. Chronic Dis. 3, A53.

Tripathi, K. D. (2013). Essentials of medical pharmacology (New Delhi: JP Medical Ltd.).

Uzbay, T. I. (2008). Hypericum perforatum and substance dependence: a review. Phytother. Res. Int. J. Devoted Pharmacol. Toxicol. Eval. Nat. Prod. Derivatives 22, 578-582. doi: 10.1002/ptr.2420

Vacca, G., Colombo, G., Brunetti, G., Melis, S., Molinari, D., Serra, S., et al. (2003). Reducing effect of Salvia miltiorrhiza extracts on alcohol intake: influence of vehicle. Phyther. Res. New Delhi. 17, 537-541. doi: 10.1002/ptr.1203

Vailati, A., Aristia, L., Sozze, E., Milani, F., Inglese, V., Galenda, P., et al. (1993). Randomized open study of the dose-effect relationship of a short course of IdB 1016 in patients with viral or alcoholic hepatitis. Fitoterapia 64, 219-228.

Verma, R., Pelto, P., Schensul, S., and Joshi, A. (2004). Sexuality in the age of aids: contemporary perspectives from communities in India. New Delhi. India: Sage Publications, pp. 156-176.

Volkow, N. D., Wang, G. J., Fowler, J. S., Logan, J., Hitzemann, R., Ding, Y. S., et al. (1996). Decreases in dopamine receptors but not in dopamine transporters in alcoholics. Alcohol. Clin. Exp. Res. 20, 1594-1598. doi: 10.1111/j.15300277.1996.tb05936.x

Volpicelli, J. R., Alterman, A. I., Hayashida, M., and O'Brien, C. P. (1992). Naltrexone in the treatment of alcohol dependence. Arch. Gen. Psychiatry 49, 876-880. doi: 10.1001/archpsyc.1992.01820110040006

Wang, J.-H., Batey, R.-G., and George, J. (2006). Role of ethanol in the regulation of hepatic stellate cell function. World J. Gastroenterol. 12, 6926-6932. doi: 10.3748/wjg.v12.i43.6926

Wang, J., Liu, L., Ball, T., Yu, L., Li, Y., and Xing, F. (2016). Revealing a 5,000-y-old beer recipe in China. Proc. Natl. Acad. Sci. 113, 6444-6448. doi: 10.1073/ pnas. 1601465113

Wang, L., Ma, R., Liu, C., Liu, H., Zhu, R., Guo, S., et al. (2017). Salvia miltiorrhiza: a potential red light to the development of cardiovascular diseases. Curr. Pharm. Des. 23, 1077-1097. doi: 10.2174/1381612822666161010105242

Weitzman, E. R., and Chen, Y.-Y. (2005). The co-occurrence of smoking and drinking among young adults in college: national survey results from the United States. Drug Alcohol Depend. 80, 377-386. doi: 10.1016/ j.drugalcdep.2005.05.008

World Health Organization. (2010). Global strategy to reduce the harmful use of alcohol. Geneva, Switzerland.

World Health Organization. (2019). Global status report on alcohol and health 2018. World Health Organization. Switzerland: Geneva.

Wright, C. W., Gott, M., Grayson, B., Smith, A. G., Sunter, A., Neill, J. C., et al. (2003). Correlation of hyperforin content of Hypericum perforatum (St John's wort) extracts with their effects on alcohol drinking in C57BL/6J mice: a preliminary study. J. Psychopharmacol. 17, 403-408. doi: 10.1177/0269881103174018

Xie, C., Lin, R. C., Antony, V., Lumeng, L., Li, T., Mai, K., et al. (1994). Daidzin, an antioxidant isoflavonoid, decreases blood alcohol levels and shortens sleep time induced by ethanol intoxication. Alcohol. Clin. Exp. Res. 18, 1443-1447. doi: 10.1111/j.1530-0277.1994.tb01448.x

Xu, B.-J., Deng, Y.-Q., and Sung, C.-K. (2004). Advances in studies on bioactivity of Hovenia dulcis. Agric. Chem. Biotechnol. 47, 1-5.

Xu, B. J., Zheng, Y. N., and Sung, C. K. (2005). Natural medicines for alcoholism treatment: a review. Drug Alcohol Rev. 24, 525-536. doi: 10.1080/ 09595230500293795

Xu, L., Yu, Y., Sang, R., Li, J., Ge, B., and Zhang, X. (2018). Protective effects of taraxasterol against ethanol-induced liver injury by regulating CYP2E1/Nrf2/ HO-1 and NF-KB signaling pathways in mice. Oxid. Med. Cell. Longev. 2018, 8284107. doi: 10.1155/2018/8284107

Yamazaki, T., Hosono, T., Matsushita, Y., Kawashima, K., Someya, M., Nakajima, Y., et al. (2002). Pharmacological studies on Puerariae Flos. IV: effects of Pueraria thomsonii dried flower extracts on blood ethanol and acetaldehyde levels in humans. Int. J. Clin. Pharmacol. Res. 22, 23-28.

Yeung, A. W. K., Aggarwal, B. B., Barreca, D., Battino, M., Belwal, T., Horbańczuk, O. K., et al. (2018). Dietary natural products and their potential to influence health and disease including animal model studies *. Anim. Sci. Pap. Rep. 36, 345-358.

Yin, H.-Q., Kim, Y.-S., Choi, Y.-J., Kim, Y.-C., Sohn, D.-H., Ryu, S.-Y., et al. (2008). Effects of tanshinone IIA on the hepatotoxicity and gene expression involved in alcoholic liver disease. Arch. Pharm. Res. 31, 659-665. doi: 10.1007/ s12272-001-1209-2

Yin, H.-Q., Choi, Y.-J., Kim, Y.-C., Sohn, D.-H., Ryu, S.-Y., and Lee, B.-H. (2009). Salvia miltiorrhiza Bunge and its active component cryptotanshinone protects primary cultured rat hepatocytes from acute ethanol-induced cytotoxicity and fatty infiltration. Food Chem. Toxicol. 47, 98-103. doi: 10.1016/ j.fct.2008.10.018

Yoshikawa, M., Harada, E., Matsuda, H., Murakami, T., Yamahara, J., and Murakami, N. (1993). Elatosides A and B, potent inhibitors of ethanol absorption in rats from the bark of Aralia elata Seem: the structure-activity relationships of oleanolic acid oligoglycosides. Chem. Pharm. Bull. 41, 20692071. doi: $10.1248 / \mathrm{cpb} .41 .2069$

Yoshikawa, M., Murakami, T., Yoshizumi, S., Murakami, N., Yamahara, J., and Matsuda, H. (1996). Bioactive saponins and glycosides. V. Acylated polyhydroxyolean-12-ene triterpene oligoglycosides, camelliasaponins A1, A2, B1, B2, C1, and C2, from the seeds of Camellia japonica L.: structures and inhibitory activity on alcohol absorption. Chem. Pharm. Bull. 44, 18991907. doi: $10.1248 / \mathrm{cpb} .44 .1899$

Yoshikawa, M., Murakami, T., Harada, E., Murakami, N., Yamahara, J., and Matsuda, H. (1996a). Bioactive saponins and glycosides. VI. Elatosides A and $B$, potent inhibitors of ethanol absorption, from the bark of Aralia elata SEEM.(Araliaceae): the structure-requirement in oleanolic acid glucuronidesaponins for the inhibitory activity. Chem. Pharm. Bull. 44, 1915-1922. doi: $10.1248 / \mathrm{cpb} .44 .1915$

Yoshikawa, M., Murakami, T., Matsuda, H., Yamahara, J., Murakami, N., and Kitagawa, I. (1996b). Bioactive saponins and glycosides. III. Horse chestnut.(1): the structures, inhibitory effects on ethanol absorption, and hypoglycemic activity of escins Ia, Ib, IIa, IIb, and IIIa from the seeds of Aesculus hippocastanum L. Chem. Pharm. Bull. 44, 1454-1464. doi: 10.1248/cpb.44.1454

Younossi, Z. M., Stepanova, M., Afendy, M., Fang, Y., Younossi, Y., Mir, H., et al. (2011). Changes in the prevalence of the most common causes of chronic liver diseases in the United States from 1988 to 2008. Clin. Gastroenterol. Hepatol. 9, 524-530. doi: 10.1016/j.cgh.2011.03.020

Younossi, Z. M. (1998). Epidemiology of alcohol-induced liver disease. Clin. Liver Dis. 2, 661-671. doi: 10.1016/S1089-3261(05)70035-0

Zhang, H.-S., and Wang, S.-Q. (2006). Salvianolic acid B from Salvia miltiorrhiza inhibits tumor necrosis factor-alpha (TNF-alpha)-induced MMP-2 upregulation in human aortic smooth muscle cells via suppression of NAD (P)H oxidase-derived reactive oxygen species. J. Mol. Cell. Cardiol. 41, 138148. doi: 10.1016/j.yjmcc.2006.03.007

Zhang, Z., Li, S., Jiang, J., Yu, P., Liang, J., and Wang, Y. (2010). Preventive effects of Flos Perariae (Gehua) water extract and its active ingredient puerarin in rodent alcoholism models. Chin. Med. 5, 36. doi: 10.1186/1749-8546-5-36

Zhu, W., Zhang, Y., Huang, Y., and Lu, L. (2017). Chinese herbal medicine for the treatment of drug addiction. Int. Rev. Neurobiol. 135, 279-295. doi: 10.1016/ bs.irn.2017.02.013

Conflict of Interest: Author NT was employed by company NTZ Lab Ltd.

The remaining authors declare that the research was conducted in the absence of any commercial or financial relationships that could be construed as a potential conflict of interest.

Copyright (c) 2020 Singh, Joshi, Tewari, Echeverría, Mocan, Sah, Parvanov, Tzvetkov, Ma, Lee, Poznański, Huminiecki, Sacharczuk, Jóźwik, Horbańczuk, Feder-Kubis and Atanasov. This is an open-access article distributed under the terms of the Creative Commons Attribution License (CC BY). The use, distribution or reproduction in other forums is permitted, provided the original author(s) and the copyright owner(s) are credited and that the original publication in this journal is cited, in accordance with accepted academic practice. No use, distribution or reproduction is permitted which does not comply with these terms. 


\section{ABBREVIATIONS}

AA

ADE

$\mathrm{ADH}$

AIDS

ALD

ALDH

ALF

ALT

AST

ATP

AUC

AUD

BAL

BCA

BCE

BDZ

CAT

CGX

CLD

CNS

$\mathrm{CRH}$

CTGF

CYP2E1

D1

D2

DHM

DA

DOPAC

DOPAL

$\mathrm{FH}$

FOS

FST

GABA

GGT

GLA

GPx

GSH

GST
Alko Alcohol

alcohol deprivation effect

alcohol dehydrogenase enzyme

acquired immunodeficiency syndrome

alcoholic liver disease

aldehyde dehydrogenase

acute liver failure

alanine aminotransferase

aspartate aminotransferase

adenosine triphosphate

area under curve

alcohol use disorder

blood alcohol level

blood alcohol concentration

Before the Common Era

benzodiazepine

catalase

Chunggan extract

chronic liver disease

central nervous system

corticotropin releasing factor

connective tissue growth factor

Cytochrome P450 2E1

dopamine receptor 1

dopamine receptor 2

dihydromyricetin

dopamine

3,4-dihydroxyphenylacetic acid

dihydroxyphenylacetic acid

Fawn-Hooded

c-fos protein

force swimming test

gamma-aminobutyric acid

gamma-glutamyl transferase

?-linolenic acid

glutathione peroxidase

glutathione-S-transferase

glutathione-S-transferase
GR

Had

HIV

HSC

L-THP

IFN- $\gamma$

IL-4

IL-10

MAO

MAPs

msP

NA

NAFLD

NEFAs

Nrf2

$\mathrm{NO}$

OR

$\mathrm{P}$

PDGF- $\beta$

PGE1

PU

ROS

RTI

Ser

SJW

sP

SOD

TGF- $\beta$

$\mathrm{THH}$

TNF $\alpha$

TCM

VACS

VEGF-A

WHO

XJL

18-MC

5-HIAL

5-HIAAA glutathione reductase

high alcohol-drinking

human immunodeficiency virus

hepatic stellate cells

Lev-tetrahydropalmatine

gamma interferon

interleukin 4

interleukin 10

monoamine oxidase

MITOGEN-activated proteins

Marchigian Sardinian

noradrenaline

non-alcoholic fatty liver disease

non-esterified fatty acids

nuclear factor erythroid 2-related factor 2

nitric oxide

odds ratio

alcohol-preferring

platelet-derived growth factor-beta

prostaglandins E1

puerarin

reactive oxygen species

road traffic injury

serotonin

St. John's wort

Sardinian alcohol-preferring

superoxide dismutase

transforming growth factor-beta

tetrahydroharmine

tumor necrosis factor-alpha

traditional Chinese medicine

Veterans Aging Cohort Study

vascular endothelial growth factor

World Health Organization

Natural Pharmacia International [NPI]

preparation \#28

18-methoxycoronaridine

5-hydroxyindole 3-acetaldehyde

5-hydroxyindole-3-acetic acid 